FHWA/IN/JTRP-2008/15

Final Report

DEVELOPMENT OF AN INTEGRATED LAND-USE TRANSPORTATION MODEL FOR INDIANA

Jon D. Fricker

Li Jin

October 2008 
Final Report

FHWA/IN/JTRP-2008/15

\title{
Development of an Integrated Land-Use Transportation Model for Indiana
}

\author{
by \\ Li Jin \\ Graduate Research Assistant \\ and \\ Jon D. Fricker \\ Principal Investigator \\ School of Civil Engineering \\ Purdue University \\ Joint Transportation Research Project \\ Project No. C-36-70G \\ File No. 3-8-8 \\ SPR-3051 \\ Prepared in cooperation with the \\ Indiana Department of Transportation \\ and the U.S. Department of Transportation \\ Federal Highway Administration
}

The contents of this report reflect the views of the authors, who are responsible for the facts and the accuracy of the data presented therein. The contents do not necessarily reflect the official views or policies of the Indiana Department of Transportation or the Federal Highway Administration at the time of publication. This report does not constitute a standard specification, or regulation.

\author{
Purdue University \\ West Lafayette IN 47907
}

October 2008 
TECHNICAL REPORT STANDARD TITLE PAGE

\begin{tabular}{|c|c|c|}
\hline $\begin{array}{l}\text { 1. Report No. } \\
\text { FHWA/IN/JTRP-2008/15 }\end{array}$ & 2. Government Accession No. & 3. Recipient's Catalog No. \\
\hline \multirow{2}{*}{\multicolumn{2}{|c|}{$\begin{array}{l}\text { 4. Title and Subtitle } \\
\text { Development of Integrated Land-Use Transportation Model for Indiana }\end{array}$}} & $\begin{array}{l}\text { 5. } \text { Report Date } \\
\text { October } 2008\end{array}$ \\
\hline & & 6. Performing Organization Code \\
\hline \multicolumn{2}{|l|}{$\begin{array}{l}\text { 7. Author(s) } \\
\text { Jon D. Fricker and Li Jin }\end{array}$} & $\begin{array}{l}\text { 8. Performing Organization Report No. } \\
\text { FHWA/IN/JTRP-2008/15 }\end{array}$ \\
\hline \multicolumn{2}{|l|}{$\begin{array}{l}\text { 9. Performing Organization Name and Address } \\
\text { Joint Transportation Research Program } \\
1284 \text { Civil Engineering Building } \\
\text { Purdue University } \\
\text { West Lafayette, IN 47907-1284 }\end{array}$} & 10. Work Unit No. \\
\hline \multicolumn{2}{|l|}{$\begin{array}{l}\text { 12. Sponsoring Agency Name and Address } \\
\text { Indiana Department of Transportation } \\
\text { State Office Building } \\
100 \text { North Senate Avenue } \\
\text { Indianapolis, IN } 46204\end{array}$} & 14. Sponsoring Agency Code \\
\hline \multicolumn{3}{|l|}{ 15. Supplementary Notes } \\
\hline
\end{tabular}

\section{Abstract}

The Indiana Department of Transportation has an operational statewide travel demand model (ISTDM). INDOT also has used the Land Use Central Indiana (LUCI) model to forecast conversion of land to residential and employment uses in future decades over a 44-county area in central Indiana. This paper describes how the LUCI model was expanded to cover the same geographic area as the ISTDM, how the internal structure of each model was made to be compatible with the other model, and how the outputs from each model were made to be suitable as inputs to the other model. The result is an integrated model system that allows forecasts of land use and travel patterns for a specified horizon year, with intermediate reports for each intervening 5-year period. The word "integrated" means that no intervention by the user is needed while the model run is under way. INTRLUDE allows the user to specify scenarios that will affect land use decisions and changes to the state network that may be proposed at certain years before the horizon year.

\author{
17. Key Words \\ Land use model, travel demand model, integrated model, \\ sensitivity analysis.
}

18. Distribution Statement

No restrictions. This document is available to the public through the National Technical Information Service, Springfield, VA 22161

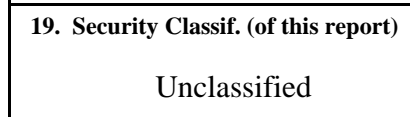

Form DOT F 1700.7 (8-69)
20. Security Classif. (of this page)

Unclassified

\begin{tabular}{|c|c|}
\hline 21. No. of Pages & 22. Price \\
93 & \\
\hline
\end{tabular}




\section{TABLE OF CONTENTS}

Page

ABSTRACT.

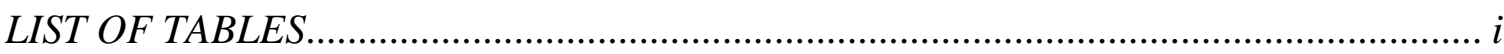

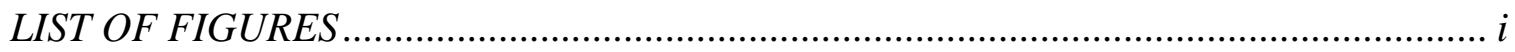

CHAPTER 1. INTRODUCTION ........................................................................ 1

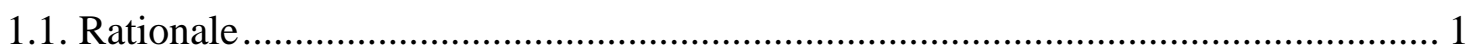

1.2. Research Objectives and Methodology ........................................................ 1

CHAPTER 2. TRANSPORTATION AND LAND USE MODELING ........................... 3

2.1. A Brief Review of Transportation Models ............................................................ 3

2.2. Review of Land Use Models and the Integrated Approach................................... 5

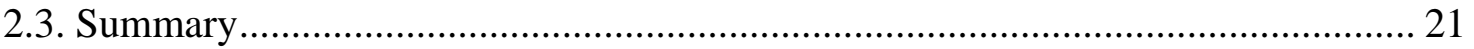

CHAPTER 3. AN INTEGRATED ISTDM-LUCI2 MODEL SYSTEM ........................ 22

3.1. The ISTDM v.4 Model ................................................................................. 23

3.2. LUCI2 Statewide Urban Simulation Model ....................................................... 33

3.3. Integrated ISTDM-LUCI2 Model Approach.................................................... 36

3.4. Comparison of the ISTDM v.4 and the Integrated ISTDM-LUCI2 Approach ...... 40

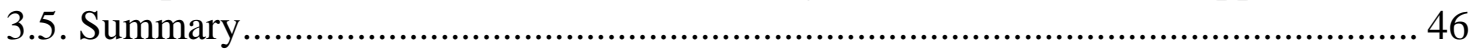

CHAPTER 4. SENSITIVITY ANALYSIS BY ISTDM-LUCI2 MODEL .................... 47

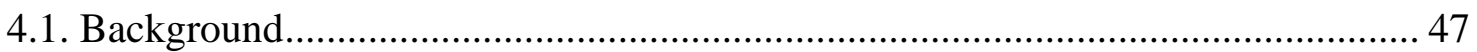

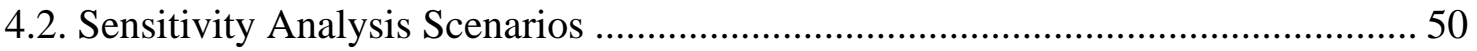

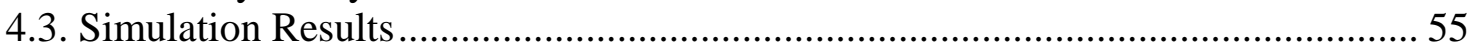

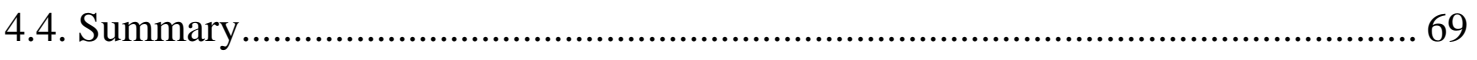

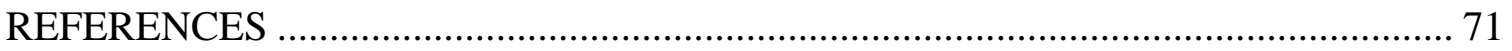

User's Guide to INTRLUDE: The INtegrated TRansportation Land $\underline{\text { Une }} \underline{\text { Demand }}$ Estimation Model for Indiana

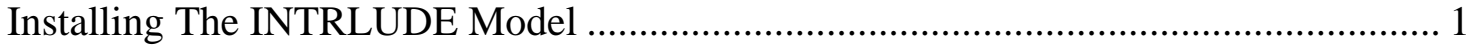

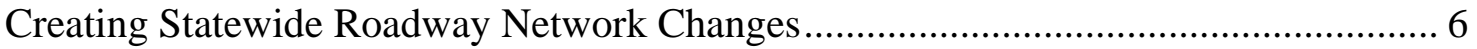

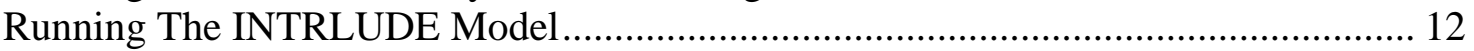

Output Files For The INTRLUDE Model. ............................................................. 18 


\section{LIST OF TABLES}

Table 2-1. Integrated land-use transport models............................................................. 7

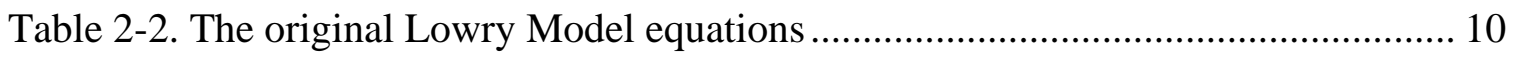

Table 2-3. Comparison of operational model characteristics ........................................ 17

Table 3-1. Trip production rates for Home-Based Work trip purpose ............................. 27

Table 3-2. Trip production rates for Home-Based Other trip purpose ............................ 28

Table 3-3. Trip production rates for Non Home-Based trip purpose............................... 28

Table 3-4. Trip production rates for long trip purpose ................................................... 28

Table 3-5. Regression models by trip purpose for trip attraction ................................... 29

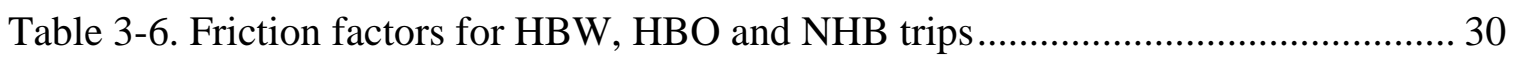

Table 3-7. Observed Mode Shares by Area Type and Trip Purpose ................................ 32

Table 3-8. Multinomial Logit Model Parameters for Long Trip Purpose ....................... 32

Table 3-9. Forecast VMT in 2030 by ISTDM v.4 and ISTDM-LUCI2 ......................... 44

Table 3-10. Forecast 2030 VMT by LOS -- ISTDM v.4 and by ISTDM-LUCI2 ........... 45

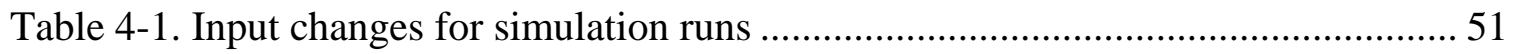

Table 4-2. BPR function coefficients by functional class............................................... 54

Table 4-3. Total VMT outputs from the base case ........................................................... 55

Table 4-4. VMT outputs by functional class from the base case ................................... 61

Table 4-5. Impact of uncertainty in population growth on VMT outputs by functional class

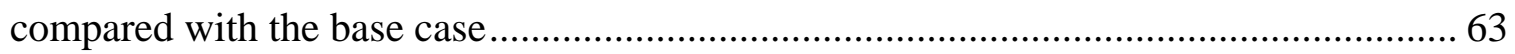

Table 4-6. Impact of uncertainty in trip generation rates on VMT outputs by functional

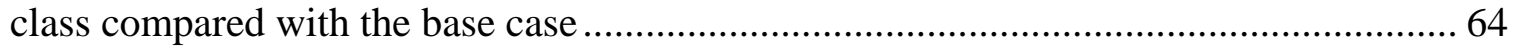

Table 4-7. Impact of uncertainty in trip attraction rates on VMT outputs by functional class

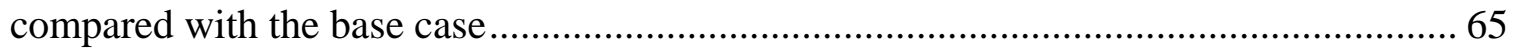

Table 4-8. Impact of uncertainty in trip distribution on VMT outputs by functional class compared with the base case.

Table 4-9. Impact of uncertainty in trip assignment on VMT outputs by functional class compared with the base case. 68 


\section{LIST OF FIGURES}

Figure 2-1. Four step travel demand model scheme .................................................. 4

Figure 2-2. Components of transportation and land use system ................................... 6

Figure 2-3. Transportation and land use cycle...................................................... 7

Figure 2-4. The original Lowry model flowchart ....................................................... 9

Figure 2-5. The modified Garin-Lowry Model........................................................... 11

Figure 2-6. The basic structure of ITLUP Model ....................................................... 14

Figure 2-7. The Interaction of the Land Use and Transportation Markets in the MEPLAN

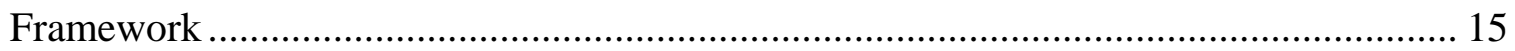

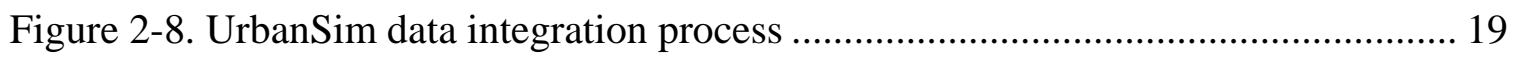

Figure 2-9. UrbanSim Model Structure and Processing ............................................... 20

Figure 2-10. Evolution of urban land-use transport models ....................................... 21

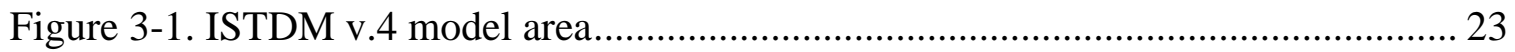

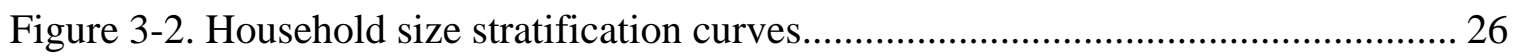

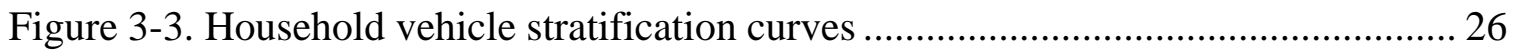

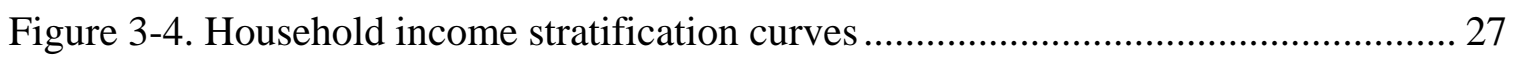

Figure 3-5. Friction Factors for Long Trips............................................................ 31

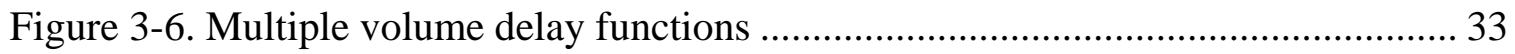

Figure 3-7. The structure of the integrated ISTDM-LUCI2 model approach................... 37

Figure 3-8. The integrated ISTDM-LUCI2 model interface ..................................... 38

Figure 3-9. Forecasted population density change from 2000 to 2030 by the ISTDM ... 41

Figure 3-10. Forecasted population density change from 2000 to 2030 by the integrated ISTDM-LUCI2 model ................................................................................... 42

Figure 3-11. The scatterplot of forecasted zonal population density changes from 2000 to

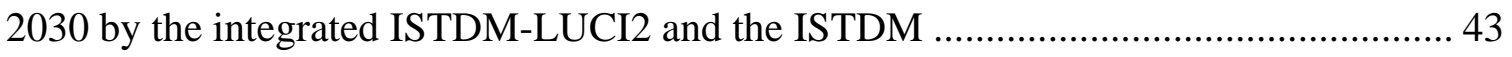

Figure 3-12. The scatterplot of VMT in 2030 for each roadway link predicted by the integrated ISTDM-LUCI2 and by the ISTDM v.4 model .......................................... 45

Figure 4-1. Friction Factors for HBW Trips ............................................................... 52

Figure 4-2. Friction Factors for HBO Trips.............................................................. 53

Figure 4-3. Friction Factors for NHW Trips............................................................. 53

Figure 4-4. Impact of uncertainty in population growth on total VMT ........................... 56

Figure 4-5. Impact of uncertainty in trip generation rates on the VMT outputs............... 57

Figure 4-6. Impact of uncertainty in trip attraction rates on the VMT outputs ................ 58

Figure 4-7. Impact of uncertainty in trip distribution on the VMT outputs..................... 59

Figure 4-8. Impact of uncertainty in trip assignment on the VMT outputs ..................... 60 


\section{CHAPTER 1. INTRODUCTION}

\subsection{Rationale}

As traffic increases in response to changing land use patterns, the requirement for precisely estimating and forecasting travel demand becomes more important. Transportation and land-use interactions must be understood, modeled, and accounted for in the planning process (Meyer and Miller, 2001). However, many current statewide travel demand models focus only on the transportation side, which causes difficulty in capturing the two-way transportation and land-use interactions.

The Clean Air Act Amendments of 1990 and the 1991 Intermodal Surface Transportation Efficiency Act (ISTEA) mandated that MPOs should integrate metropolitan land-use and transportation planning. In responding to the USDOT emphasis on assessing the impacts of transportation improvements using a transportation and land-use model system, an INtegrated TRansportation Land Use DEmand Model (INTRLUDE) for Indiana has been built in this research by linking transportation and land-use simulation models.

\section{$\underline{1.2}$ Research Objective and Methodology}

The main objective of this research is to develop an integrated transportation and land-use model system for Indiana. The following tasks are to be fulfilled in this research.

- Develop the integrated transportation land use demand model (INTRLUDE). The outputs from the INTRLUDE model system are then compared with the outputs from the original ISTDM model. 
- Conduct a univariate sensitivity analysis using the INTRLUDE model system. The sensitivity of VMT outputs is investigated when given plausible prespecified amounts of variation in travel model parameters, input data and exogenous population growth rate. 


\section{CHAPTER 2. TRANSPORTATION AND LAND USE MODELING}

The relationships between transportation, land use and the environment are at the heart of urban growth. Because of the two-way interaction effects of transportation and land use system, the Clean Air Act Amendments of 1990, the 1991 Intermodal Surface Transportation Efficiency Act (ISTEA) mandated that MPOs should integrate metropolitan land use and transportation planning (Waddell, 2002). In this chapter, the existing operational transportation and land use modeling systems are reviewed.

\subsection{A Brief Review of Four-Step Travel Demand Models}

Four-step travel demand model has been widely used in the U.S for decades (Niemeiera and Mannering, 2007; Lo and Wong, 2002). It is a four-stage, sequential algorithm (Meyer and Miller, 2001; Pfaffenbichler, 2003). See Figure 2-1.

An advantage of the four-step model is that it is a feasible way to reduce the extremely complex system of traveler behavior into analytically manageable components. The four-step model can deal with relatively simple techniques and reasonable amounts of data (Meyer and Miller, 2001). 


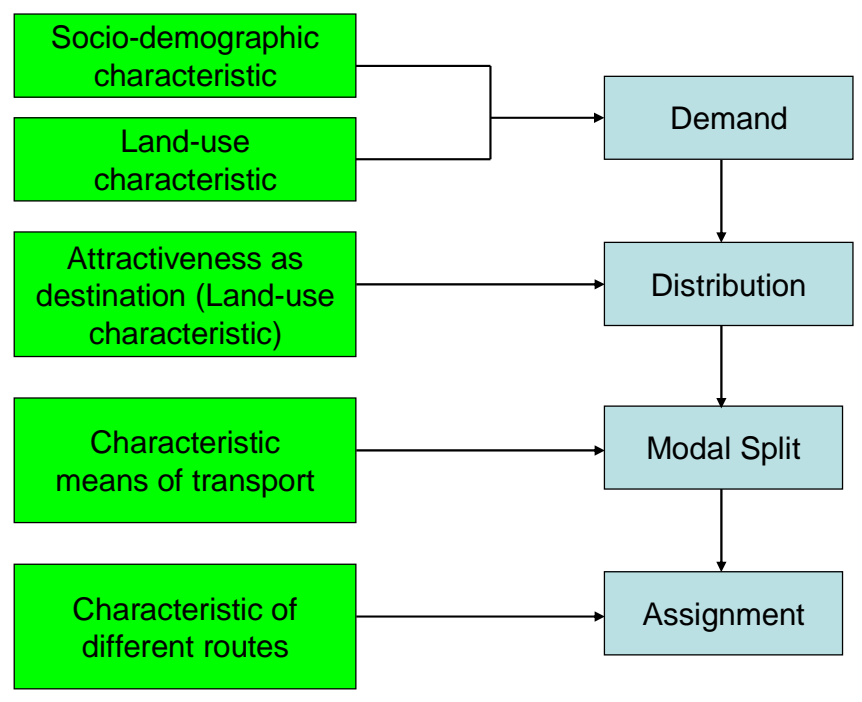

Figure 2-1. Four step travel demand model scheme (Pfaffenbichler, 2003)

The four major steps are:

1. Trip generation

2. Trip distribution

3. Mode Choice

4. Trip assignment

The geographic unit of analysis in the four step travel demand model is traffic analysis zone (TAZ). Each zone is characterized by population and land-use characteristics that allow the calculation of the number of trips produced and attracted to that zone.

The literatures provide a detailed overview of the four-step travel demand model (Hensher and Button, 2002; Ortúzar and Willumsen, 2001; Meyer and Miller, 2001). Hence, only a brief review for the four-step travel demand model is given here.

In the trip generation step, models are used to predict number of trips that are generated by and attracted to each zone in the study area, usually on a daily or a peakperiod basis (Meyer and Miller, 2001). Typically, at least three different trip purpose are defined, namely, home-based work trips (HBW), home-based other (HBO), and nonhome-based trips (NHB). For trip productions, cross classification analyses are more common than regression based models. Households in each zone are grouped based on socioeconomic characteristics, such as household size, automobile ownerships, and/or 
household income. Trip productions in each zone are then calculated by multiplying the corresponding trip rate from the sample data with the number of households. For trip attractions, regression models are more commonly used on relevant zonal land use characteristics.

The trip distribution step is used to distribute trip ends from each zone $i$ to all trip attraction zones $j$. The gravity model is the most commonly used in this step. The production constrained version of the gravity model is:

$$
T_{i j}=\frac{P_{i}\left[A_{j} f_{i j}\right]}{\sum_{j=1}^{n} A_{j} f_{i j}}
$$

where:

$P_{i}$ is the total number of trips produced in zone $i$

$A_{j}$ is the total number of trips attracted to zone $j$

$f_{i j}$ is the friction factor

The friction factor converts interzonal travel times into a trip length distribution that reflects the observed travel length distribution. The commonly used trip length distributions are exponential, power, or gamma distributions (Hensher and Button, 2002).

The mode choice model predicts the percentage of trips by made different modes. The multinomial logit model is commonly used in this step. It produces disaggregate results that must be aggregated to the zonal level (Ortúzar and Willumsen, 2001).

The last step is trip assignment, which assigns the predicted trips between each origin-destination pair to actual routes through the road network. The assignment algorithm is usually based on the assumption of user equilibrium (UE). The UE solution is usually obtained by using the Frank-Wolfe algorithm (Hensher and Button, 2002).

\section{$\underline{2.2 \text { A Brief Review of Land Use Models and the Integrated Approach }}$}

The relationship between transportation and land use system is highly complex. Land use is associated with demographic and economic attributes. Spatial interactions 
explain movements of passengers and freight. The transportation system moves passengers and freight by certain modes on each traffic link (Rodrigue et al., 2006).

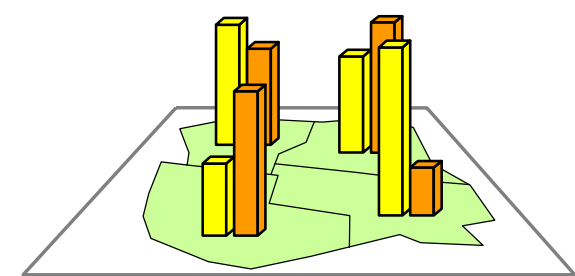

Spatial Accumulation (demand)

- Economic base theory

- Location theory

- Traffic generation and

attraction models

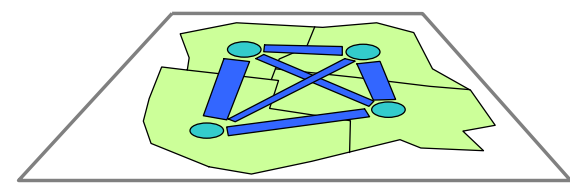

Friction of Space

- Spatial interaction models

- Distance decay parameters

- Modal split

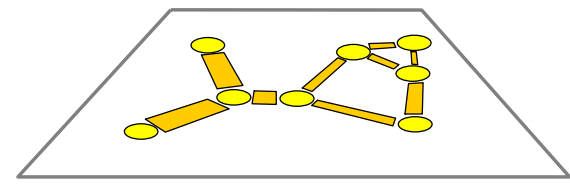

Transport Infrastructures

(supply)

- Accessibility

- Traffic assignment models

- Transport capacity

Figure 2-2. Components of transportation and land use system (Rodrigue et al., 2006)

Figure 2-2 shows that spatial accumulation is on the demand side. Economic base theory, location theory, transportation generation and attraction models are developed for the spatial accumulation. Traffic infrastructures are on the supply side. Friction of space links the demand and supply side. Spatial interaction models, distance decay parameters, and mode split choice modes are developed for friction of space.

Two-way interactions between urban land use and transportation lead to the transportation and land use feedback cycle showed in Figure 2-3. Transportation system creates spatial accessibility. Spatial accessibility influences location decisions for the land use system. The land use system -- residential, industrial or commercial -- affects the locations of human activities such as living, working, shopping, education or leisure. These human activities form trip patterns in the transportation system (Wegener and Fuerst, 2004). 


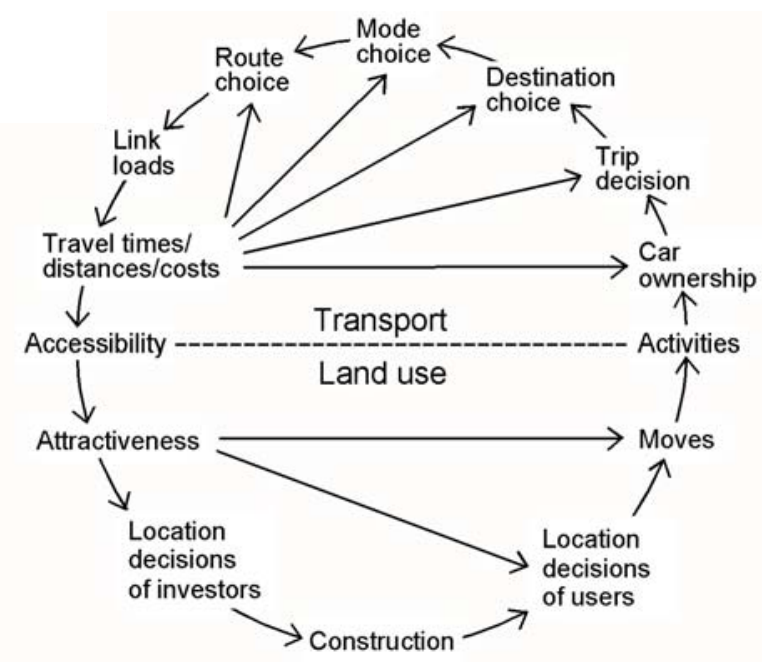

Figure 2-3. Transportation and land use cycle (Wegener and Fuerst, 2004)

Wegener and Fuerst (2004) reviewed seventeen land use transport models that are operational (Table 2-1).

Table 2-1. Integrated land-use transport models (Wegener and Fuerst, 2004)

\begin{tabular}{|c|c|c|c|c|c|c|c|c|}
\hline \multirow{3}{*}{ Models } & \multicolumn{8}{|c|}{ Speed of change } \\
\hline & \multicolumn{2}{|c|}{ Very slow } & \multicolumn{2}{|c|}{ Slow } & \multicolumn{2}{|c|}{ Fast } & \multicolumn{2}{|c|}{ Immediate } \\
\hline & Networks & Land use & Workpalces & Housing & Employment & Population & $\begin{array}{l}\text { Goods } \\
\text { transport }\end{array}$ & Travel \\
\hline BOYCE & + & & & & + & + & & + \\
\hline CUFM & & + & + & + & + & + & & \\
\hline DELTA/START & + & + & + & + & + & + & + & + \\
\hline HUDS & & & & + & + & + & & \\
\hline IMREL & + & + & + & + & + & + & & + \\
\hline IRPUD & + & + & + & + & + & + & & + \\
\hline ITLUP & + & + & & & + & + & & + \\
\hline KIM & + & & & & + & + & + & + \\
\hline LILT & + & + & + & + & + & + & & + \\
\hline MEPLAN & + & + & + & + & + & + & + & + \\
\hline METROSIM & + & + & + & + & + & + & & + \\
\hline MUSSA & + & + & & & + & + & & + \\
\hline POLIS & & + & & & + & + & & + \\
\hline RURBAN & & + & & & + & + & & + \\
\hline STASA & + & + & + & + & + & + & + & + \\
\hline TRANUS & + & + & + & + & + & + & + & + \\
\hline URBANSIM & & + & + & + & + & + & & + \\
\hline
\end{tabular}


The review in this chapter covers several integrated models, including original Lowry, Garin-Lowry, ITLUP, POLIS, MEPLAN, Kim's Chicago model, and URBANSIM. ITLUP is a Lowry type model. POLIS is a mathematical programmingbased model. MEPLAN is based on spatial input-output analysis. Kim's Chicago model employs urban economics. URBANSIM is a microsimulation model (Zhao et al., 2003).

\subsubsection{Original Lowry Model}

One of the first operational transportation and land use models is the model developed by Lowry in 1964 for the Pittsburgh region (Pfaffenbichler, 2003). Its premises were expanded by several other models, known as "Lowry-type" models (Rodrigue et al., 2006).

The core assumption of the Lowry model is that the "basic" sector, including industrial, business, and administrative establishments, is treated as exogenous to the model. This basic sector has impacts on the employment of two other sectors, retail and resident (Lowry, 1964).

Given the basic establishments, the Lowry model allocates their labor forces to residential areas using a function of work-to-home distribution from a “Gravity Model”. The retail employments serving this population are allocated using a resident-to-shop and workplace-to-shop distribution. These new workers for the retail employments must be allocated to residences, which generate iterations until equilibrium (Meyer and Miller, 2001). Constraints on zonal population and employment densities are also included.

Figure 2-4 presents a flowchart of the original Lowry model. 


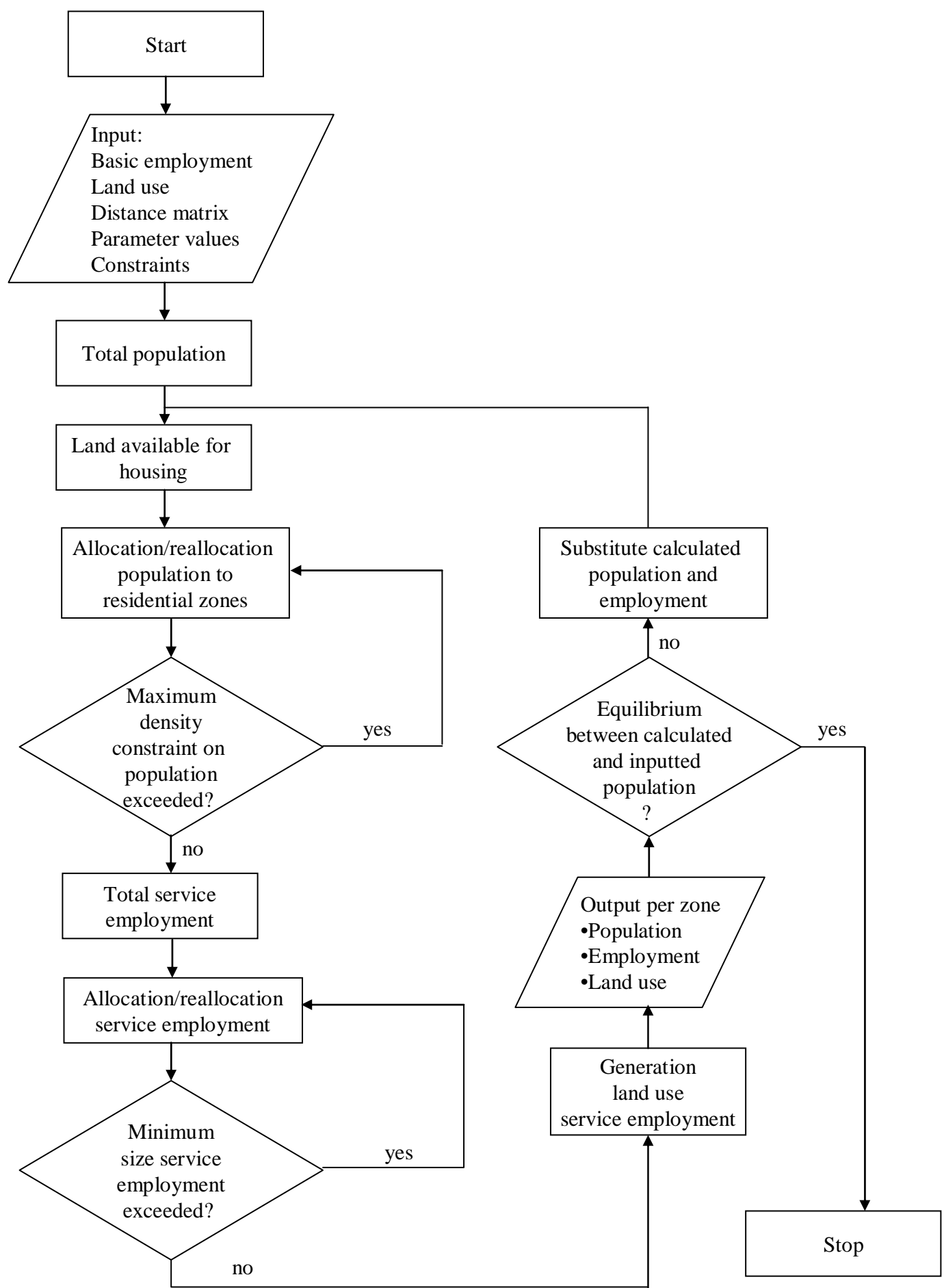

Figure 2-4. The original Lowry model flowchart (Van Est, 1979)

The original Lowry model includes nine simultaneous equations (Equations 2-2 to Equation 2-10 in Table 2-2) and three inequalities (Equations 2-11 to Equation 2-13 in Table 2-2) (Lowry, 1964). 
Table 2-2. The original Lowry Model equations (Lowry, 1964)

Land Use

$$
A_{j}=A_{j}^{U}+A_{j}^{B}+A_{j}^{R}+A_{j}^{H}
$$

Retail Sector

$$
\begin{aligned}
& E^{k}=a^{k} N \\
& E_{j}^{k}=b^{k}\left(\sum_{i=1}^{n} \frac{c^{k} N_{i}}{T_{i j}^{k}}+d^{k} E_{j}\right) \\
& E^{k}=\sum_{j=1}^{n} E_{j}^{k} \\
& E_{j}=E_{j}^{B}+\sum_{k=1}^{m} E_{j}^{k} \\
& A_{j}^{R}=\sum_{k=1}^{m} e^{k} E_{j}^{k}
\end{aligned}
$$

Household Sector

$$
\begin{aligned}
& N=f \sum_{j=1}^{n} E_{j} \\
& N_{j}=g \sum_{i=1}^{n} \frac{E_{i}}{T_{i j}} \\
& N=\sum_{j=1}^{N} N_{j}
\end{aligned}
$$

Constraints

$$
\begin{aligned}
& E_{j}^{k} \geq Z^{k} \text { or } E_{j}^{k}=0 \text { for all } j, k \\
& N_{j} \leq Z_{j}^{H} A_{j}^{H} \\
& A_{j}^{R} \leq A_{j}-A_{j}^{U}-A_{j}^{B}
\end{aligned}
$$

Variables

$A=$ area of land (thousands of square feet)

$E=$ employment (number of persons)

$N=$ population(number of households)

$T=$ index of trip distribution

$Z=$ constraints
Superscripts and Subscripts

$U=$ unusable land

$B=$ basic sector

$R=$ retail sector

$H=$ household sector

$k=$ class of establishments within retail sector $(k=1, \ldots ., m)$

$i, j=$ tracts or zones within region

$$
(i, j=1, \ldots, n)
$$

$a, b, c, d, e, f, g=$ coefficients 


\subsubsection{Garin-Lowry Model}

Garin (1966) extended the original Lowry Model in several ways. The GarinLowry Model explicitly incorporates interaction submodels that distribute all activities at every iteration of the calculation. The entire Garin-Lowry Model is in matrix notation, which simplifies the precise presentation of the model and exposes the underlying equilibrium inherent in the iterative solution procedure (Berechman and Small, 1988; Batty, 1972). The basic structure of the Garin-Lowry model is shown in Figure 2-5.

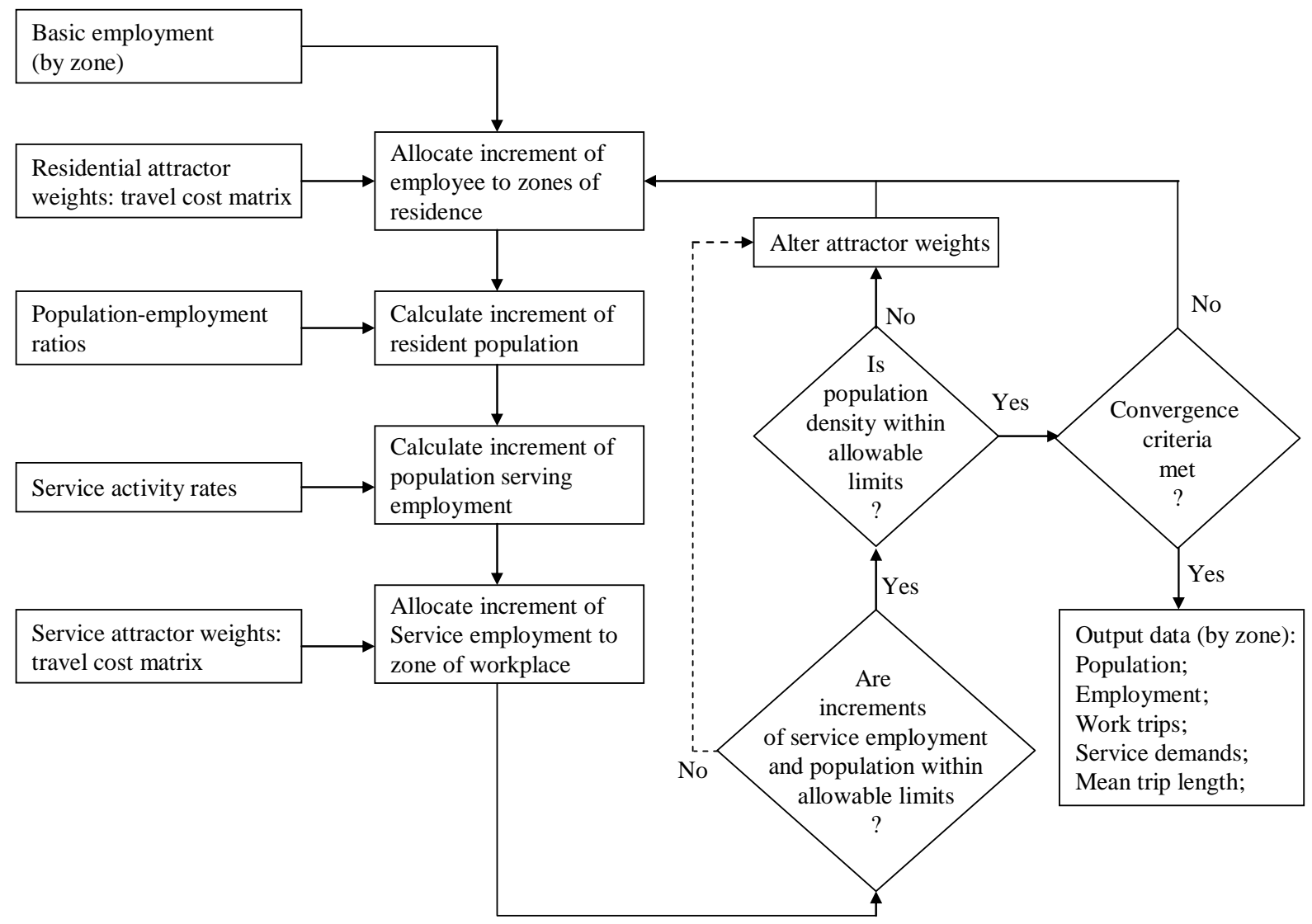

Figure 2-5. The modified Garin-Lowry Model (Berechman and Small, 1988)

The input data include zonal levels of basic employment, interzonal travel cost matrices for home-to-work and home-to-shopping trips, zonal levels of attractiveness for residential and service location, and control parameters for the economic-based mechanism. Based on these inputs, the workers in the basic employment sector are allocated to residential zones. The incremental residential population and the resulting incremental dependent service employment are then calculated. This increment of 
employment is distributed to workplace zones, and the corresponding increment in population is then derived and distributed spatially to residential zones. This entire iterative process continues until the it converges. At each iteration, a check is made to ascertain that zonal densities of service and residential population are within preset bounds. If they are not, an iterative procedure is applied to reallocate the latest increments by changing the zonal attraction parameters (Berechman and Small, 1988).

The Garin-Lowry Model has been used successfully to replicate observed spatial distributions of land-use activities, and in analyzing the impacts of major changes. The model has a simple structure and the spatial-allocation mechanism within the model mimics the result of randomness in the decisions of individuals. The main disadvantage of the Garin-Lowry model is its lack of any underlying economic or behavioral theory (Berechman and Small, 1988).

\subsubsection{ITLUP Model}

Integrated Transportation and Land-Use model package (ITLUP) represents the first fully operational integrated transportation and land use model (Putman, 1983). This model combines two separate components: a land use model and a transportation network model. The land use model is a modification of Goldner's version of the Garin-Lowry Model of land use. The network component is a conventional capacity-constraint incremental assignment model of a transportation network (Berechman and Small, 1988).

Figure 2-6 shows the basic scheme of the ITLUP Model. Base year data include the spatial distribution of all employment and residential activities, the characteristics of households by zone, and characteristics of the uncongested base-year highway network. These are inputs to the land use and network models in order to generate an estimate of the base year travel cost on the congested highway network. For a forecast year, it is only basic employment for which data on spatial distribution must be supplied; for population and other employment, regional totals are the only data requirements. Each iteration includes the land use model (producing a trip matrix), followed by an application of the network-assignment model (producing a trip cost matrix). In the first iteration, the base 
year travel cost matrix for the congested network serves as the required input to the land use model. Iterations continue until the distribution of activities stops changing (Berechman and Small, 1988).
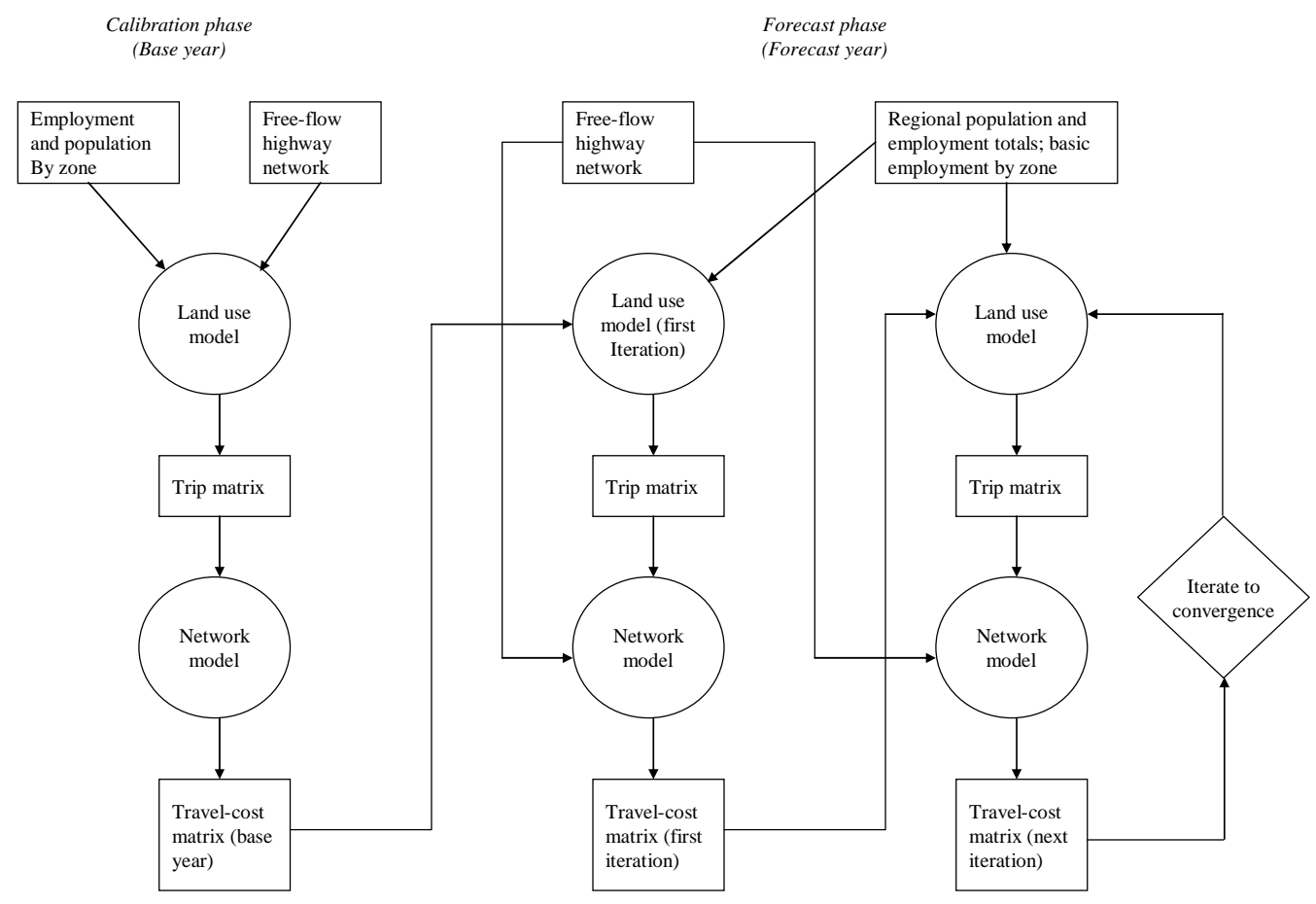

Figure 2-6. The basic structure of ITLUP Model (Berechman and Small, 1988)

The greatest advantage of ITLUP is its explicit attention to the transportation network. Simulations consider highway congestion and the resulting reallocation of activities. The direct linkage of the transportation and land use model components provide a fuller explanation of many urban development phenomena. The main disadvantage of ITLUP model is that it contains neither demand nor supply functions, nor a price mechanism for achieving market mechanism (Berechman and Small, 1988).

By modifying the calibration techniques and the spatial allocation formulae, the revised land use component of the ITLUP model was called a Disaggregate Residential Allocation Model (DRAM) and an Employment Allocation Model (EMPAL), which in the early 1990s were the most widely applied land use models in the United States (Timmermans, 2006). DRAM uses the attractiveness of a zone and the accessibility of a 
zone's workers to jobs in other zones as the principal factors in allocating households to zones. EMPAL allocates employment based on the employment in the previous time period and the attractiveness of the zone for households (Krishnamurthy and Kockelman, 2003).

\subsubsection{POLIS Model}

In the 1980s, the Association of Bay Area Governments (ABAG) developed the Projective Optimization Land Use System (POLIS) for the San Francisco Bay Area (Zhao et al., 2003). The POLIS model is formulated as a nonlinear mathematical programming problem. Locations of jobs and housing, and travel patterns are modeled simultaneously. The objective function maximizes the location surplus, or utility, associated with the multimodal travel to work trips, the shopping trips, and the agglomeration benefits for employers. Linear constraints reflect the planning constraints, including land use controls and exogenous locations of employments (Prastacos, 1985).

The POLIS model differs from the operational Lowry type models in several aspects. It considers the location of basic and nonbasic employment and housing in an internally consistent approach, and attempts to replicate economic behavior at the microlevel. It analyzes the location of economic activity in terms of agglomeration economics and proximity to labor, rather than established patterns at the base year; it applies itself to the testing of issues such as land-use controls, scarcity of housing, and shifts in the sectoral composition of employment (Prastacos, 1985). The lagged effects of transportation investment on land use are not modeled (Zhao et al., 2003).

\subsubsection{MEPLAN Model}

The well-known model based on spatial input/output economic analysis is MEPLAN, developed by Marcial Echenique and Partners Ltd. in the United Kingdom (Yen, 1996). The basis of the modeling framework is the interaction between two types 
of parallel markets. One concerns land and the occupying activities, and the other concerns transport (Abraham, 1999). The nature of this interaction is shown in Figure 27. A basic relationship is the effect on locational accessibility of travel cost and time changes, which has the feedback to a set of activity location models in a temporally lagged manner (Southworth, 1995).

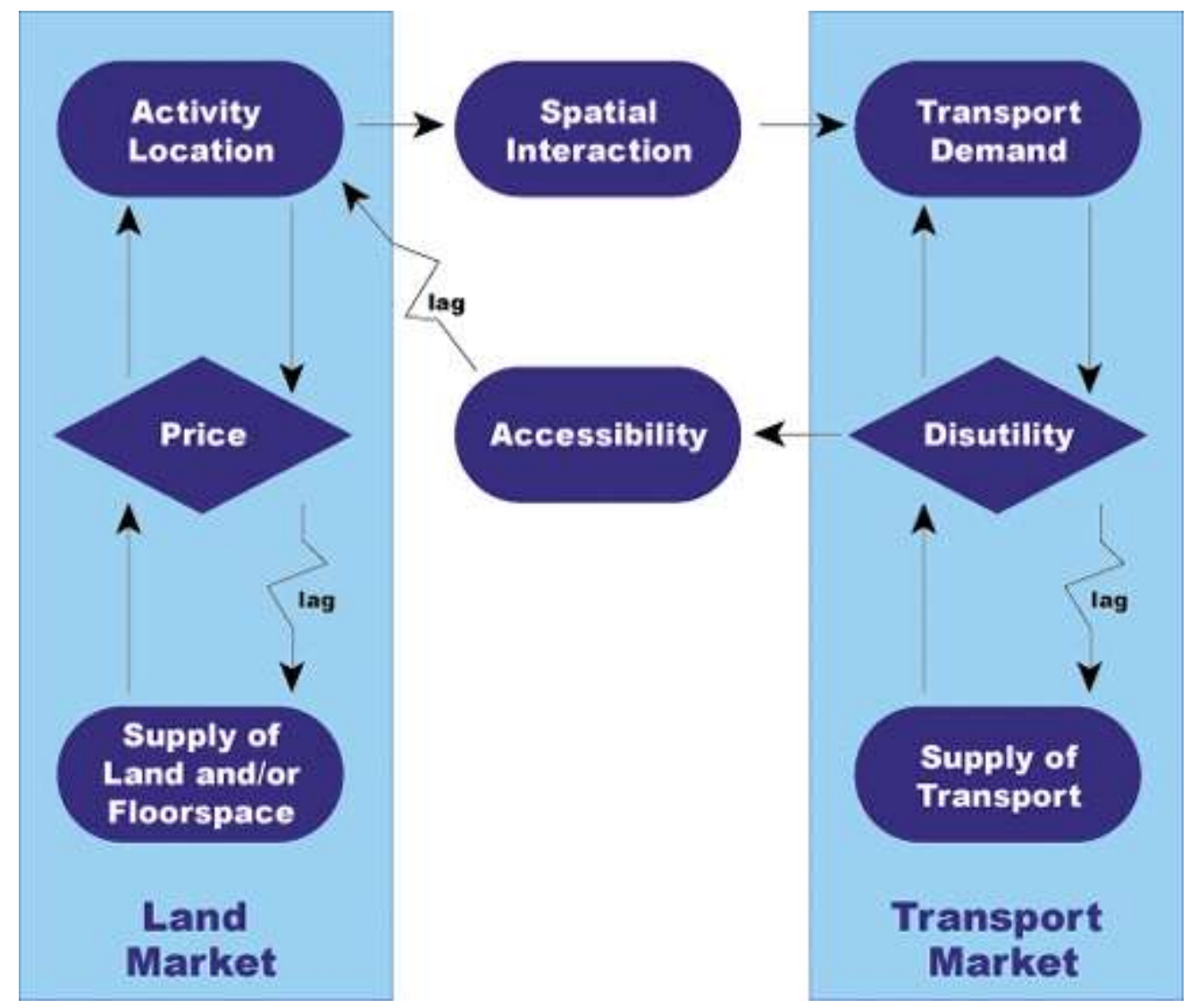

Figure 2-7. The Interaction of the Land Use and Transportation Markets in the MEPLAN Framework (Johnston et al., 2000)

The basis of the land market model is a spatially disaggregate social accounting matrix or input-output table that includes technical coefficients and different categories of space, representing different types of buildings or land. Volumes of activities in the different sectors are allocated to geographic zones using logit models of location choice, with the attractiveness of zones based on the costs of inputs to the productivity activity (including related transport costs), location-specific disutilities (zonal specific constants), and the cost of transporting the resulting production to consuming activities (Abraham, 1999). 
The resulting economic interactions among activities in different zones are used to generate origin-destination matrices of different types of trips, such as home-to-work trips for labor movements from producers (households) to consumers (employers) and goods movements for various industry-to-industry interactions. These matrices are loaded on a multimodal network with capacity restraint using typical nested logit mode forms for mode and route choice (Abraham, 1999).

The strength of the MEPLAN model includes the realistic representation of current and continuing patterns, the close linkages between different industry and household types, and the market-based nature of the model. The weaknesses include the aggregate nature of the model and the possibility of difficulties in establishing realistic, alternative, specific constants (Abraham, 1999).

\subsubsection{Kim’s Chicago Model}

Kim's Integrated Urban Systems model for Chicago integrates a general system equilibrium with probabilistic spatial interactions, combined transportation-facility location models, and equilibrated demand and supply over networks (Zhao et al., 2003). It offers a computationally tractable model with strong ties back to urban economic principles. The model generates a general equilibrium solution between the demand and supply of transportation and activity locations in the strict economic sense (Southworth, 1995).

The objective function of the model is a joint minimization of the solution to a Wardrop equilibrium assignment of flows to network links; the total costs of exporting commodities out of the urban system; and the total land plus rental costs summed all over the zones, commodities, and production techniques used in the urban system. Kim has managed to calibrate the model using various and extensive data sources collected for the Chicago region. The main advantage of this approach is that it demonstrates the possibility of bringing important aspects of urban economic theory into intersectional, spatial-interaction-based discrete choice model in order to move towards more comprehensive urban modeling frameworks (Southworth, 1995). 


\subsubsection{URBANSIM Model}

UrbanSim is a simulation model for integrated planning and analysis of urban development, incorporating the interactions between land use, transportation, and public policy (Zhao et al., 2003). The design of UrbanSim differs significantly from several existing operational modeling approaches. It pursues an approach that is disaggregate and based on predicting changes over small time steps. Table 2-3 shows the differences by comparing some key features of UrbanSim and other land use and transport models (Waddell, 2002).

Table 2-3. Comparison of operational model characteristics (Waddell, 2002)

\begin{tabular}{|c|c|c|c|c|}
\hline Characteristic & DRAM/EMPAL & $\begin{array}{l}\text { MEPLAN and } \\
\text { TRANUS }\end{array}$ & CUF-2 & UrbanSim \\
\hline Model Structure & Spatial Interaction & Spatial Input-Output & Discrete Choice & Discrete Choice \\
\hline $\begin{array}{l}\text { Household Location } \\
\text { Choice }\end{array}$ & Modeled & Modeled & Not Modeled & Modeled \\
\hline Household Classification & Aggregate, 8 Categories & Aggregate, User Defined & Not Represented & $\begin{array}{l}\text { Disaggregate, Income, } \\
\text { Persons, Workers, Child }\end{array}$ \\
\hline $\begin{array}{l}\text { Employment Location } \\
\text { Choice }\end{array}$ & Modeled & Modeled & Not Modeled & Modeled \\
\hline $\begin{array}{l}\text { Employment } \\
\text { Classification }\end{array}$ & Aggregate, 8 Categories & Aggregate, User Defined & Not Modeled & $\begin{array}{l}\text { Disaggregate, } 10-20 \\
\text { Sectors }\end{array}$ \\
\hline $\begin{array}{l}\text { Real Estate } \\
\text { Development }\end{array}$ & Not Modeled & Modeled & Modeled & Modeled \\
\hline $\begin{array}{l}\text { Real Estate } \\
\text { Classification }\end{array}$ & 4 Land Uses & Aggregate, User Defined & 7 land Uses & 24 Development Types \\
\hline Real Estate Measures & Acres & Acres, Units, Floorspace & Acres & Acres, Units, Floorspace \\
\hline Real Estate Prices & Not Modeled & Modeled & Not Modeled & Modeled \\
\hline Geographic Basis & $\begin{array}{l}\text { Census Tracts of } \\
\text { Aggregates }\end{array}$ & $\begin{array}{l}\text { User Defined Zones (2- } \\
300)\end{array}$ & Grid Cells & Grid Cells \\
\hline Temporal Basis & $\begin{array}{l}\text { Quasi-dynamic, } \\
\text { Equilibrium ( } 5-10 \text { year } \\
\text { steps) }\end{array}$ & $\begin{array}{l}\text { Cross-Sectional } \\
\text { Equilibrium }\end{array}$ & Annual, Dynamic & Annual, Dynamic \\
\hline $\begin{array}{l}\text { Interaction with Travel } \\
\text { Modes }\end{array}$ & Yes & Yes & No & Yes \\
\hline $\begin{array}{l}\text { Modular Model } \\
\text { Structure }\end{array}$ & Partial & No & No & Yes \\
\hline Software Access & Proprietary & Proprietary & NA & Open Source \\
\hline
\end{tabular}

The data integration process for UrbanSim is shown in Figure 2-8. The input data are called the data store, including parcel files from tax assessor offices, business establishment files from commercial sources, census and PUMS data, and GIS data representing environmental, political and planning boundaries. The data store represents 
each household in the metropolitan area as an individual object and locations use grid cells of 150 by 150 meters (Waddell, 2002).

The structure and processing sequence of UrbanSim are shown in Figure 2-8. UrbanSim has eight core models (Waddell, 2002):

- Demographic Transition Model simulates births and deaths in the population of households with externally imposed population control totals. The distribution of income groups, age, size can also be specified. Iterative proportional fitting is used to determine how many households of each type are to be created or deleted.

- Economic Transition Model is responsible for modeling job creation and loss. Employment control totals determine employment targets. The distribution of business sector can be specified.

- Household Mobility Model simulates households deciding whether to move, based on historical data.

- Employment Mobility Model simulates which jobs will move from their current locations during a particular year.

- Household Location Model locates each household that has no current location from a sample of locations with vacant housing units. A multinomial logit model is calibrated to observed data using attributes of the housing in the grid cell (price, density age), neighborhood characteristics (land use mix, density, average property values, local accessibility to retail), and regional accessibility to jobs.

- Employment Location Model is responsible for determining a location for each job that has no location. A sample of locations is randomly selected from the set of all possible alternatives.

- Real Estate Development Model simulates developer choices about the location and type of construction to undertake, including both new development and redevelopment of existing structures.

- Land Price Model simulates land prices of each grid cell as the characteristics of locations change over time, based on urban economic theory. The model is 
calibrated from historical data using a hedonic regression to include the effect of site, neighborhood, accessibility, and policy effects on land prices.

Data Store
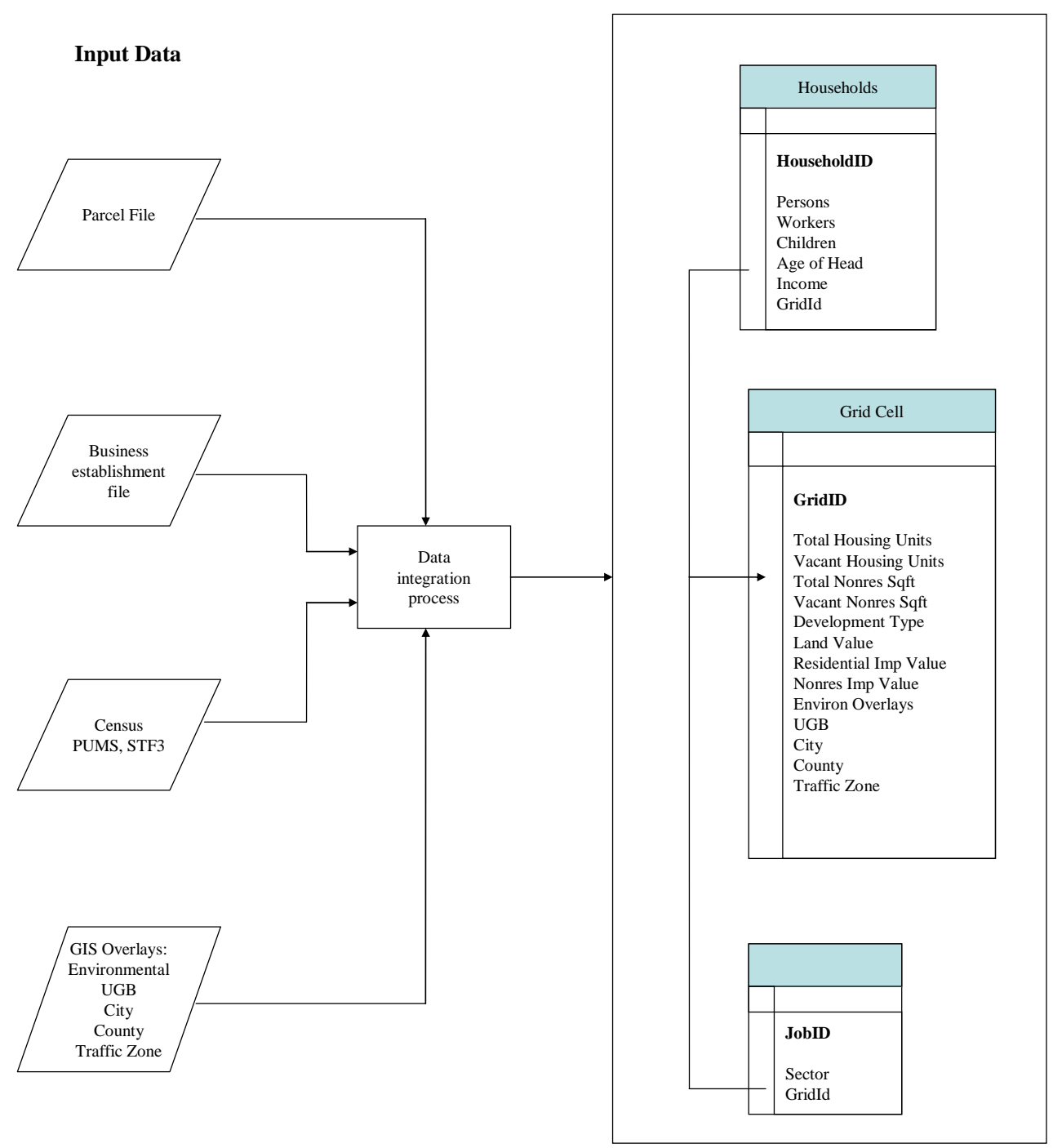

Figure 2-8. UrbanSim data integration process (Waddell, 2002) 


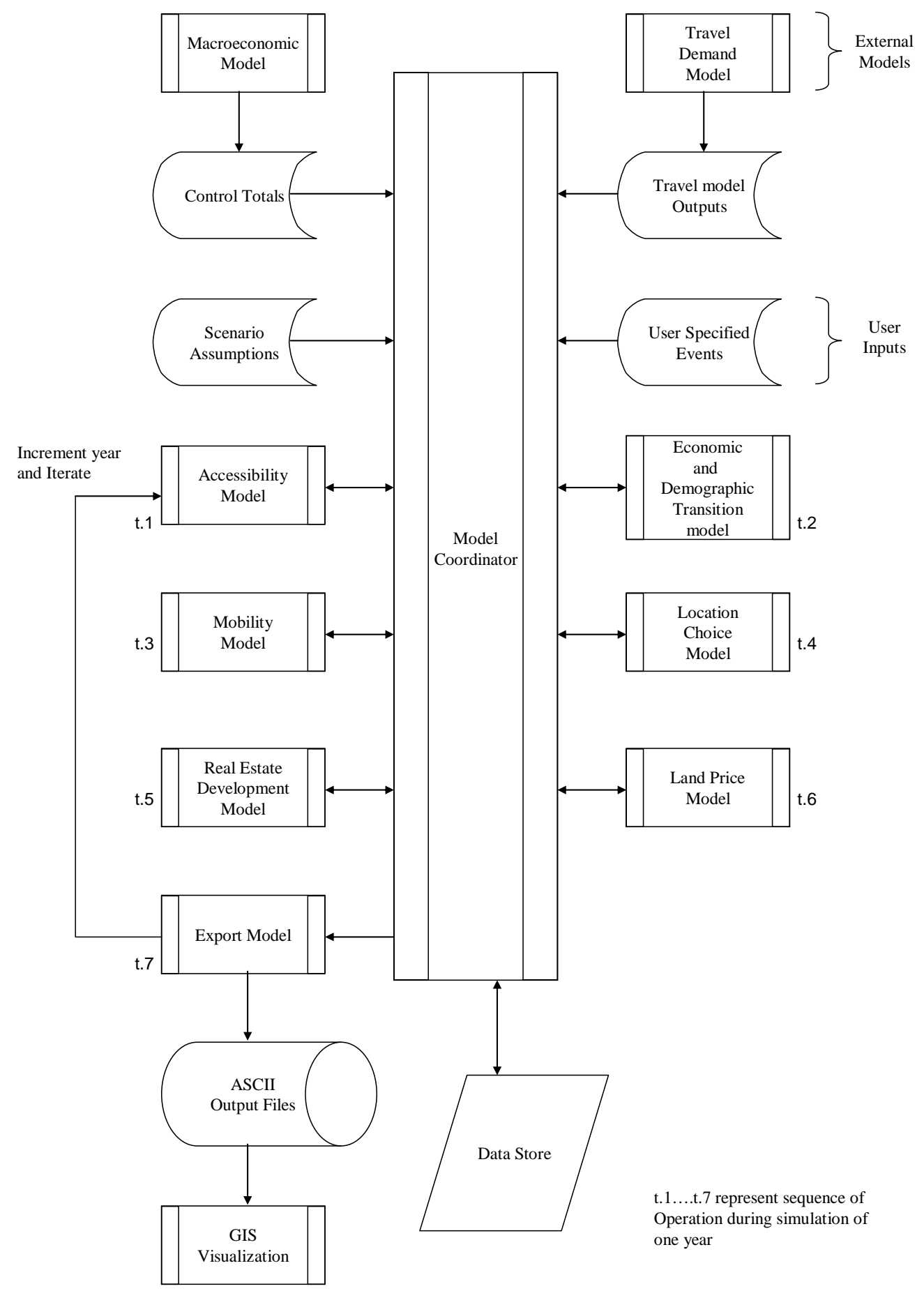

Figure 2-9. UrbanSim Model Structure and Processing (Waddell, 2002) 


\section{$\underline{2.3 \text { Summary }}$}

Two major trends in transportation and land use modeling can be derived from the existing literature (Pfaffenbichler, 2003):

- Using a disaggregate approach

- The integration of GIS systems

The past and future evolution of transportation and land use models is shown in Figure 2-10. The activity based model is the ideal goal in the future.

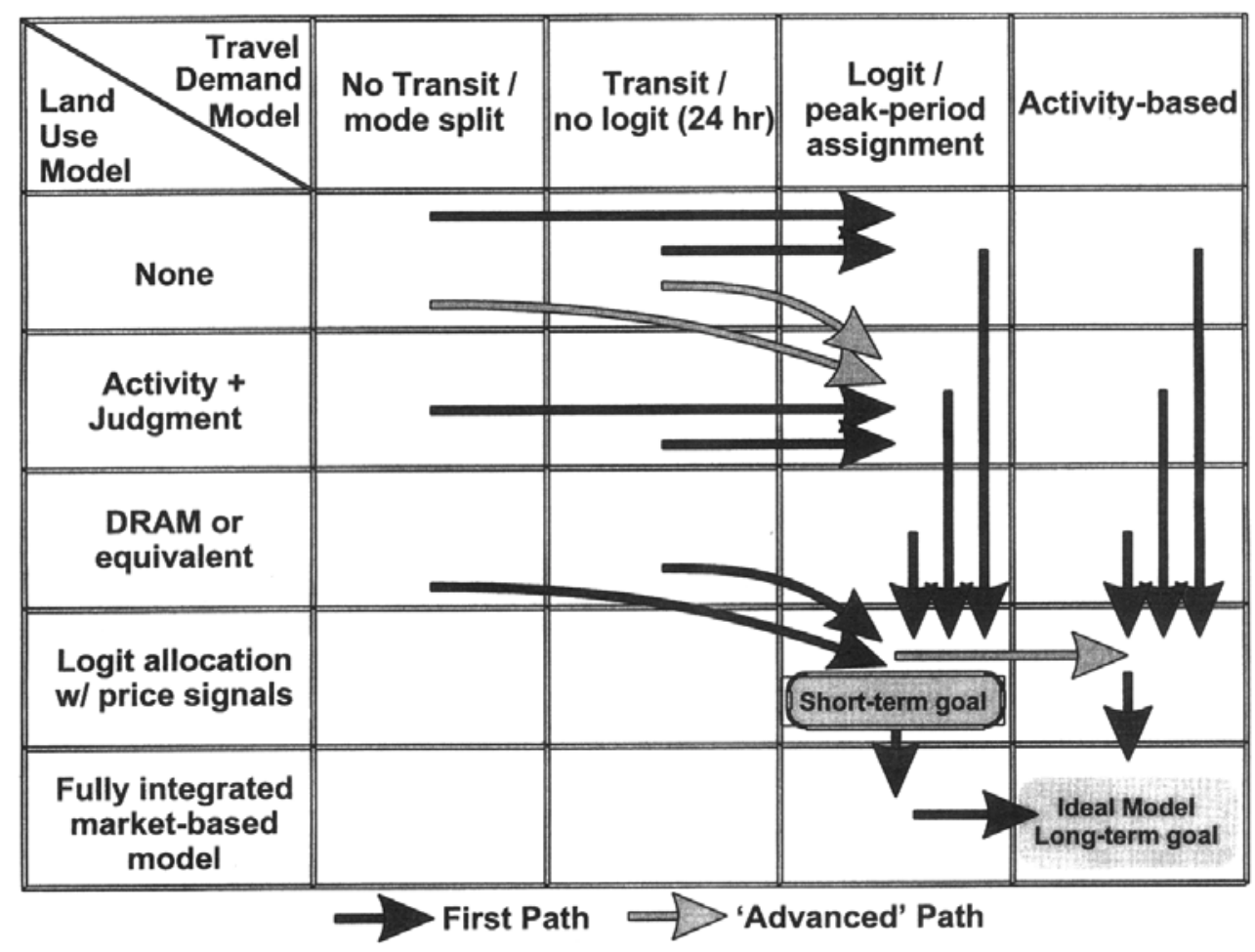

Figure 2-10. Evolution of urban land-use transport models (Miller et al., 1998)

The Indiana statewide travel demand and land use models have an extremely large scope. It is unrealistic to deal with such large statewide models using a disaggregate approach, due to the computational capability. Therefore, the aggregate "Land Use in Central Indiana 2” (LUCI2) urban simulation statewide model is chosen to be integrated with the Indiana's statewide travel demand model. Different traffic improvement and land use scenarios can be compared and tested in this integrated transportation and land use model environment. 


\section{CHAPTER 3. AN INTEGRATED ISTDM-LUCI2 MODEL SYSTEM}

In responding to the USDOT emphasis on assessing the impacts of transportation improvements using a transportation-land use model system, an integrated model system has been built upon past and current INDOT’s work by linking transportation and land use simulation models (Fricker and Ottensmann, 2005).

The Indiana Statewide Travel Demand Model v.4 (ISTDM v.4), developed by Bernardin, Lochmueller \& Associates, Inc. and Cambridge Systematics, Inc., is a fourstep travel demand model that includes all ninety-two counties in Indiana and encompasses parts of neighboring states.

The Land Use in Central Indiana (LUCI) urban simulation model, developed by Ottensmann (2003), was initially implemented for a 44-county region in central Indiana. The model generated alternative development scenarios incorporating different policy choices about future land use developments using urban development data in year 1985, 1993, and 2000, derived from Landsat Thematic Mapper satellite images with 30-meter resolution. The LUCI model relied on the random utility and discrete choice theory as the basis for predicting urbanization. The LUCI2 urban simulation model, which extends the LUCI model, covers the entire state and is integrated with the ISTDM model in this study.

In this chapter, the ISTDM v.4 and the LUCI2 urban simulation model are briefly introduced. The integrated ISTDM-LUCI2 model approach is then presented and the outputs from the integrated ISTDM-LUCI2 model system are compared with the outputs from the original ISTDM model. 


\subsection{The ISTDM v.4 Model}

\subsubsection{Introduction}

The ISTDM v.4 includes county roads and local streets for all ninety-two counties. The base year network consists of over 20,000 links (or 11,200 road miles) for state jurisdictional highways and over 11,900 links (or 7,800 road miles) for local roads in Indiana (ISTDM Upgrade-Technical Memorandum, 2005).

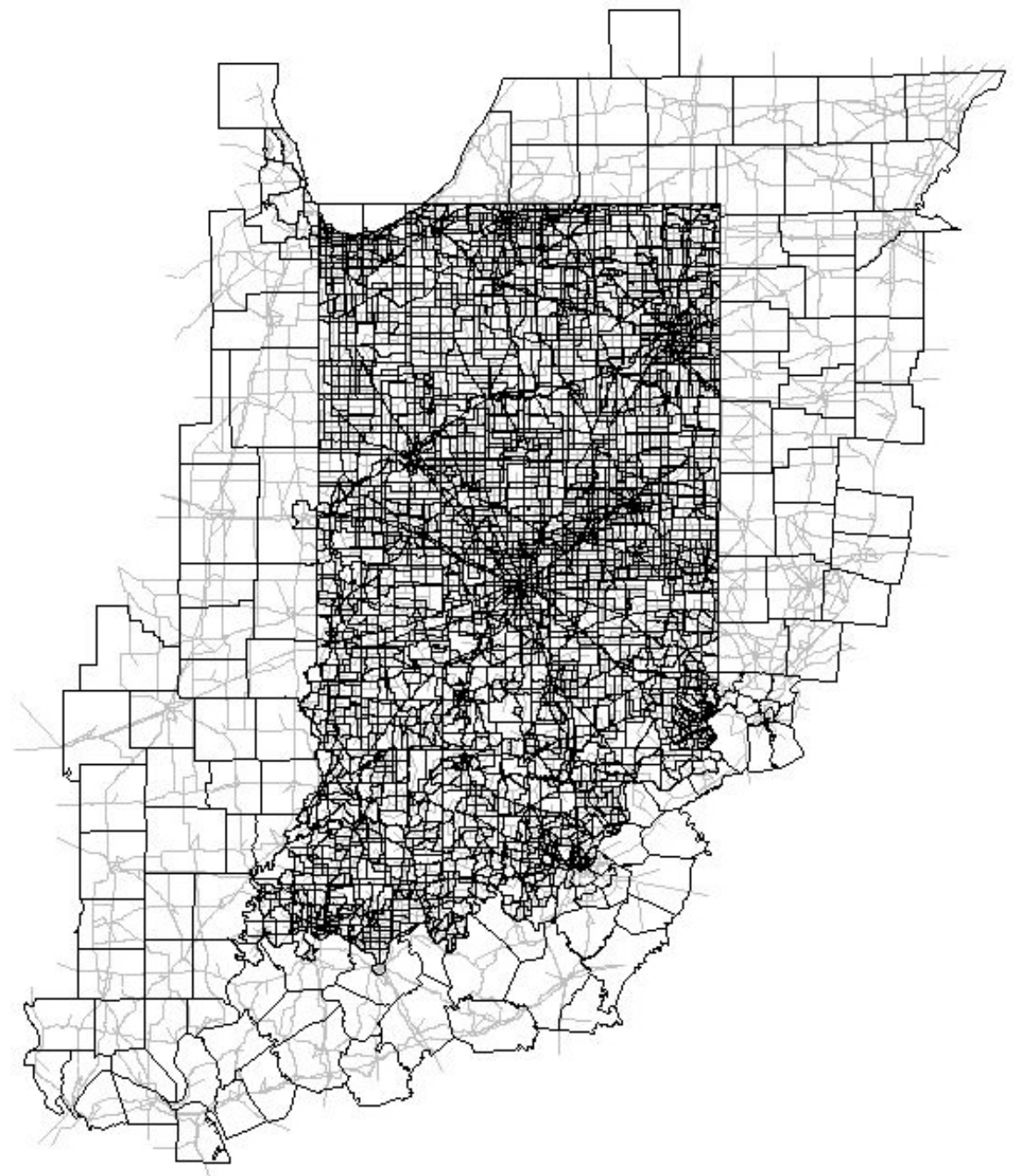

Figure 3-1. ISTDM v.4 model area 
The ISTDM v.4 model has 4720 TAZs (including 141 external TAZs). These traffic TAZ zones are conjoined with the roadway network via 9,900 centroid connectors. Figure 3-1 shows the ISTDM v.4 roadway network and TAZs.

Several enhancements are made in the ISTDM v.4 model, compared with the previous version of the ISTDM. The main improvements include (ISTDM UpgradeTechnical Memorandum, 2005):

- Network and traffic analysis zone developments: INDOT's new Road Inventory Data (RID) for year 2000 is attached to the roadways network. TAZ structure is refined by adding a significant number of TAZs within Indiana. These refinements in the network and TAZ data improve the model's overall reliability and accuracy.

- Traffic signals: the locations of traffic signals along with priority of signal approaches and number of upstream signals are coded statewide in the road network. This information associated with traffic signals is used for estimating realistic link impedance.

- New procedures for estimating free-flow speed and capacity: a new procedure was developed to estimate free-flow speed and link capacity based on the Highway Capacity Manual 2000.

- Development of stratification curves: stratification curves are used to place households into classification categories over time based on average zonal characteristics.

- Trip generation models: the base year trip generation models are updated based on year 2000 census data.

- Gravity model factors: new friction factor curves are recalibrated to address the refined transportation network. Friction factors for long trips are developed by a smoothing curve. K-factors are applied by trip purpose and validated to account for factors not explained by fraction factors.

- Model choice: model shares for HBW, HBO, and NHB trip purposes are reviewed and updated to account for the area types, based on the 1995 Indiana Travel Survey and the 2001 NHTS Survey. 
- Truck model: freight and non-freight trucks are estimated separately. For freight trucks, base year 1993 truck trip tables from the Indiana University study are factored up to a year 2000 level by commodity group. Non-freight truck trip tables are estimated with ODME procedures, using link freight loadings subtracted from INDOT link counts.

- Trip assignment: the trip assignment process is changed from free-flow based assignment of trucks as a "pre-load" to "simultaneous multi-modal multi-class assignment”. Multiple volume-delay functions are specified, based on extensive experimentation with the functions made during model validation.

\subsubsection{Trip Generation}

Home-based work, home-based other, non-home-based, and long purpose trips are analyzed in the trip generation step. In the ISTDM v.4, trip production models are estimated using cross-classification techniques. Trip attraction models are estimated using regression techniques. Models are developed using the 1995 Indiana Household Survey and the 2001 NHTS dataset (ISTDM Upgrade-Technical Memorandum, 2005).

In order to apply the cross-classified trip rates developed from the analysis of the household survey data, it is necessary to understand the distribution of the household types within each TAZ. In the base year, this distribution is available from Census data, and in the ISTDM v.4 for future years, the breakout (cross-classification) is estimated by the application of stratification curves as a function of the average zonal characteristics. Figure 3-2 to Figure 3-4 present the stratification curves applied to the average zonal variables. 


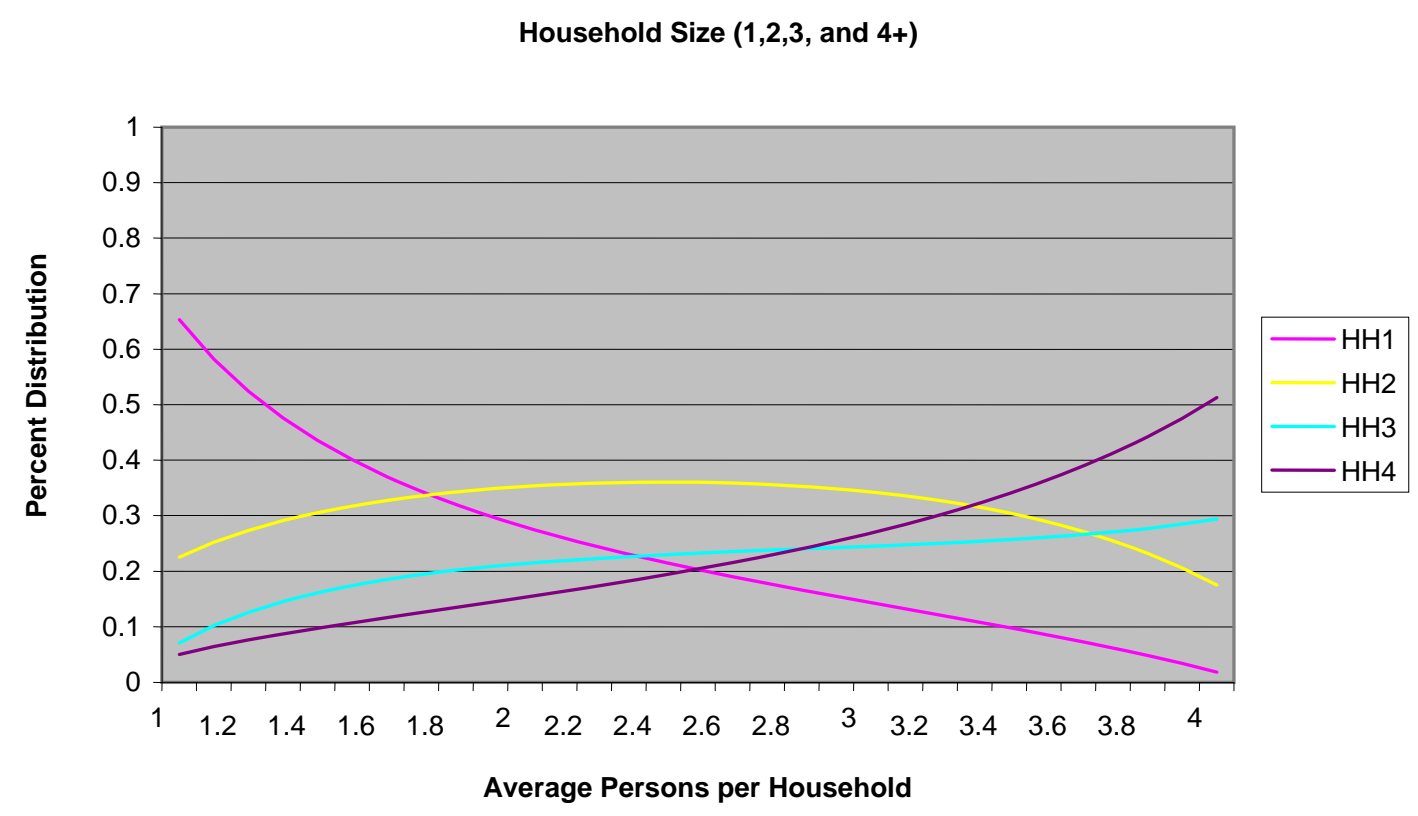

Figure 3-2. Household size stratification curves (Source: ISTDM Upgrade-Technical Memorandum, 2005)

Household Vehicles (0, 1, 2, 3+)

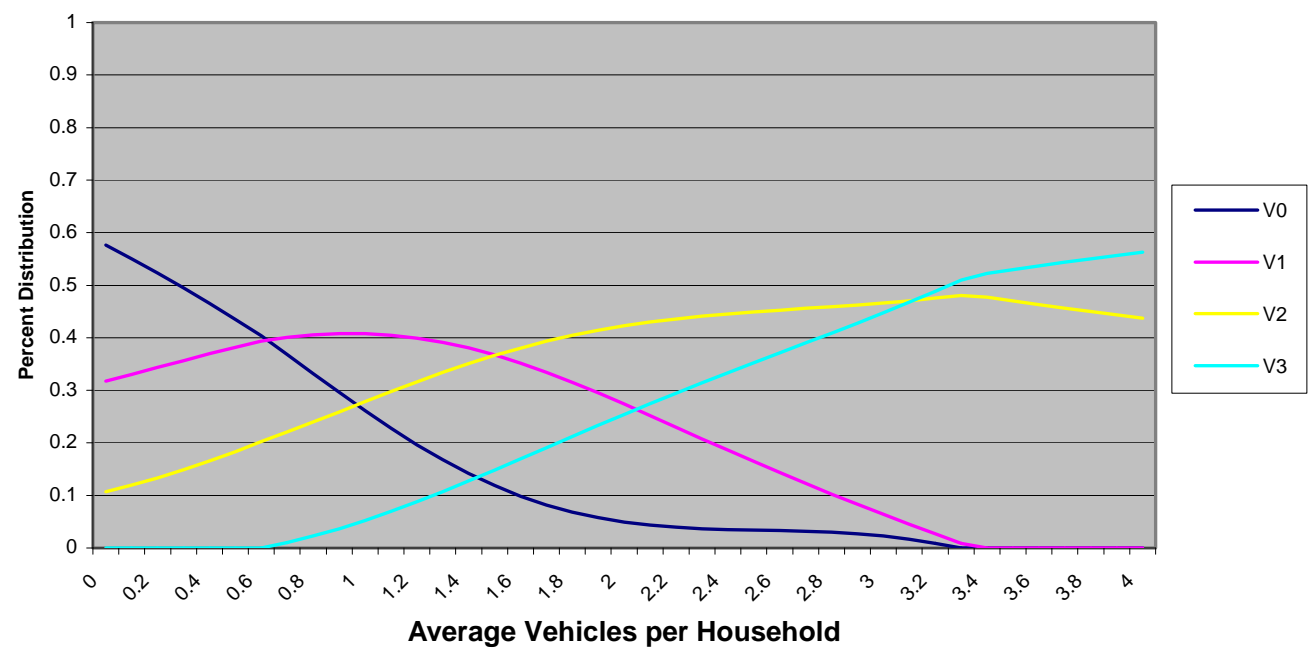

Figure 3-3. Household vehicle stratification curves (Source: ISTDM Upgrade-Technical Memorandum, 2005) 


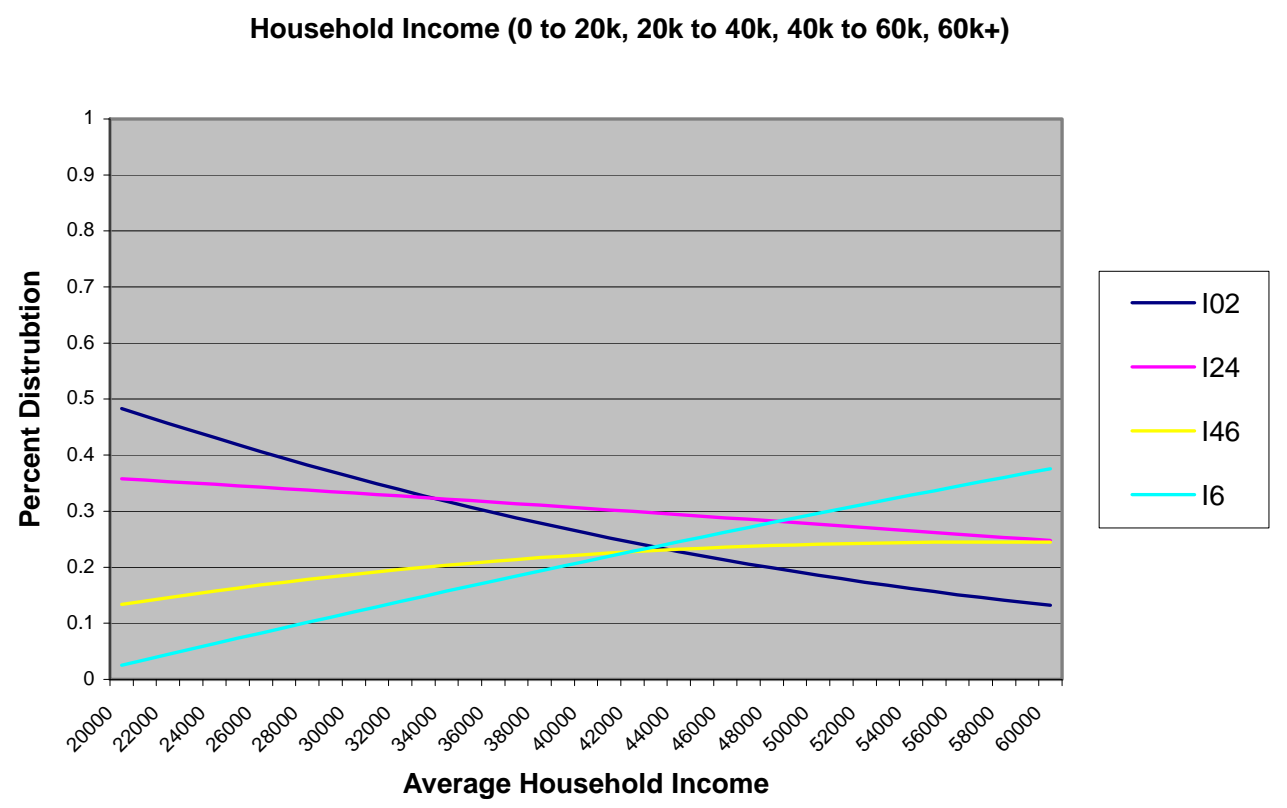

Figure 3-4. Household income stratification curves (Source: ISTDM Upgrade-Technical Memorandum, 2005)

The cross-classified trip rates are developed based on the observed data from the 1995 Indiana Travel Survey and the 2001 NHTS. Tables 3-1 to 3-4 show the crossclassified trip production rates by area type, household size, and auto ownership or income category for each trip purpose.

Table 3-1. Trip production rates for Home-Based Work trip purpose

(Average weekday trips per household)

\begin{tabular}{|c|c|c|c|c|c|}
\hline \multirow{3}{*}{ Area Type } & \multirow{2}{*}{ Household Size } & \multicolumn{4}{|c|}{ Vehicles Available } \\
\cline { 2 - 6 } & & $\mathbf{0}$ & $\mathbf{1}$ & $\mathbf{2}$ & $\mathbf{3 +}$ \\
\hline \multirow{3}{*}{ Urban } & 1 & 0.564 & 1.127 & 1.127 & 1.127 \\
\cline { 2 - 6 } & 2 & 1.235 & 1.678 & 2.147 & 2.147 \\
\cline { 2 - 6 } & 3 & 1.571 & 1.786 & 2.752 & 3.396 \\
\cline { 2 - 6 } & $4+$ & 2.027 & 2.120 & 3.101 & 3.785 \\
\hline \multirow{3}{*}{ Suburban } & 1 & 0.513 & 1.015 & 1.015 & 1.015 \\
\cline { 2 - 6 } & 2 & 1.118 & 1.518 & 1.939 & 1.939 \\
\cline { 2 - 6 } & 3 & 1.426 & 1.621 & 2.492 & 3.077 \\
\cline { 2 - 6 } & $4+$ & 1.826 & 1.918 & 2.810 & 3.426 \\
\hline \multirow{3}{*}{ Rural } & 1 & 0.574 & 1.149 & 1.149 & 1.149 \\
\cline { 2 - 6 } & 2 & 1.262 & 1.703 & 2.185 & 2.185 \\
\cline { 2 - 6 } & 3 & 1.600 & 1.826 & 2.800 & 3.457 \\
\cline { 2 - 6 } & $4+$ & 2.062 & 2.154 & 3.159 & 3.857 \\
\hline
\end{tabular}

Source: ISTDM Upgrade-Technical Memorandum, 2005 
Table 3-2. Trip production rates for Home-Based Other trip purpose

(Average weekday trips per household)

\begin{tabular}{|c|c|c|c|c|c|}
\hline \multirow{2}{*}{ Area Type } & \multirow{2}{*}{ Household Size } & \multicolumn{4}{|c|}{ Vehicles Available } \\
\cline { 2 - 6 } & & $\mathbf{0}$ & $\mathbf{1}$ & $\mathbf{2}$ & $\mathbf{3 +}$ \\
\hline \multirow{3}{*}{ Urban } & 1 & 1.264 & 2.404 & 2.404 & 2.404 \\
\cline { 2 - 6 } & 2 & 2.945 & 4.863 & 5.235 & 5.235 \\
\cline { 2 - 6 } & 3 & 4.874 & 6.838 & 6.973 & 7.424 \\
\cline { 2 - 6 } & $4+$ & 7.797 & 9.297 & 11.158 & 12.377 \\
\hline \multirow{4}{*}{ Suburban } & 1 & 1.077 & 2.051 & 2.051 & 2.051 \\
\cline { 2 - 6 } & 2 & 2.513 & 4.154 & 4.462 & 4.462 \\
\cline { 2 - 6 } & 3 & 4.164 & 5.836 & 5.959 & 6.339 \\
\cline { 2 - 6 } & $4+$ & 6.657 & 7.939 & 9.529 & 10.565 \\
\hline \multirow{3}{*}{ Rural } & 1 & 1.036 & 1.969 & 1.969 & 1.969 \\
\cline { 2 - 6 } & 2 & 2.421 & 3.980 & 4.287 & 4.287 \\
\cline { 2 - 6 } & 3 & 3.990 & 5.600 & 5.713 & 6.082 \\
\cline { 2 - 6 } & $4+$ & 6.390 & 7.621 & 9.149 & 10.134 \\
\hline
\end{tabular}

Source: ISTDM Upgrade-Technical Memorandum, 2005

Table 3-3. Trip production rates for Non Home-Based trip purpose

(Average weekday trips per household)

\begin{tabular}{|c|c|c|c|c|c|}
\hline \multirow{2}{*}{ Area Type } & \multirow{2}{*}{ Household Size } & \multicolumn{4}{|c|}{ Vehicles Available } \\
\cline { 2 - 6 } & & $\mathbf{0}$ & $\mathbf{1}$ & $\mathbf{2}$ & $\mathbf{3 +}$ \\
\hline \multirow{3}{*}{ Urban } & 1 & 0.676 & 1.625 & 1.625 & 1.625 \\
\cline { 2 - 6 } & 2 & 1.151 & 2.335 & 2.561 & 2.561 \\
\cline { 2 - 6 } & 3 & 1.828 & 2.730 & 2.923 & 3.633 \\
\cline { 2 - 6 } & $4+$ & 2.121 & 3.803 & 4.942 & 5.033 \\
\hline \multirow{3}{*}{ Suburban } & 1 & 0.923 & 2.226 & 2.226 & 2.226 \\
\cline { 2 - 6 } & 2 & 1.580 & 3.190 & 3.508 & 3.508 \\
\cline { 2 - 6 } & 3 & 2.503 & 3.744 & 4.000 & 4.964 \\
\cline { 2 - 6 } & $4+$ & 2.892 & 5.200 & 6.759 & 6.893 \\
\hline \multirow{3}{*}{ Rural } & 1 & 0.656 & 1.600 & 1.600 & 1.600 \\
\cline { 2 - 6 } & 2 & 1.139 & 2.287 & 2.523 & 2.523 \\
\cline { 2 - 6 } & 3 & 1.795 & 2.687 & 2.872 & 3.569 \\
\cline { 2 - 6 } & $4+$ & 2.082 & 3.734 & 4.852 & 4.944 \\
\hline
\end{tabular}

Source: ISTDM Upgrade-Technical Memorandum, 2005

Table 3-4. Trip production rates for long trip purpose

(Average weekday trips per household)

\begin{tabular}{|c|c|c|c|c|}
\hline \multirow{2}{*}{ Income Category } & \multicolumn{4}{|c|}{ Vehicles Available } \\
\cline { 2 - 5 } & $\mathbf{0}$ & $\mathbf{1}$ & $\mathbf{2}$ & $\mathbf{3 +}$ \\
\hline \$0 to $\$ 20 \mathrm{k}$ & 0.0099 & 0.0300 & 0.0579 & 0.0595 \\
\hline \$20k to \$40k & 0.0199 & 0.0599 & 0.1157 & 0.1188 \\
\hline \$40k to \$60k & 0.0245 & 0.0737 & 0.1424 & 0.1461 \\
\hline \$60k & 0.0377 & 0.1136 & 0.2195 & 0.2252 \\
\hline
\end{tabular}

Source: ISTDM Upgrade-Technical Memorandum, 2005 
Trip attraction rates are estimated from the 1995 Indiana household survey. Table 35 shows the regression parameters for the trip attraction models.

Table 3-5. Regression models by trip purpose for trip attraction

\begin{tabular}{|c|c|c|}
\hline Trip Purpose & Variable & $\begin{array}{l}\text { Parameter } \\
\text { Estimate }\end{array}$ \\
\hline \multirow{3}{*}{$\begin{array}{l}\text { Home-Based } \\
\text { Work Trips }\end{array}$} & Intercept & 0.000 \\
\hline & $\begin{array}{l}\text { Employment in Retail, FIRE, Education, Services, and Government } \\
\text { Sectors }\end{array}$ & 1.400 \\
\hline & $\begin{array}{l}\text { Employment in Non-Retail; Construction; Manufacturing; Agriculture, } \\
\text { Forestry and Fisheries; and Transportation Sectors }\end{array}$ & 1.120 \\
\hline \multirow{5}{*}{$\begin{array}{l}\text { Home-Based } \\
\text { Other Trips }\end{array}$} & Intercept & 0.000 \\
\hline & Employment in Retail Sector & 4.850 \\
\hline & Employment in FIRE, Education, Services, and Retail Sectors & 3.200 \\
\hline & Employment in Education Sector & 1.750 \\
\hline & Households & 1.650 \\
\hline \multirow{5}{*}{$\begin{array}{l}\text { Non-Home- } \\
\text { Based Trips }\end{array}$} & Intercept & 0.000 \\
\hline & Employment in Retail Sector & 4.490 \\
\hline & Employment in FIRE, Education, Services, and Government Sectors & 1.130 \\
\hline & $\begin{array}{l}\text { Employment in Non-Retail, Construction, Manufacturing, and } \\
\text { Transportation Sectors }\end{array}$ & 0.380 \\
\hline & Households & 0.590 \\
\hline \multirow{5}{*}{ Long Trips } & Intercept & 0.000 \\
\hline & Total Employment & 0.023 \\
\hline & Employment in FIRE, Education, Services, and Government Sectors & 0.090 \\
\hline & $\begin{array}{l}\text { Employment in Agriculture, Forestry and Fisheries; Mining; } \\
\text { Construction; Manufacturing; Non-Retail; and FIRE Sectors }\end{array}$ & 0.030 \\
\hline & Employment in Retail and Services Sectors & 0.020 \\
\hline
\end{tabular}

Source: ISTDM Upgrade-Technical Memorandum, 2005

Note: Fire means Finance, Insurance, Real Estate

\subsubsection{Trip Distribution}

The friction factor in the Gravity model is the key component that represents the magnitude of impedances in traffic flows between pairs of TAZs. Friction factors are calibrated to observed travel times obtained from the 1995 Indiana Travel Survey and the 2001 NHTS. Table 3-6 presents the friction factors for home-based work, home-based other and non-home-based trips which are expressed by trip length in minutes (ISTDM Upgrade-Technical Memorandum, 2005). 
Table 3-6. Friction factors for HBW, HBO and NHB trips

\begin{tabular}{|c|c|c|c||c|c|c|c|}
\hline Trip Length & HBW & HBO & NHB & Trip Length & HBW & HBO & NHB \\
\hline 1 & 92.1 & 175.3 & 118.5 & 31 & 1240.0 & 128.8 & 52.3 \\
\hline 2 & 500.0 & 1000.0 & 7500.0 & 32 & 600.0 & 82.6 & 45.3 \\
\hline 3 & 2000.0 & 18000.0 & 12000.0 & 33 & 359.7 & 132.3 & 42.4 \\
\hline 4 & 5000.0 & 32000.0 & 15000.0 & 34 & 290.0 & 74.4 & 46.7 \\
\hline 5 & 10000.0 & 45916.3 & 20000.0 & 35 & 149.4 & 158.3 & 18.6 \\
\hline 6 & 15000.0 & 44415.5 & 25000.0 & 36 & 237.3 & 31.6 & 11.5 \\
\hline 7 & 32794.2 & 39789.1 & 30000.0 & 37 & 188.2 & 90.8 & 12.5 \\
\hline 8 & 42000.0 & 32876.8 & 40000.0 & 38 & 187.2 & 44.4 & 10.7 \\
\hline 9 & 32000.0 & 47258.0 & 45000.0 & 39 & 141.0 & 32.4 & 7.6 \\
\hline 10 & 15000.0 & 45645.2 & 22000.0 & 40 & 145.0 & 22.3 & 9.7 \\
\hline 11 & 10000.0 & 31233.7 & 13287.2 & 41 & 164.9 & 22.0 & 11.3 \\
\hline 12 & 6862.8 & 22055.5 & 7768.0 & 42 & 111.5 & 22.5 & 13.2 \\
\hline 13 & 6862.8 & 15589.0 & 3000.0 & 43 & 112.2 & 32.2 & 10.6 \\
\hline 14 & 5459.0 & 9782.0 & 2492.4 & 44 & 63.1 & 12.5 & 14.3 \\
\hline 15 & 6421.5 & 4736.1 & 2492.4 & 45 & 121.7 & 10.2 & 6.6 \\
\hline 16 & 3618.6 & 3536.9 & 2000.0 & 46 & 117.6 & 14.9 & 6.8 \\
\hline 17 & 2994.9 & 2129.7 & 1400.0 & 47 & 74.2 & 13.5 & 2.4 \\
\hline 18 & 2227.1 & 2696.8 & 1200.0 & 48 & 78.6 & 12.0 & 13.1 \\
\hline 19 & 1878.7 & 2089.9 & 1001.1 & 49 & 64.3 & 14.0 & 5.2 \\
\hline 20 & 2638.1 & 1401.2 & 702.5 & 50 & 57.8 & 6.2 & 10.6 \\
\hline 21 & 2277.3 & 1196.9 & 484.0 & 51 & 92.8 & 3.2 & 1.3 \\
\hline 22 & 1917.7 & 1087.3 & 331.5 & 52 & 34.2 & 11.7 & 3.2 \\
\hline 23 & 1447.1 & 605.7 & 231.2 & 53 & 25.8 & 16.6 & 2.4 \\
\hline 24 & 1056.6 & 521.0 & 167.5 & 54 & 44.2 & 12.6 & 2.0 \\
\hline 25 & 886.3 & 500.7 & 149.6 & 55 & 55.8 & 11.0 & 4.2 \\
\hline 26 & 932.7 & 444.6 & 168.2 & 56 & 29.7 & 7.8 & 2.1 \\
\hline 27 & 578.6 & 308.3 & 91.1 & 57 & 31.7 & 2.3 & 2.7 \\
\hline 28 & 628.4 & 229.3 & 89.2 & 58 & 27.7 & 2.3 & 1.7 \\
\hline 29 & 483.8 & 220.7 & 84.4 & 59 & 31.3 & 0.0 & 3.9 \\
\hline 30 & 812.0 & 224.7 & 50.0 & 60 & 20.5 & 3.2 & 0.7 \\
\hline
\end{tabular}

Source: ISTDM Upgrade-Technical Memorandum, 2005

The friction factors for long trips are smoothed by using a modified version of exponential function in the following form:

$$
\mathrm{FF}_{\mathrm{LNG}}=425,000 \cdot e^{(-564.29 / T T-0.04 \cdot T T)}+1.5
$$

where:

$\mathrm{FF}_{\mathrm{LNG}}=$ friction factors for long trips, and

$\mathrm{TT}=$ travel time in minutes 
Figure 3-5 shows the smoothed friction factor curve for long trips with the unsmoothed friction factors used for the ISTDM v.3.

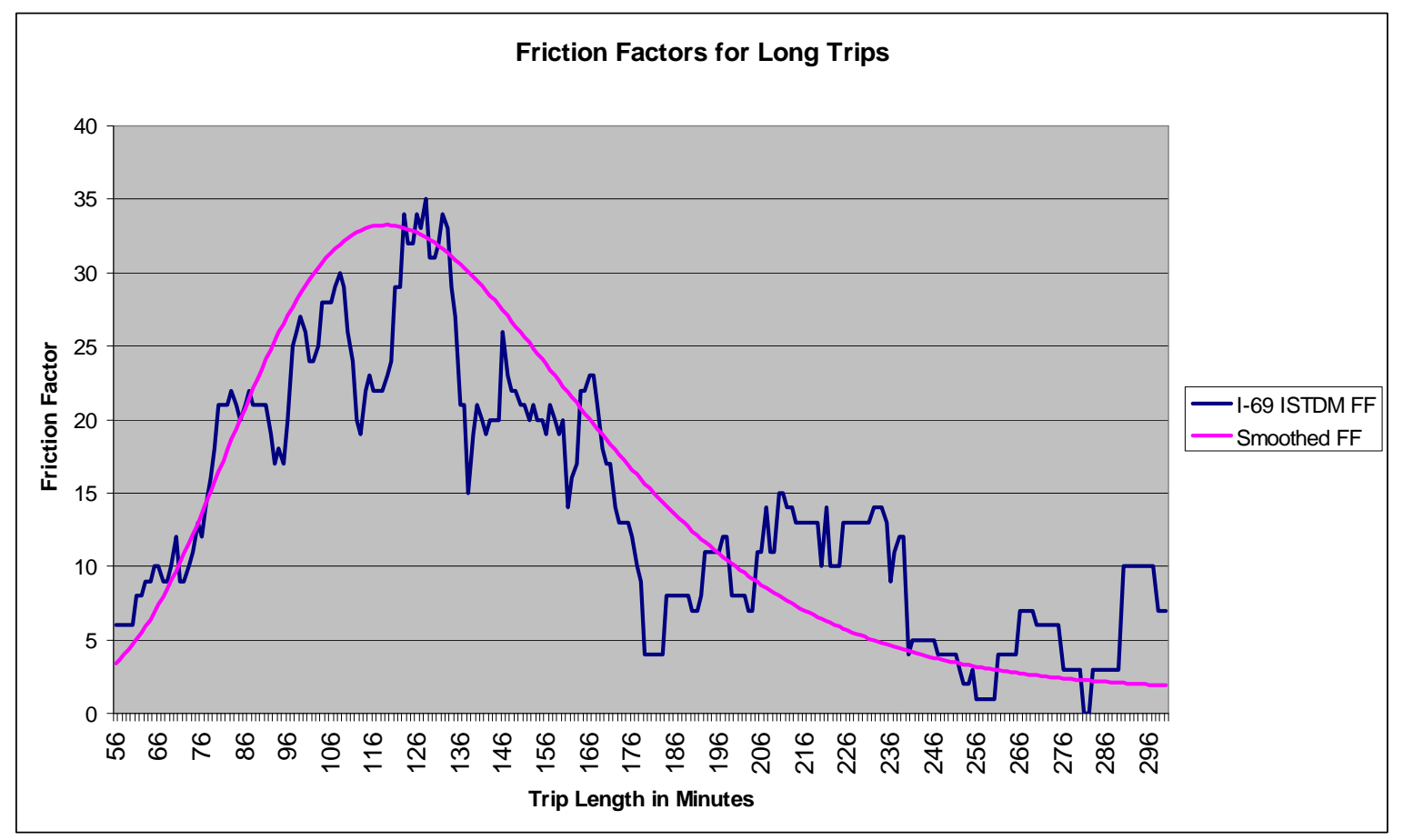

Figure 3-5. Friction Factors for Long Trips

(Source: ISTDM Upgrade-Technical Memorandum, 2005)

\subsubsection{Mode Choice}

The mode choices for HBW, HBO, and NHB trip purposes are based on the 1995 Indiana Travel Survey and the 2001 NHTS data. Table 3-7 shows the observed mode shares developed from the survey data. 
Table 3-7. Observed Mode Shares by Area Type and Trip Purpose

\begin{tabular}{|c|c|c|c|c|}
\hline Trip Purpose & Mode & Urban & Suburban & Rural \\
\hline \multirow{4}{*}{ HBW } & Auto & $93.8 \%$ & $99.7 \%$ & $98.1 \%$ \\
\cline { 2 - 5 } & Bus & $1.4 \%$ & $0.0 \%$ & $0.0 \%$ \\
\cline { 2 - 5 } & Walk & $1.2 \%$ & $0.3 \%$ & $1.9 \%$ \\
\cline { 2 - 5 } & Bike & $3.6 \%$ & $0.0 \%$ & $0.0 \%$ \\
\hline \multirow{4}{*}{ HBO } & Auto & $80.3 \%$ & $80.9 \%$ & $77.4 \%$ \\
\cline { 2 - 5 } & Bus & $1.3 \%$ & $0.2 \%$ & $0.0 \%$ \\
\cline { 2 - 5 } & School Bus & $8.8 \%$ & $15.7 \%$ & $16.8 \%$ \\
\cline { 2 - 5 } & Walk & $7.4 \%$ & $2.8 \%$ & $4.8 \%$ \\
\cline { 2 - 5 } & Bike & $2.2 \%$ & $0.5 \%$ & $1.0 \%$ \\
\hline \multirow{3}{*}{ NHB } & Auto & $97.7 \%$ & $97.4 \%$ & $97.0 \%$ \\
\cline { 2 - 5 } & Walk & $2.2 \%$ & $2.6 \%$ & $3.4 \%$ \\
\cline { 2 - 5 } & Bike & $0.1 \%$ & $0.0 \%$ & $0.1 \%$ \\
\hline
\end{tabular}

Source: ISTDM Upgrade-Technical Memorandum, 2005

The multinomial logit model is used for the long trip purpose. Table 3-8 presents the initial constants and coefficients transferred from the California High Speed Rail Study Model and the final bias constant applied during the re-calibration of the upgraded ISTDM.

Table 3-8. Multinomial Logit Model Parameters for Long Trip Purpose

\begin{tabular}{|c|c|c|}
\hline Variable & Original Values & Adjusted Values \\
\hline Cost (\$) & -0.0276 & -0.0276 \\
\hline IVTT - Line Haul Travel Time (min) & -0.0069 & -0.0069 \\
\hline OVTT - Access/Egress Time (min) & -0.0083 & -0.0083 \\
\hline Bias Constant & -0.87 & -1.15 \\
\hline
\end{tabular}

Source: ISTDM Upgrade-Technical Memorandum, 2005

\subsubsection{Trip Assignment}

The simultaneous multi-modal multi-class assignment (MMA) method is used in the ISTDM v.4 instead of the assignment based on a "pre-load". By this method, trucks are loaded to the network at the same time as auto trips. Truck assignment does not depend on free-flow conditions, but is subject to congestion-based situations. With the MMA method, truck loadings are more realistic (ISTDM Upgrade-Technical Memorandum, 2005).

The ISTDM v.4 has twenty-four hour trip assignment. Time-of-day procedures are removed. This change of design greatly reduces the model's run time. It also addresses 
possible issues regarding the independent validity of the time-of-day period assignments which could not independently validated due to lack of detailed count data in electronic form (ISTDM Upgrade-Technical Memorandum, 2005).

Multiple volume-delay functions (VDF) are specified by functional classification on the basis of extensive experimentation with the functions made during model validation. The sets of volume-delay parameters for the Indiana statewide model are presented in Figure 3-6 (ISTDM Upgrade-Technical Memorandum, 2005).

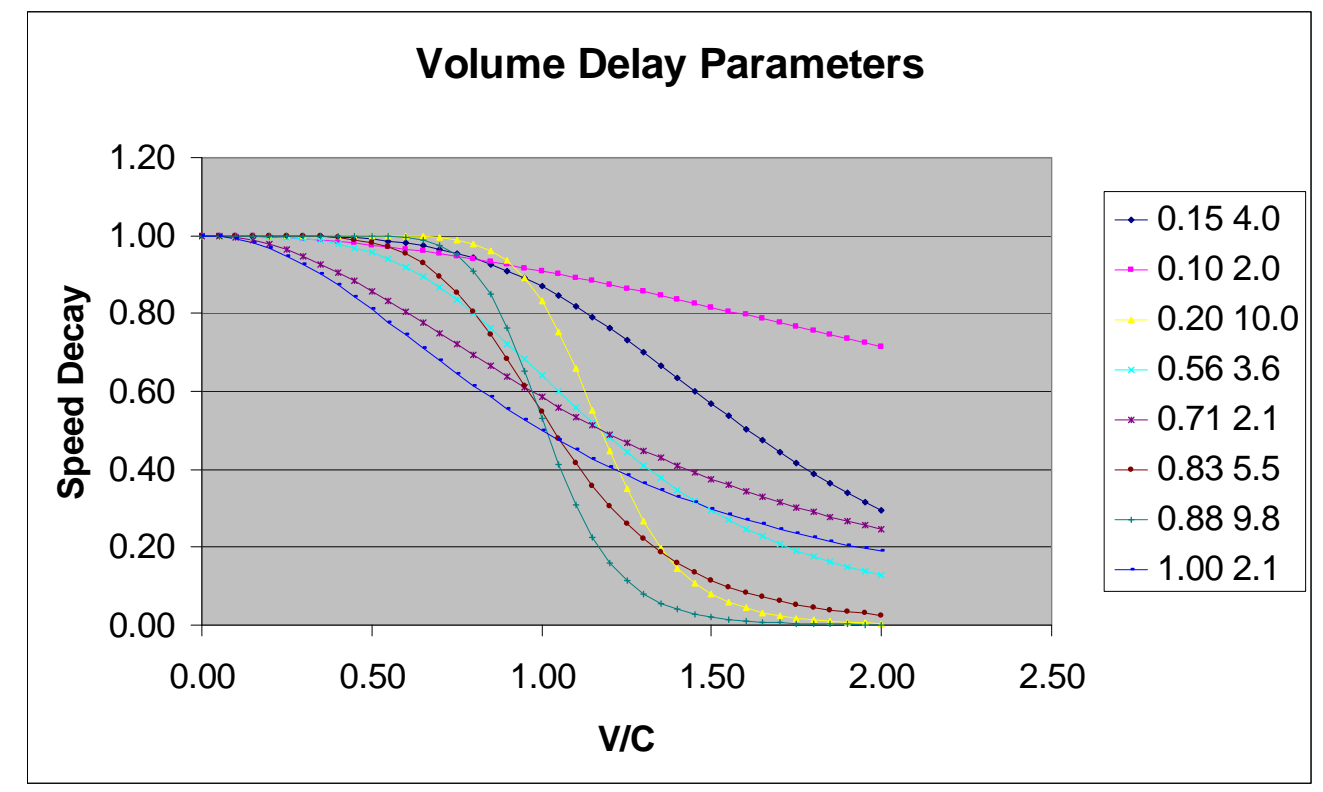

Figure 3-6. Multiple volume delay functions

(Source: ISTDM Upgrade-Technical Memorandum, 2005)

\subsection{LUCI2 Statewide Urban Simulation Model}

The LUCI2 statewide urban simulation model predicts changes in employment and conversion of nonurban land to residential and employment-related uses. The simulation model uses random utility theory, with aggregate logit discrete choice models for converting available nonurban land to residential and employment-related land uses (Ottensmann, 2007). 


\subsubsection{Residential Allocation model}

The residential development model of the LUCI2 urban simulation model includes two parts: a probability of residential development model and a density of residential development model. The formula for the probability of residential development model is an aggregate logit model (Ottensmann, 2007).

$$
\operatorname{logit}\left(p_{i}\right)=\log \left(\frac{p_{i}}{1-p_{i}}\right)
$$

where $p_{i}$ is the proportion of land converted to residential use. The equation for the aggregated logit model is:

$$
\operatorname{logit}\left(p_{i}\right)=\beta_{0}+\sum_{k} \beta_{k} X_{i k}
$$

where $\operatorname{logit}\left(p_{i}\right)$ is the logit proportion of converted land from year 1995 to year 2000 (reduced by 0.625 from year 1993 to year 2000 to match five-year period), $X_{i k}$ is the matrix of independent variables that include accessibility to employment in year 1995, sewer service dummy, proportion of residential land in the simulation zone and its square in year 1993, and logit proportion of converted land to residential from year 1985 to year 1993.

The accessibility to employment in year 1995 is calculated using the following formula:

$$
A_{i}=\sum_{j} E_{j} e^{\beta T_{i j}}
$$

where $E_{j}$ is employment in TAZ $j, T_{i j}$ is the congested travel time from TAZ $i$ to TAZ $j$, which is the output from the Indiana statewide four-step travel demand model, and $\beta$ is an empirically determined accessibility coefficient.

The formula for the population density of new residential development is a multiple regression model

$$
\log \left(D_{i}\right)=\beta_{0}+\sum_{k} \beta_{k} X_{i k}
$$

where $\log \left(D_{i}\right)$ is the natural logarithm of population density in year 2000, $X_{i k}$ is the matrix of independent variables, which includes the log accessibility to employment 
using year 2000 INDOT employment, sewer service dummy, and the natural logarithm of the percentage of students passing the Indiana Graduation Qualifying Examination in year 2002. The accessibility is calculated as equation 3-4 with different parameters $\beta$.

The urban development in the model is driven by an exogenous forecast population growth input for the entire region.

\subsubsection{Employment Allocation model}

For the employment development model, the first step is the prediction of employment changes by industry for each TAZ zone. This is a multiple regression model as shown in equation 3-5. The dependent variable is the change in employment in service industries from year 1995 to year 2000. The independent variables include the change in accessibility to population from year 1990 to year 1995, population in TAZs in year 1995, population change in TAZs from year 1990 to year 1995, change in urban land in TAZs from year 1985 to year 1993, percent of land area as employment-related land use in year 1993, and percent of the land area in the TAZ available for urban development in year 1993. The accessibility is calculated using equation 3-4 with different parameters $\beta$ (Ottensmann, 2007).

The next stage is the simulation of employment-related development for each simulation zone. Two models are developed. The first model predicts employment density (employment-related land required per employee) for each TAZ. The second model predicts the probability of land conversion to employment-related land use. The formula for the prediction of employment density is a multiple regression model as in equation 3-5. The dependent variable is the natural logarithm of employment-related land use per employee in year 2000. The independent variables include the housing units built before year 1940, population change from year 1995 to year 2000, and percent of urban land in year 2000. The formula for the prediction of the probability of land conversion to employment-related land use is an aggregate logit model as shown in equations 3-2 and 3-3. The dependent variable is the logit proportion of increase in the amount of 
employment-related land from year 1995 to year 2000 (reduced by 0.625 from year 1993 to year 2000). The independent variables include the log accessibility to population, sewer service dummy, and employment-related land use in year 1993. The accessibility is calculated using equation 3-4 with different parameters $\beta$.

\subsection{The Integrated ISTDM-LUCI2 Model Approach}

The integrated ISTDM-LUCI2 model approach can be described as "quasidynamic”. Accessibility to both employment and population plays an important role in shaping urban development. In the previous LUCI2 urban simulation model, distance was used instead of travel time to measure accessibility. In the integrated ISTDM-LUCI2 approach, updated congested travel times from the travel demand models are used to measure accessibility in the LUCI2 statewide urban simulation model during each fiveyear simulation period. Because an urban activity system is extremely dynamic, thousands of land use and travel decisions are made in response to policy changes and other influences. Before a new equilibrium can be reached, other changes and influences occur, setting off another series of decisions. For modeling purposes, a five-year simulation period has been adopted to estimate changes that occur as land use and transportation systems affect each other. The use of congested travel times, rather than distances, greatly improves the measure of accessibility.

The lagged outputs from the LUCI2 statewide urban simulation model (employment and residential growth) serve as feedback to the ISTDM v.4, forming a quasi-dynamic model for each five-year simulation period. Figure 3-7 shows the basic structure of the integrated ISTDM-LUCI2 model approach. 


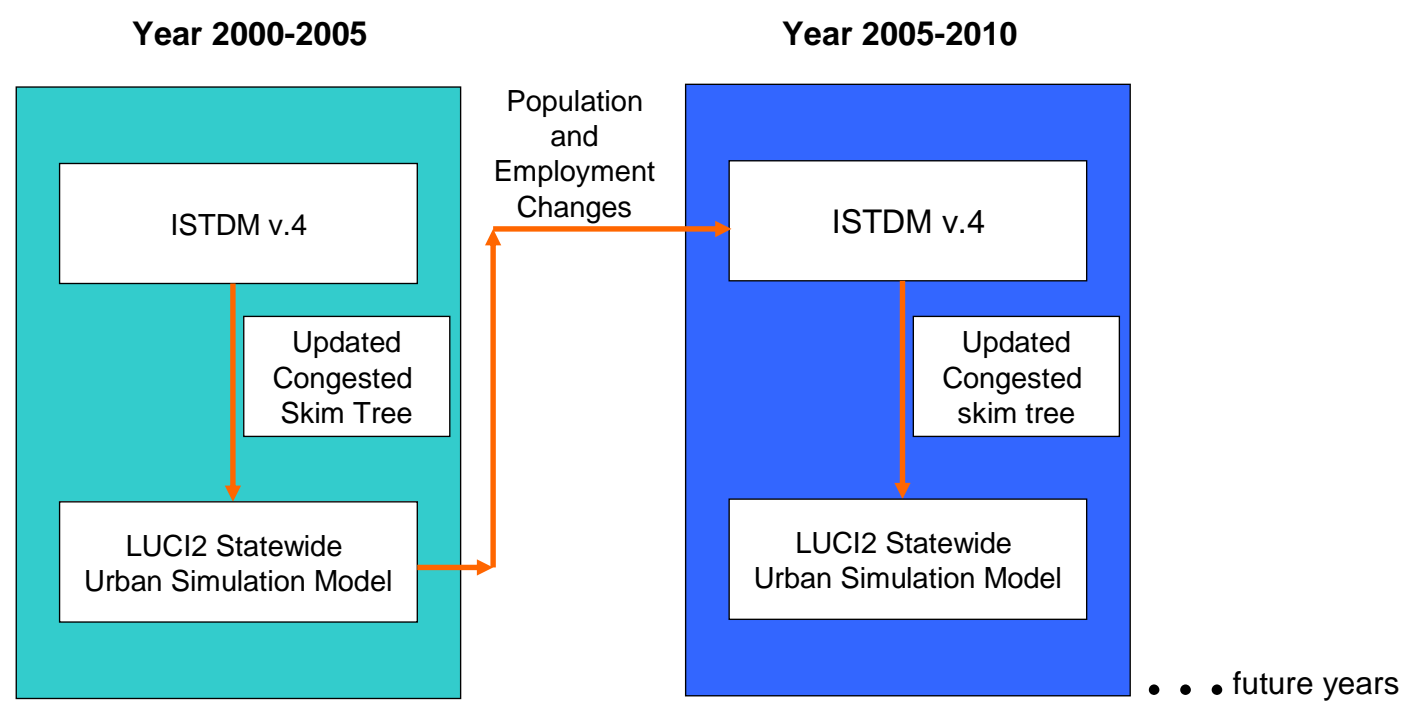

Figure 3-7. The structure of the integrated ISTDM-LUCI2 model approach

In developing the integrated ISTDM v.4 and LUCI2 model, the most important and challenging task is to introduce the time variable. Because the ISTDM v.4 model doesn't include the time variable, it is a static model approach and can't be applied toward any target year defined by users. Therefore, the long-range effects of transportation improvement can not be captured by the ISTDM v.4 model. However, by the integrated ISTDM v.4 and LUCI2 model approach, users can choose the target year and test long effects of different transportation improvement and land use scenarios. The introduction of time variable to the integrated ISTDM v.4 and LUCI2 model improve the whole model process.

After users specify the target year, the time index variable is created in the GISDK macro program. Multiple five-year exchanges between the ISTDM v.4 and LUCI2 are executed until reaching the target year. In each five-year period, because the ISTDM v.4 is a sequential model which means that the output from each model step is the input for the next model step, the time index variable is added in each model step to identify the current time period in the ISTDM v.4. The congested skim derived after the final step (trip assignment) and the time index variable is sent to the LUCI2 command line only 
program. After running the LUCI2 model, the outputs of LUCI2 is used as the inputs of the first step of ISTDM v.4.

File format conversion is another problem that needs to be solved. Because the LUCI2 can't output file with DBF format, the outputs from the LUCI2 must be converted to the DBF file format in the GIS software. In the automated integrated ISTDM v.4 and LUCI2 model process, the TXT file format can be successfully converted to the DBF file in each five-year period.

The integrated ISTDM v.4 and LUCI2 model requires the user friendly interface developed in the GIS software. Users can use the interface to specify multiple ISTDM v.4 and LUCI2 scenarios and then run the integrated ISTDM v.4 and LUCI2 model. The LUCI2 model runs as a "black box" each five-year period. All LUCI2 scenarios can be chosen by users in the developed interface.

The interface for the integrated ISTDM v.4 and LUCI2 model is shown in Figure 38. In this interface, different policy scenarios related to transportation and land use improvements can be easily tested and compared using the integrated ISTDM-LUCI2 model toward the future years.

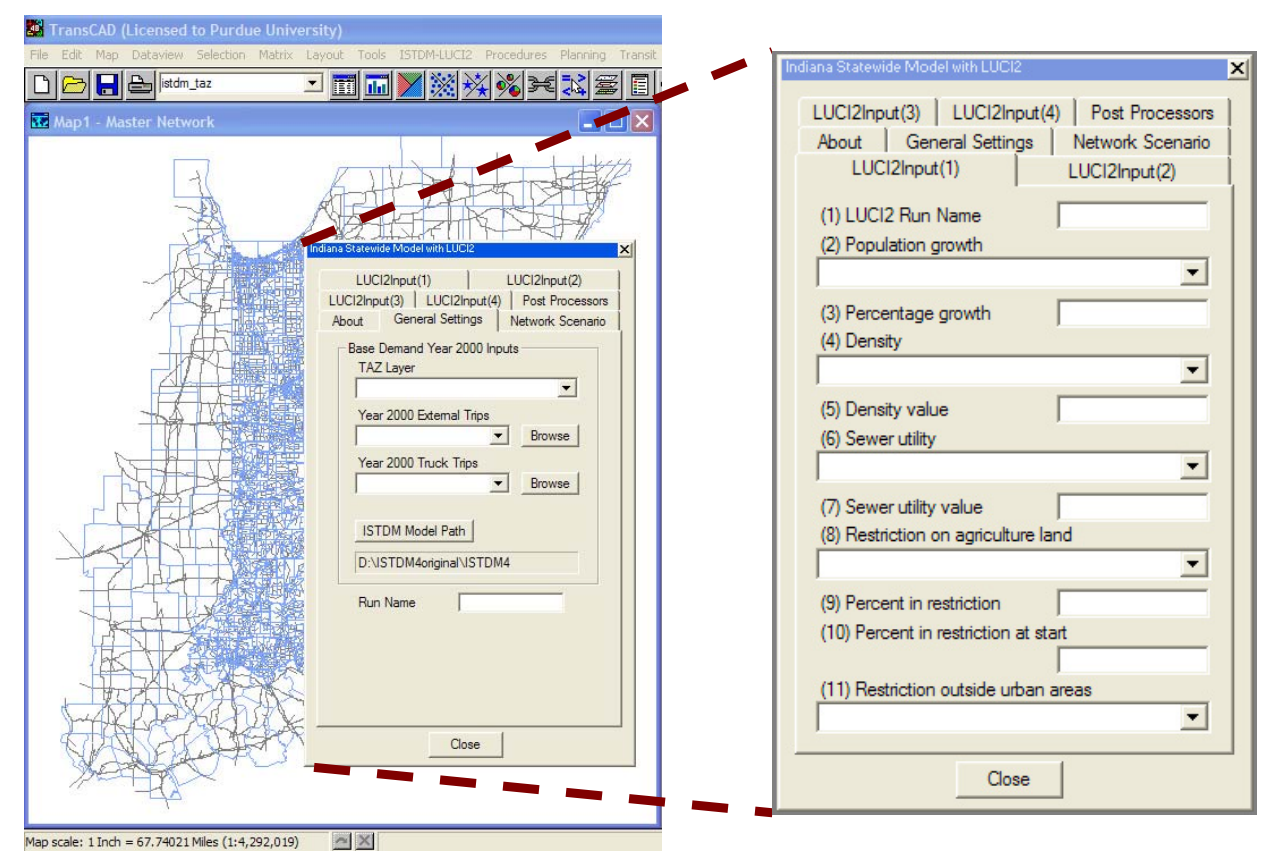

Figure 3-8. The integrated ISTDM-LUCI2 model interface 
To further explain how the exchange between the ISTDM v.4 and LUCI2 works, the output of the ISTDM v.4 is called the congested skim tree and used as the input for the LUCI2. Congested skim tree has the shortest congested travel time for any two zones. It is a matrix file and derived after trip assignment because travel volume on each link will affect the travel speed and travel time and must be known before building the congested skim tree. The congested skim tree measures the accessibility better than the free flow skim tree because of better representation of traffic conditions. The fields which are used as the inputs for ISTDM v.4 coming from the outputs of LUCI2 include:

POP (Total Population)

A_AGFORFIS (Employment Category: Farming)

B_MINING (Employment Category: Mining)

C_CONSTRUC (Employment Category: Construction)

D_MANUFACT (Employment Category: Manufacturing)

E_TRANSPUB (Employment Category: Transportation, Communications, Utilities)

F_WHOLESAL (Employment Category: Wholesale)

G_RETAILTR (Employment Category: Retail)

H_FIRE (Employment Category: Finance, Insurance, Real Estate)

I_SVCS (Employment Category: Services)

J_PUBADMIN (Employment Category: Government)

TOT_EMP (Total Employment)

Some required fields for the ISTDM v.4 are not included in the outputs of the LUCI2 model, they have to be interpolated. In the integrated ISTDM and LUCI2 model, because year 2000 and 2030 TAZ dataview files exist, the below fields are interpolated between year 2000 and year 2030 in the integrated ISTDM and LUCI2 model approach.

AVGHHSZE (Persons per Household)

VEH_PER_HH (Vehicle per Household)

MEANHHINC (Mean Household Income)

EDUCATION (Education Employment)

Because the ISTDM v.4 mode uses the number of household in each zone for trip production step, the number of households is calculated by zonal population / zonal 
persons per household. The number of population is updated by the LUCI2 in each fiveyear period. The zonal household size is updated by the interpolation from year 2000 and year 2030 TAZ dataview files and the extrapolation beyond year 2030 .

The auto external trips and truck trips are interpolated between year 2000 and year 2030 and extrapolated beyond year 2030.

\subsection{Comparison of the ISTDM v.4 and the Integrated ISTDM-LUCI2 Approach}

The population growth forecast for year 2030 on the zonal level is produced by the ISTDM v.4 based on historical growth rates and an accessibility-based regression model (ISTDM Upgrade-Technical Memorandum, 2005). To compare the population growth forecast results at the zonal level with the original ISTDM v.4 and integrated ISTDMLUCI2 model approach, the base year 2000 roadway network is adopted in the integrated ISTDM-LUCI2 model with the option of total population equal to ISTDM v.4 forecast in year 2030.

Figure 3-9 shows the zonal population density change from year 2000 to year 2030 in the ISTDM v.4. Figure 3-10 shows the zonal population density change from 2000 to 2030 in the integrated ISTDM-LUCI2 model. 


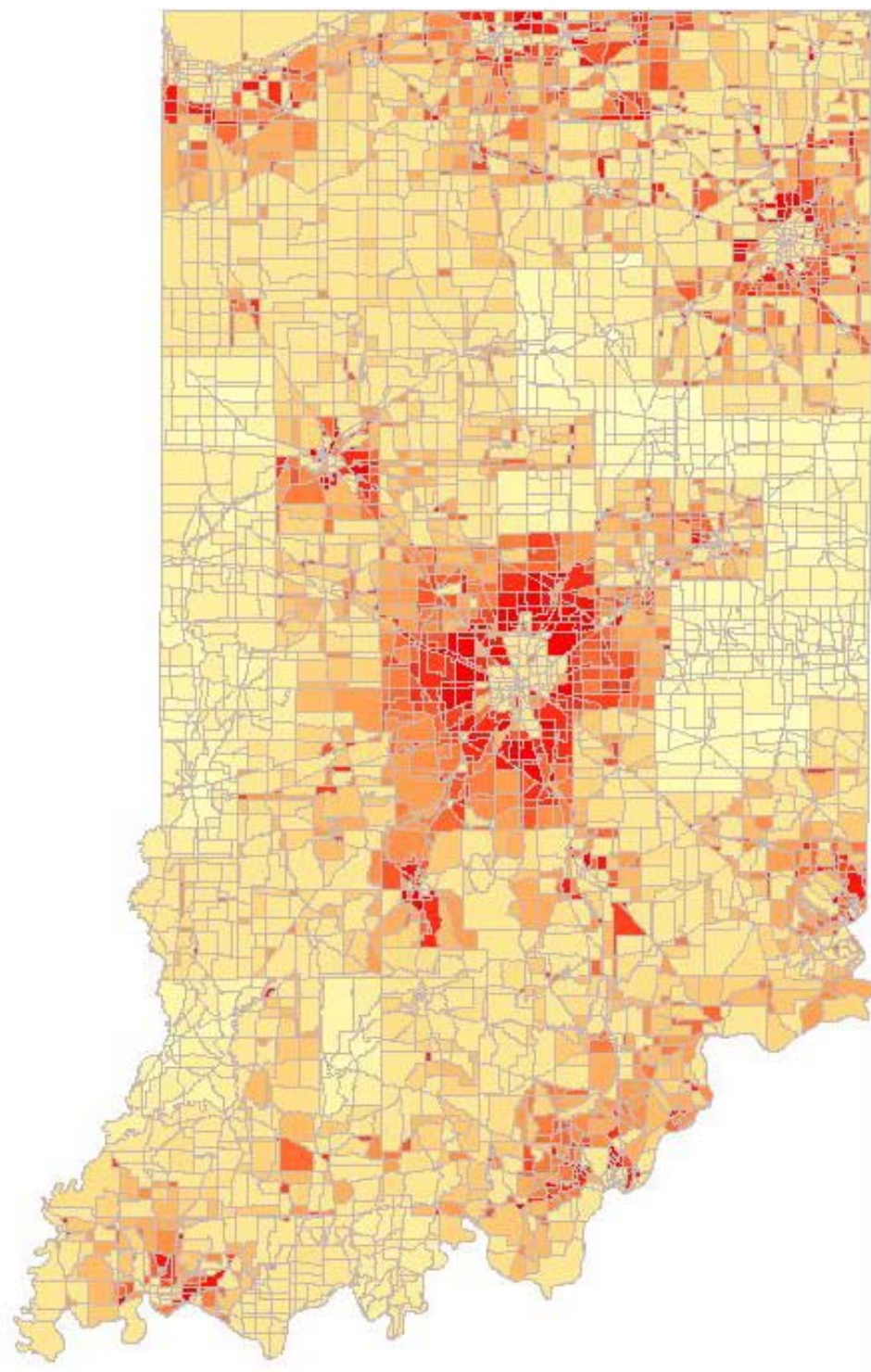

Original PopDenschg2000-2030 -10000.00 to -5.57 (183) -5.57 to -2.36 (183)

-2.36 to -0.91 (183) -0.91 to $0.00(1423)$ 0.00 to $0.30(42)$

0.30 to $2.10(183)$

2.10 to 4.84 (184)

4.84 to $8.69(183)$

8.69 to 14.00 (183)

14.00 to $21.06(183)$

21.06 to $32.90(183)$

32.90 to 45.40 (183)

45.40 to 63.20 (184)

63.20 to 88.20 (183)

88.20 to 129.86 (183)

129.86 to 190.00 (183)

190.00 to 299.00 (183)

299.00 to $563.00(183)$

D6 563.00 to 10000.00 (184)

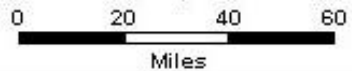

Figure 3-9. Forecasted population density change from 2000 to 2030 by the ISTDM 


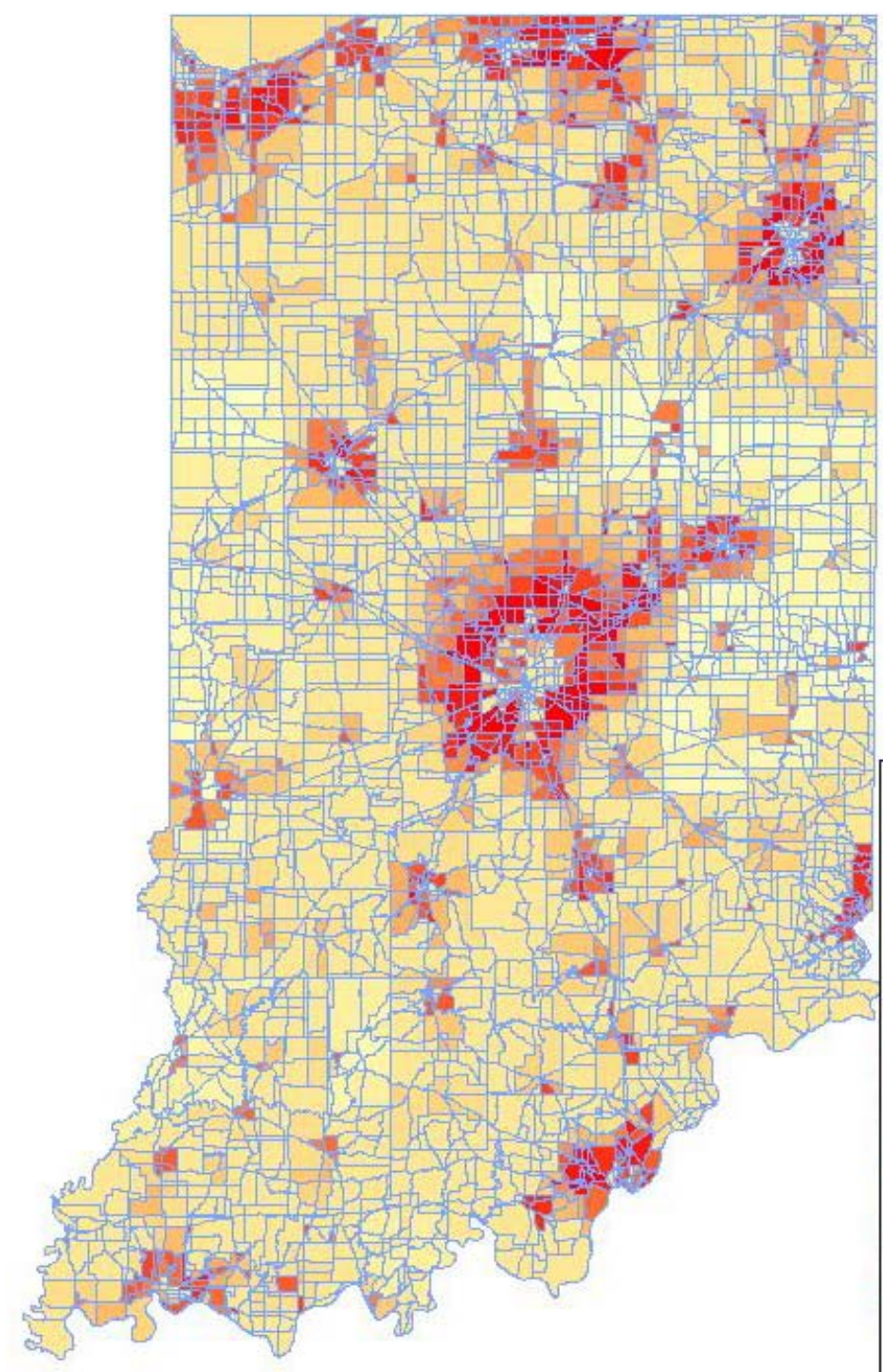

\begin{tabular}{|l} 
ISTDMLUCI2 PopDenschg2000-2030 \\
-10000.00 to $-5.57(104)$ \\
-5.57 to $-2.36(139)$ \\
-2.36 to $-0.91(163)$ \\
-0.91 to $0.00(148)$ \\
0.00 to $0.30(1939)$ \\
0.30 to $2.10[227)$ \\
2.10 to $4.84[136)$ \\
4.84 to $8.69[133)$ \\
8.69 to $14.00(153)$ \\
14.00 to $21.06(144)$ \\
21.06 to $32.90(121)$ \\
32.90 to $45.40(75)$ \\
45.40 to $63.20(119)$ \\
63.20 to $88.20(124)$ \\
88.20 to $129.96[160)$ \\
129.96 to $190.00(164)$ \\
190.00 to $299.00(184)$ \\
299.00 to $563.00(168)$ \\
563.00 to $10000.00(178)$ \\
0 \\
30 \\
\hline
\end{tabular}

Figure 3-10. Forecasted population density change from 2000 to 2030 by the integrated ISTDM-LUCI2 model

Comparing the two figures, large positive population density changes around cities are more common in the integrated ISTDM-LUCI2 model than in the ISTDM v.4 model. Figure 3-11 shows a scatterplot of the forecasted zonal population density change from year 2000 to year 2030 by the ISTDM v.4 and the integrated ISTDM-LUCI2 model. The scatterplot doesn't follow a linear trend. 


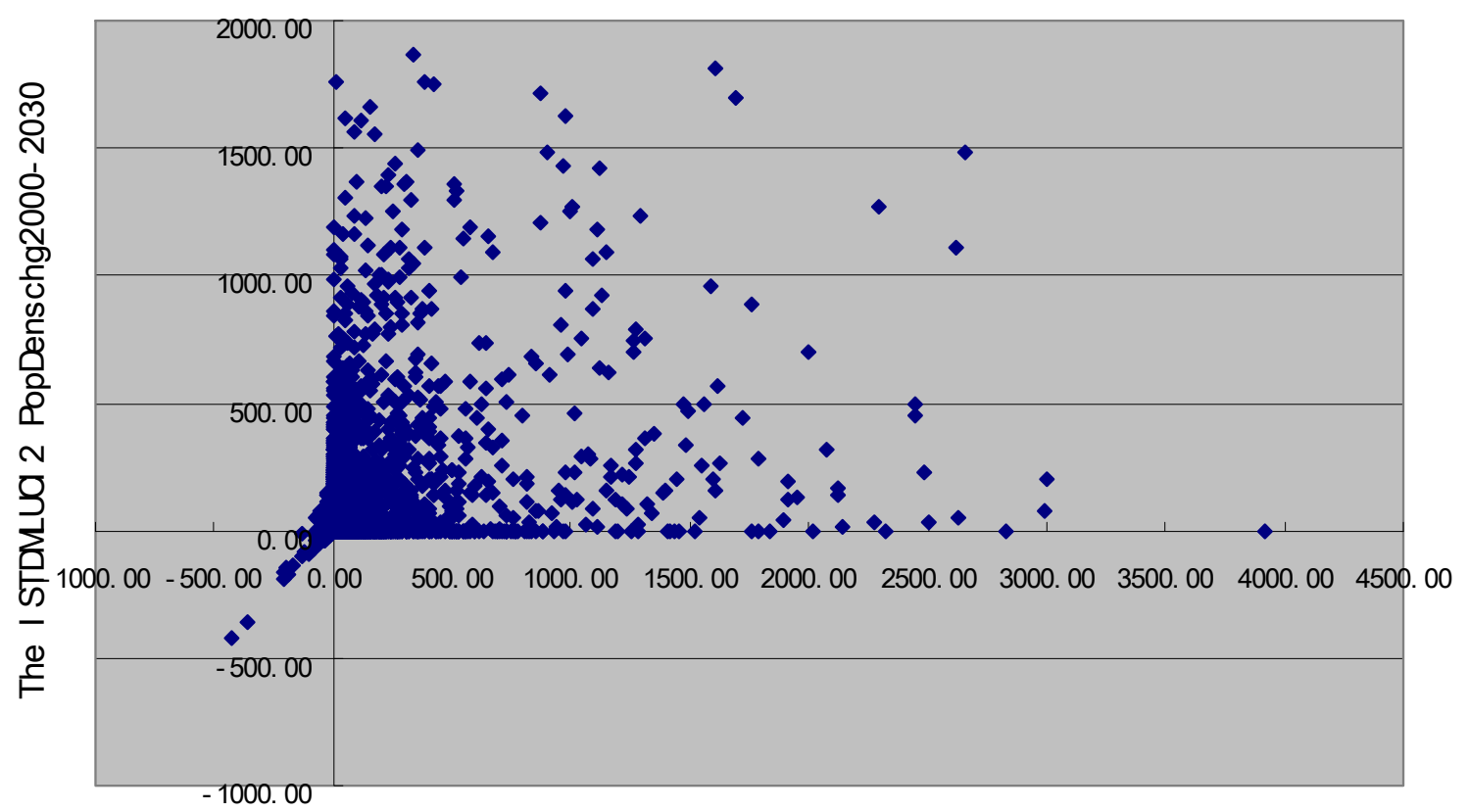

The I STDM PopDenschg2000-2030

Figure 3-11. The scatterplot of forecasted zonal population density changes from 2000 to 2030 by the integrated ISTDM-LUCI2 and the ISTDM

Using the zonal population density changes forecasted by the integrated ISTDMLUCI2 model as the dependent variable and the zonal population density changes forecasted by the ISTDM v.4 model as the independent variable, the simple linear regression has an R-square equal to 0.1110 , which indicates low explanatory power.

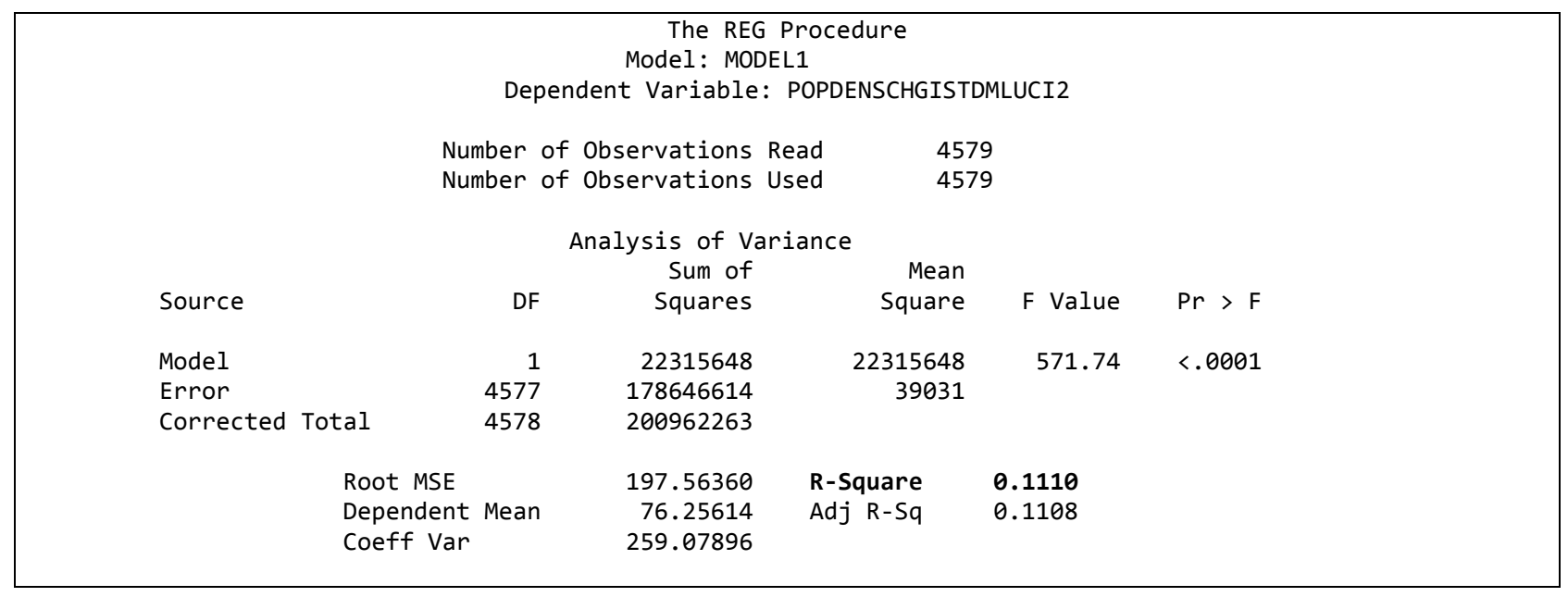




\begin{tabular}{|llrrrrr|}
\hline & & Parameter Estimates & & \\
Variable & Label & Parameter & Standard & \\
& & Estimate & Error & $t$ Value & Pr $>|t|$ \\
Intercept & Intercept & 1 & 52.53362 & 3.08355 & 17.04 & $<.0001$ \\
POPDENSCHISTDM & POPDENSCHISTDM & 1 & 0.25756 & 0.01077 & 23.91 & $<.0001$ \\
\hline
\end{tabular}

The VMT forecasted in year 2030 by the ISTDM v.4 and the ISTDM-LUCI2 model is shown in Table 3-9. The forecasted increase in VMT is the highest for Rural Interstates at 25.21 percent. The lowest decrease is for Rural Local Roads at -1.62 percent. The total VMT increase across all functional classes is 12.37 percent.

Table 3-9. Forecast VMT in 2030 by ISTDM v.4 and ISTDM-LUCI2

\begin{tabular}{lrrr}
\hline CLASS & $\begin{array}{l}\text { VMT in2030 } \\
\text { (ISTDM) }\end{array}$ & $\begin{array}{l}\text { VMT in2030 } \\
\text { (ISTDMLUCI2) }\end{array}$ & $\begin{array}{l}\text { VMT } \\
\text { Increase }\end{array}$ \\
\hline Rural Interstates & 28372018 & 35524357 & $25.21 \%$ \\
\hline Other Rural Principal Arterials & 18836716 & 22406573 & $18.95 \%$ \\
\hline Rural Minor Arterials & 15913805 & 18011157 & $13.18 \%$ \\
\hline Rural Major Collectors & 32655108 & 35897566 & $9.93 \%$ \\
\hline Rural Minor Collectors & 1323458 & 1380220 & $4.29 \%$ \\
\hline Rural Local Roads & 126144 & 124105 & $-1.62 \%$ \\
\hline Urban Interstates & 23466854 & 25602394 & $9.10 \%$ \\
\hline Other Urban Freeways \& & 3382325 & 3875429 & $14.58 \%$ \\
Expwys & 29814215 & 31351853 & $5.16 \%$ \\
\hline Other Urban Principal Arterials & 12533665 & 13043390 & $4.07 \%$ \\
\hline Urban Minor Arterials & 1810462 & 1838836 & $1.57 \%$ \\
\hline Urban Collectors & 58818 & 62580 & $6.40 \%$ \\
\hline Urban Local Roads & 168293589 & 189118461 & $12.37 \%$ \\
\hline Totals & & & \\
\hline
\end{tabular}

The forecasted VMT by LOS in 2030 from the ISTDM v.4 and the ISTDM-LUCI2 model is shown in Table 3-10. The VMT by LOS D, E and F have higher increases in the ISTDM-LUCI2 model, which means that more roadways in the statewide network are predicted to be congested from the ISTDM-LUCI2 model than from the ISTDM v.4 model, given the same total population growth in year 2030. 
Table 3-10. Forecast 2030 VMT by LOS -- ISTDM v. 4 and by ISTDM-LUCI2

\begin{tabular}{lrrr}
\hline VMT by LOS & \multicolumn{1}{l}{$\begin{array}{l}\text { VMT in2030 } \\
\text { (ISTDM) }\end{array}$} & $\begin{array}{l}\text { VMT in2030 } \\
\text { (ISTDMLUCI2) }\end{array}$ & \multicolumn{1}{l}{ VMT Increase } \\
\hline VMT by LOS A & 38940401.23 & 33937162.84 & $-12.85 \%$ \\
\hline VMT by LOS B & 50082328.82 & 49580175.59 & $-1.00 \%$ \\
\hline VMT by LOS C & 35991362.31 & 44663123.50 & $24.09 \%$ \\
\hline VMT by LOS D & 20457276.75 & 29247968.49 & $42.97 \%$ \\
\hline VMT by LOS E & 9629073.79 & 14283033.10 & $48.33 \%$ \\
\hline VMT by LOS F & 13193146.01 & 17406997.46 & $31.94 \%$ \\
\hline
\end{tabular}

The forecasted VMT in 2030 for each roadway link by the ISTDM v.4 and the ISTDM-LUCI2 model are shown in Figure 3-12. The simple linear regression has the R square equal to 0.9793 and the beta estimate equal to 1.1664 , which means that the roadway links are predicted to be more congested by the ISTDM-LUCI2 model than by the ISTDM v.4 model.

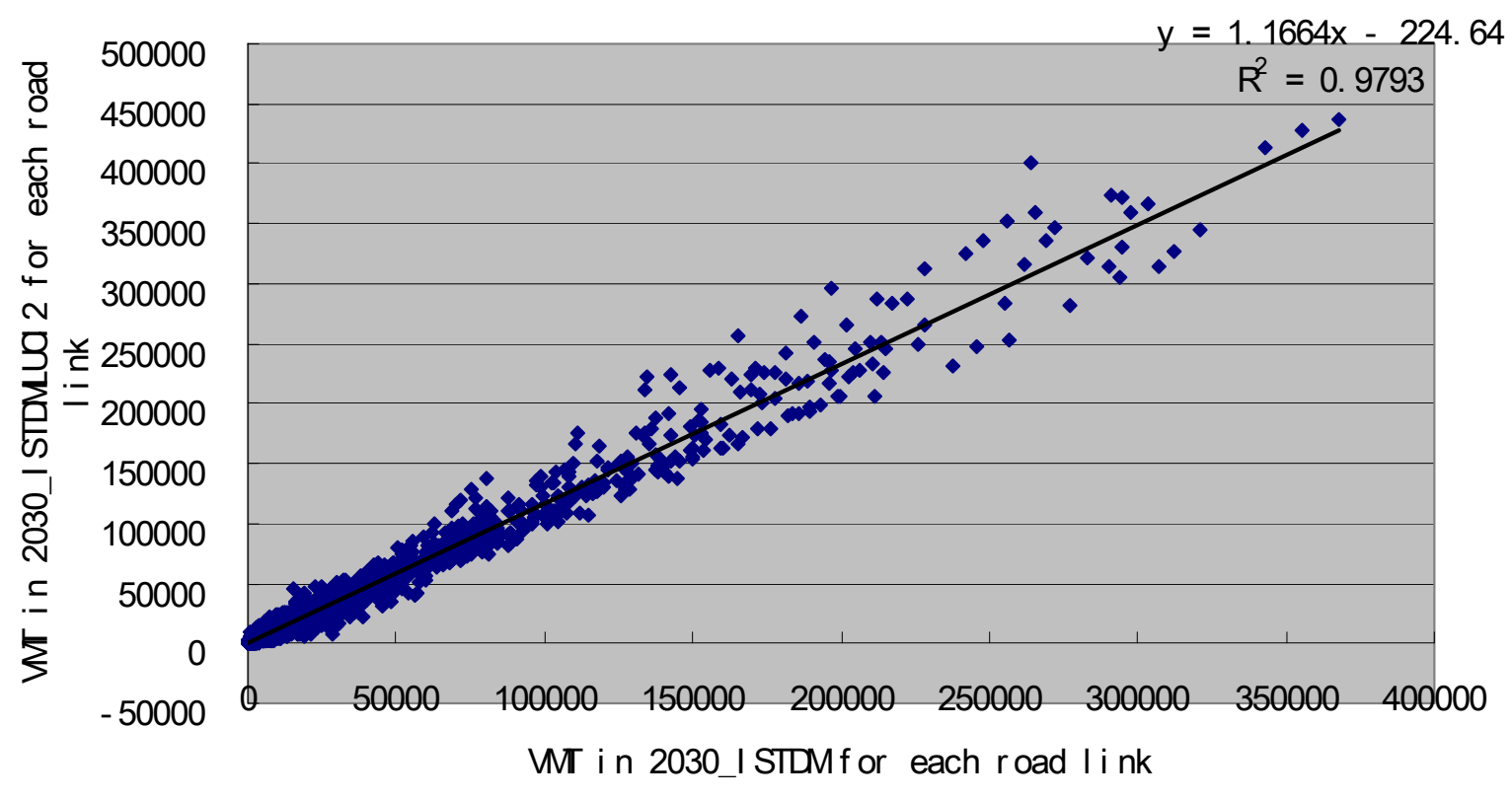

Figure 3-12. The scatterplot of VMT in 2030 for each roadway link predicted by the integrated ISTDM-LUCI2 and by the ISTDM v.4 model 


\section{$\underline{3.5 \text { Conclusions }}$}

In this study, the developed integrated ISTDM-LUCI2 model can help test the transportation and land use effects using different policy scenarios for future years. By developing an integrated transportation and land use model system, it is expected to achieve better predictions for exploring policy alternatives and possible urban futures than the original ISTDM model.

The outputs from the integrated ISTDM-LUCI2 model show different zonal population growth and forecasted VMT for each roadway link in year 2030 with from the ISTDM v.4, given the same total population growth across the state in year 2030. The roadway links are predicted to be more congested by the integrated ISTDM-LUCI2 model than by the ISTDM v.4 model. The predicted zonal population growth by the integrated ISTDM-LUCI2 model is quite different from the prediction by the ISTDM v.4 model. 


\section{CHAPTER 4. SENSITIVITY ANALYSIS BY ISTDM-LUCI2 MODEL}

In this chapter, a univariate sensitivity analysis using the ISTDM-LUCI2 model system is conducted. Uncertainty exists in statewide travel demand forecasting and land use models. Both input data and adopted model parameters can vary to some extent from their true values because of model misspecification, imperfect input information, and innate randomness of events. The aim of this chapter is to study the sensitivity of outputs from the integrated ISTDM-LUCI2 model system for Indiana to plausible prespecified amounts of variation on travel model parameters, input data and exogenous population growth rate.

\section{$\underline{4.1 \text { Background }}$}

Uncertainty in empirical quantities can arise for a variety of reasons, such as (Morgan and Henrion, 1990):

- Random error and statistical variation

- Systematic error and subjective judgment

- Linguistic imprecision

- Variability

- Randomness and unpredictability

- Disagreement

- Approximations

Travel demand predictions involve substantial uncertainty, which can derive from model misspecification, imperfect input information, and innate randomness in events 
(Krishnamurthy and Kockelman, 2003). Therefore, sensitivity and uncertainty analysis is of great importance for policy and risk analysis. With explicit recognition of uncertainty in travel demand forecasts, policy-makers can understand the influence of the values of model parameters and input data. They can make a more informed choice when deciding where to allocate more financial resources to collect input data and calibrate model parameters. Greater effort can be devoted to acquiring input data and adopting model parameters when the impact of a change in each on the output is known.

The Intermodal Surface Transportation Efficiency Act (ISTEA) of 1991 required that metropolitan and statewide transportation plans be integrated with land use plans (Miller et al., 1999). It would be helpful to do a statewide sensitivity and uncertainty analysis when using these complex integrated transportation and land use models. This study introduces a univariate uncertainty analysis using Indiana's integrated ISTDMLUCI2 model system.

A few studies have been conducted to quantify uncertainty in predictions of travel demand using a four-step travel demand model or an integrated transportation-land use model system.

Zhao and Kockelman (2002) investigated uncertainty propagation in four-step travel demand models over a 25-zone network. Monte Carlo simulation and sensitivity analysis were used to quantify variability in model outputs. Their results suggested that uncertainty was compounded over the four stages of a transport model and highly correlated across outputs. Traffic assignment, the final step of the model, was found to reduce uncertainty developed in the first three steps. However, in general, it could not reduce final flow uncertainty below the levels of input uncertainty.

Pradhan and Kockelman (2002) studied the uncertainty propagation in an integrated land use-transportation model framework using 271 traffic analysis zones (TAZs). Urban development was modeled using UrbanSim (Waddell, 2002). A factorized design approach was employed in this study. They found that, while several model inputs may affect model outputs in the short run, only those inputs that had a cumulative effect were possible to have a significant impact on outputs in the long run. Their results also suggested that uncertainty in model outputs may increase for the first few years. 
However, the level of uncertainty appeared to come down in the later years, as households, jobs, and developers responded to changed input conditions.

Krishnamurthy and Kockelman (2003) examined the propagation of uncertainty for 1074 traffic serial zones (TAZs) using Putman’s Integrated Transportation and Land-use package (ITLUP) and Urban Transportation Planning Package's (UTPP) traditional fourstep travel demand model. The ITLUP consists of a Disaggregate Residential Allocation Model (DRAM) and an Employment Allocation Model (EMPAL) (Putman, 1983). Results indicated that output variations were most sensitive to the exponent of the link performance function, the split of trips between peak and off-peak periods, and several trip production and attraction rates.

A study conducted by Clay and Johnston (2005) introduced the univariate uncertainty analysis of an Integrated Land Use and Transportation Model: MEPLAN was applied to the 81 zones (including 10 external zones) of the Sacramento Area Council of Governments (SACOG) model. The study found that uncertainty in the socioeconomic forecasts did not dominate the final amounts of error observed in the model outputs.

Because of the high computational cost and complexity associated with statewide travel demand systems, no previous research has looked at sensitivity and uncertainty analysis for statewide models. This study, however, investigates the uncertainty of the statewide travel demand predictions arising from the model parameters and input data involved in using the integrated ISTDM-LUCI2 model system for Indiana. Outputs from the Land Use in Central Indiana 2 (LUCI2) urban simulation model act as the inputs to Indiana's statewide four-step travel demand model (ISTDM). Congested skim trees from the traffic assignment stage of the ISTDM are fed forward to the LUCI2 urban simulation model for the next 5-year period.

In calculating uncertainty, the past studies used different methods. Monte Carlo techniques had been often used to draw input values from multivariate distributions (Krishnamurthy and Kockelman, 2003; Zhao and Kockelman, 2002). Because the underlying multivariate distributions were not known to the researchers, they were normally chosen by unverified assumptions. Clay and Johnston (2005) used another 
technique to compute the univariate uncertainty. They varied exogenous production rates, commercial trip generation rates, and a concentration parameter by $\pm 10 \%, \pm 25 \%$ and $\pm 50 \%$ per source, based on careful review of previous studies and consultation with the firm that calibrated the model.

In this study, uncertainty is calculated in the same way as Clay and Johnston. Given unknown probability distributions of model parameters and input data, the moment estimations of output distribution will have bias if the assumption of input distribution does not closely approximate the actual one. Also, because the Monte Carlo technique requires large sample sets to cover the possible ranges of all inputs, it is very difficult to apply Monte Carlo technique for the integrated statewide models, due to the long computing time for each run. Therefore, only one set of the model parameter or input data varies by $\pm 10 \%$ per run in this study. The variations of $\pm 10 \%$ to the true value are considered to happen in practice with high probability for all the model parameters and input data. The variations of $25 \%$ and $50 \%$ are not applied, because only small and realistic variations of the model parameters and input data are of interest for this study.

In each simulation run, keeping all the other model parameters or input data the same as the base case, the value of one set of model parameters or input data is changed by $\pm 10 \%$. The statewide VMT outputs are then compared with the base case (with all the model parameters or input data unchanged) and the results are analyzed.

ISTDM and LUCI2 exchange input/output data for each five-year period in the integrated ISTDM-LUCI2 mode system. The simulation is set to run from year 2000 to year 2030. A total of 53 model runs are performed in this study, with each run taking about 8 hours to finish on the computer with Intel Core2 Duo $1.80 \mathrm{GHz}$ and $1 \mathrm{~GB}$ $667 \mathrm{MHz}$ RAM.

\subsection{Sensitivity Analysis Scenarios}

The integrated ISTDM-LUCI2 model system is a four-step travel demand model that links the LUCI2 urban simulation land use model to the statewide roadway network. 
The trip purposes considered in this sensitivity study are Home-Based Work (HBW), Home-Based Other (HBO) and Non Home-Based (NHB) trips. Table 4-1 presents all the variations of the model parameters and input data for this sensitivity study. It does not include the base case run, which keeps all model parameters at their original values. The travel demand component specifications are described below.

Table 4-1. Input changes for simulation runs

\begin{tabular}{llcc}
\hline Model & Model parameters & Uncertainty & \multicolumn{2}{c}{$\begin{array}{c}\text { Simulation } \\
\text { runs }\end{array}$} \\
\hline Land use & Population growth rate & $\pm 10 \%$ & 2 \\
Trip production & $\begin{array}{l}\text { Trip production rates for each area } \\
\text { type and trip purpose }\end{array}$ & $\pm 10 \%$ & 18 \\
Trip attraction & $\begin{array}{l}\text { Trip attraction rates for each trip } \\
\text { purpose }\end{array}$ & $\pm 10 \%$ & 6 \\
Trip distribution & Gamma function parameter b or c & $\pm 10 \%$ & 12 \\
Trip assignment & Link performance function a and b & $\pm 10 \%$ & 14 \\
\hline
\end{tabular}

Trip production rates are developed based on the observed data from the 1995 Indiana Travel survey and the 2001 NHTS (ISTDM Upgrade-Technical Memorandum, 2005). They are cross-classified by household size and auto ownership within each area type (urban, suburban, and rural) for each trip purpose (HBW, HBNW, and NHB). The uncertainty of trip production rates for each area type and trip purpose is assigned to be $\pm 10 \%$ during the simulation runs.

Trip attractions are defined as below:

$$
\begin{aligned}
& A_{H B W}=f\left(\text { Employment }_{\text {retail,etc. }}, \text { Employment }_{\text {non-retail,etc. }}\right) \\
& A_{H B O}=f\left(\text { Employment }_{\text {retail }}, \text { Employment }_{\text {fire,etc. }}, \text { Employment }_{\text {education }}, \text { Households }\right) \\
& A_{N H B}=f\left(\text { Employment }_{\text {retail }}, \text { Employment }_{\text {fire,etc. }}, \text { Employment }_{\text {non-retail,etc. }}\right)
\end{aligned}
$$

where $A_{H B W}, A_{H B O}$ and $A_{\text {NHB }}$ are the trip attractions for HBW, HBO and NHW. Employment $_{\text {retail }}$ is defined as the number of retail jobs in the corresponding zone. The range of trip attraction rates for each trip purpose is assigned to be $\pm 10 \%$ during the simulation runs.

In the trip distribution step, the friction factor function in the gravity model is the key component. The factors were calibrated to the observed travel times obtained from 
the 1995 Indiana travel survey and the 2001 NHTS in the integrated ISTDM-LUCI2 model system. In order to make the sensitivity analysis feasible, gamma function distributions are used to fit the observed travel times as follows:

$$
F\left(t_{i j}\right)=t_{i j}^{-b} e^{-c * t_{i j}}
$$

Figure 4-1 to 4-3 show the nonlinear fits for HBW, HBO, NHW trips by the gamma functions.

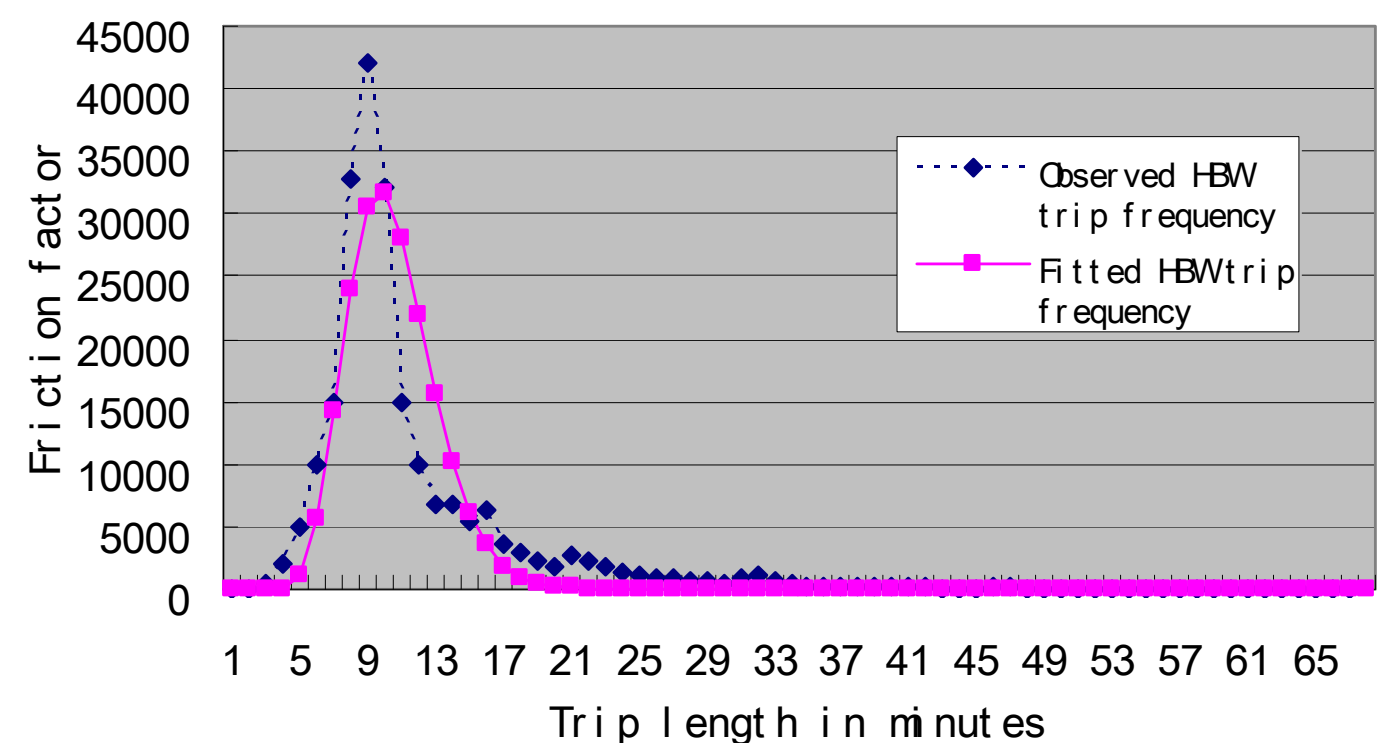

FIGURE 4-1. Friction factors for HBW trips 


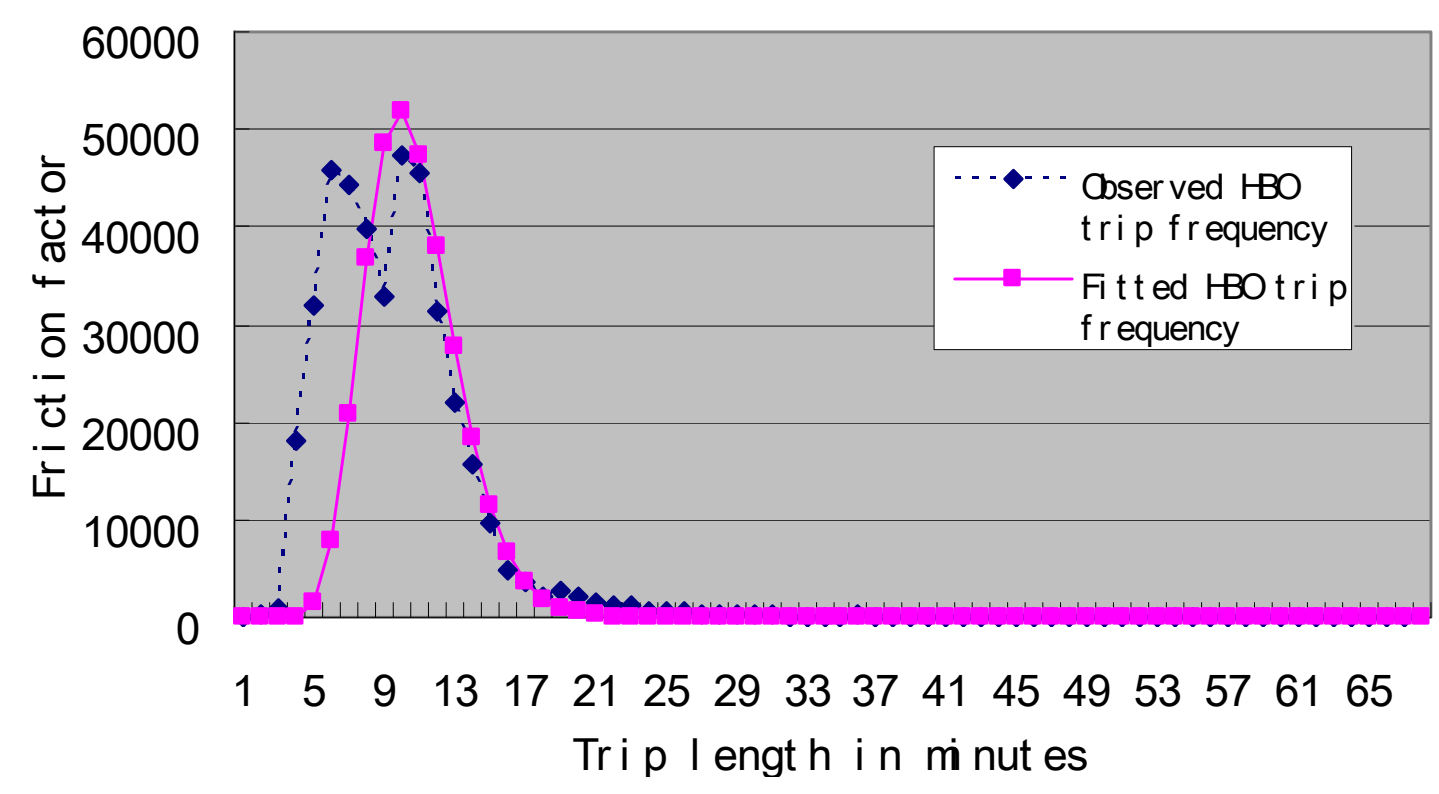

FIGURE 4-2. Friction factors for HBO trips

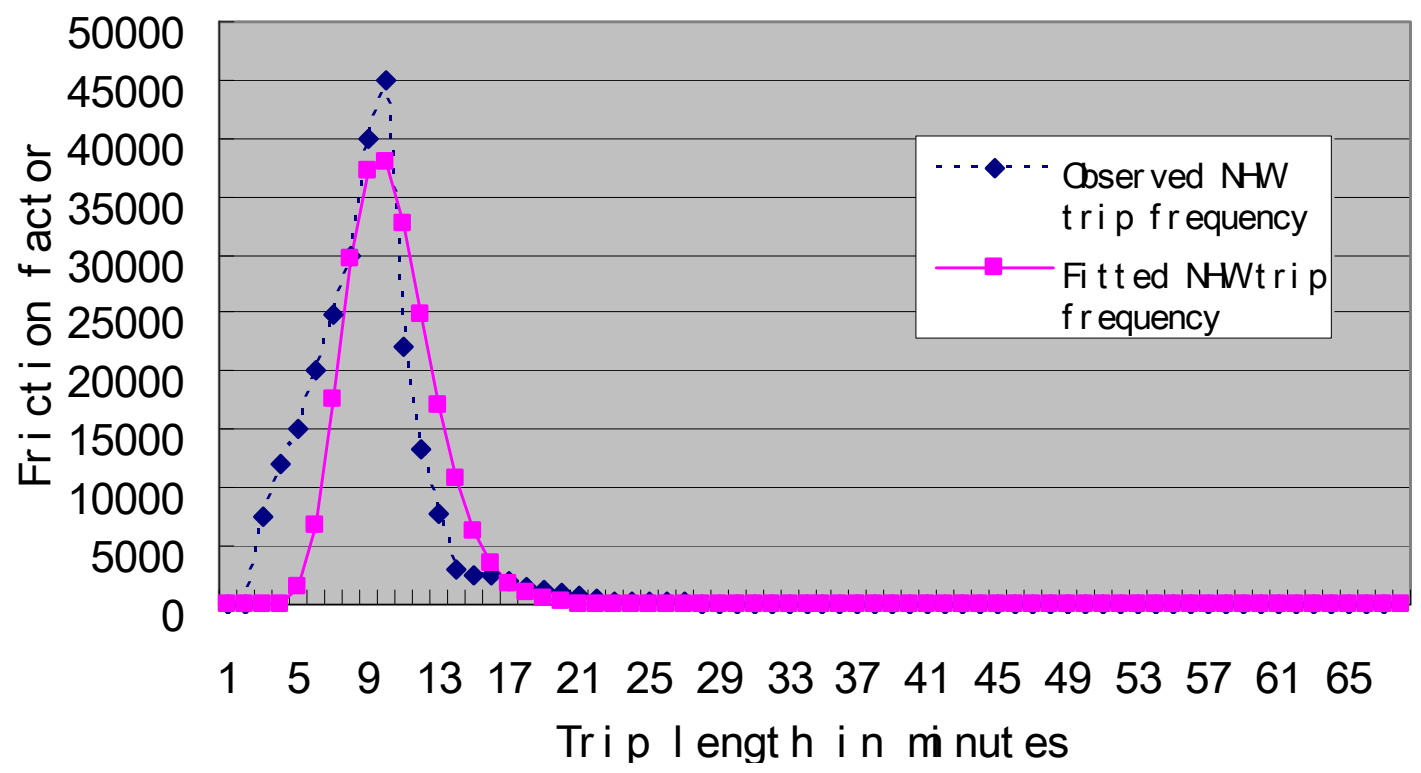

FIGURE 4-3. Friction factors for NHW trips

The value of $\mathrm{b}$ or $\mathrm{c}$ in the fitted gamma functions for each trip purpose is assigned to be $\pm 10 \%$ during the simulation runs. 
The mode shares developed for ISTDM are based on the 1995 Indiana household survey. They are extracted as a table and classified by area type (urban, suburban, or rural) for each trip purpose. No multinomial logit models are used for the shorter trip purposes (HBW, HBO, NHW). Multinomial logit model is only used for long trips that have trip length more than 56 minutes. The sensitivity analysis of mode shares is not investigated in this study, because no model share parameters for shorter trip purposes (HBW, HBO, NHW) exist in the ISTDM.

The ISTDM employs a simultaneous multi-modal multi-class assignment (MMA) method for trip assignment using user equilibrium over a 24-hour period. The maximum number of iterations is 200 and the convergence criterion is set to be 0.0050 . Toll impedances are converted to travel times and the trip assignment is based on travel times. Multiple volume-delay functions (VDF) are used by functional classification on the basis of extensive experimentation during model validation (ISTDM Upgrade-Technical Memorandum, 2005). The Bureau of Public Roads volume-delay function is defined as:

$$
t=t_{f}\left[1+a\left(\frac{V}{C}\right)^{b}\right]
$$

where $t$ is the travel time of a given link at traffic flow $V, t_{f}$ is the free flow travel time, $C$ is the link capacity, and $a$ and $b$ are volume delay function coefficients.

Table 4-2 shows different $a$ and $b$ by the functional class. The variations of $a$ and $b$ for the functional class are assigned to be $\pm 10 \%$ during the simulation runs.

TABLE 4-2. BPR function coefficients by functional class

\begin{tabular}{lcc}
\hline Functional class & $a$ & $b$ \\
\hline Functional class 1 & 0.71 & 2.1 \\
Functional class 2 & 0.71 & 2.1 \\
Functional class 6 & 0.71 & 2.1 \\
Functional class 7 & 0.88 & 9.8 \\
Functional class 8 & 0.88 & 9.8 \\
Functional class 11 & 0.83 & 5.5 \\
Functional class 12 & 0.71 & 2.1 \\
Functional class 14 & 0.88 & 9.8 \\
Functional class 16 & 0.56 & 3.6 \\
Functional class 17 & 0.56 & 3.6 \\
Functional class 19 & 0.56 & 3.6 \\
\hline
\end{tabular}

(Source: ISTDM Upgrade-Technical Memorandum, 2005) 


\subsection{Simulation Results}

\subsubsection{Total VMT}

In this study, sensitivity and uncertainty analyses are processed by varying one set of the model parameters or input data per simulation run. The outputs of total VMT are compared with the total VMT output from the base case. Table 4-3 presents the total VMT when using all the original model parameters and input data, and the default population growth rate, which is 4.725 percent over 5 years.

TABLE 4-3. Total VMT outputs from the base case

\begin{tabular}{ccc}
\hline Year & VMT & Increase from year 2000 (\%) \\
\hline 2000 & 92950222.46 & 0 \\
2005 & 97931196.38 & 5.36 \\
2010 & 106059808.21 & 14.10 \\
2015 & 114630216.69 & 23.32 \\
2020 & 123388016.04 & 32.75 \\
2025 & 132482531.12 & 42.53 \\
2030 & 142285147.38 & 53.08 \\
\hline
\end{tabular}

Figure 4-4 shows the percent change in the total VMT outputs caused by $\pm 10 \%$ variations of exogenous population growth rate (4.725 percent over 5 years), compared with the base case at the corresponding year. 


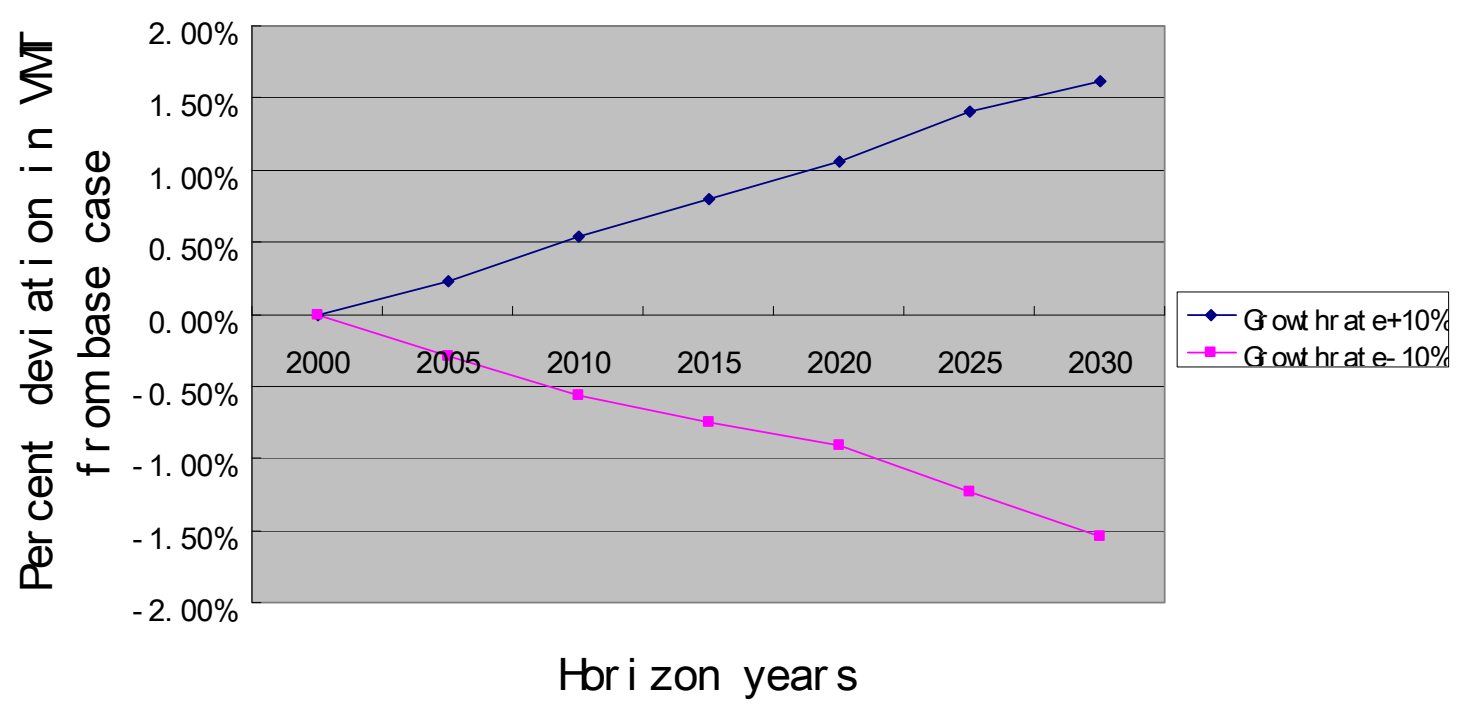

Figure 4-4. Impact of uncertainty in population growth on total VMT

Because population growth rate only affects future-year traffic patterns, the total VMT outputs from the different levels of population growth rate are the same as the base case in model year 2000. In model year 2005, the total VMT output increases $0.23 \%$ when the population growth rate increases $10 \%$ between year 2000 and 2005; it decreases $0.29 \%$ when the population growth rate decreases $10 \%$ between year 2000 and 2005 . In model year 2030, the total VMT output increases $1.62 \%$ when the population growth rate increases 10\% for each five year period between year 2000 and 2030; it decreases 1.54\% when the population growth rate decreases $10 \%$ for each five year period between year 2000 and 2030. The sensitivity effect on the total VMT outputs will increase or decrease with the model year because the growth rate increases or decrease $10 \%$ for each five year period in this study.

Figure 4-5 shows the impacts of changes in trip generation rates on the total VMT outputs over time. The name 'HBWUrban+10\%' means that all trip generation rates for HBW trips in urban have been increased by 10 percent. The pattern or shape is very stable across all total VMT outputs in this figure. In model year 2000, the largest positive total VMT change is $1.16 \%$, when the trip generation rates increase $10 \%$ for rural HBW trips. The most smallest negative total VMT change is $-1.13 \%$, when the trip generation rates decrease 10\% for rural HBW trips. From model year 2005 to 2030, the largest 
positive total VMT change is $1.12 \%$, when the trip generation rates increase $10 \%$ for HBW trips in rural at model year 2025; The most negative total VMT change is $-1.11 \%$, when the trip generation rates decrease $10 \%$ for HBW trips in urban areas at model year 2030. People who live in rural areas generally have longer home-to-work distances. Therefore, trip generation rates for rural HBW trips have the highest sensitivity effects on total VMT.
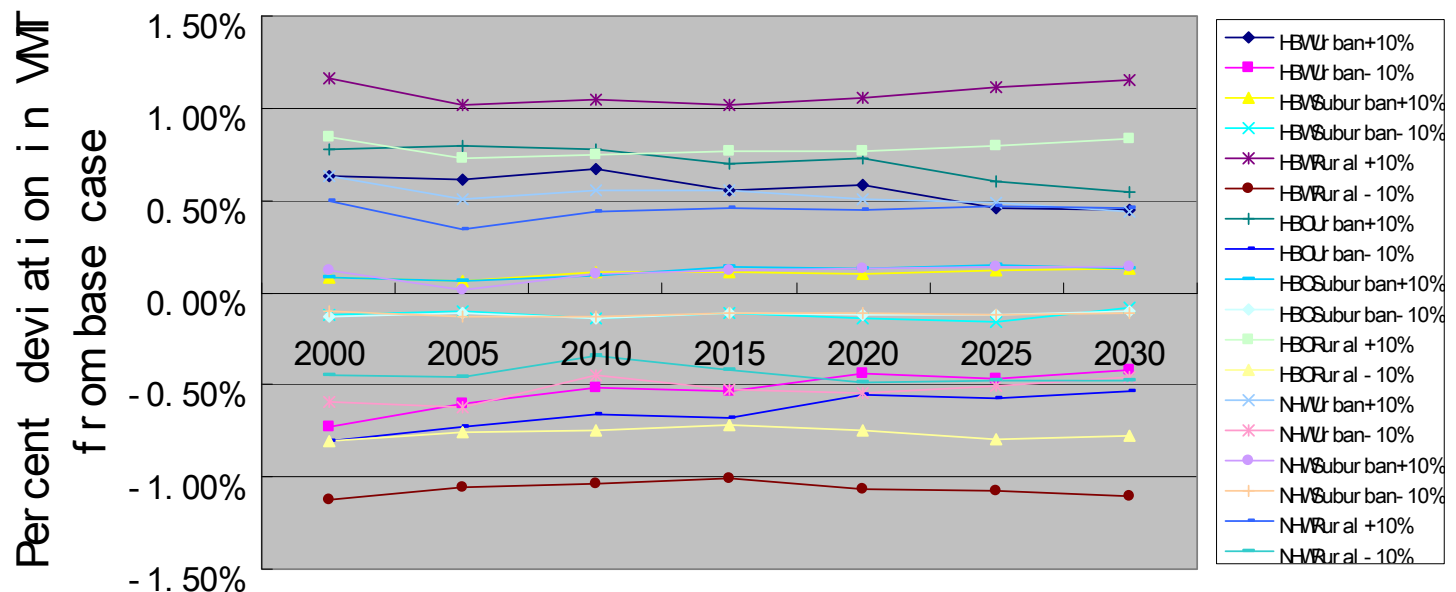

\section{Hor i zon years}

Figure 4-5. Impact of uncertainty in trip generation rates on the VMT outputs

The impacts of uncertainty in trip attraction rates on total VMT outputs over time are plotted in Figure 4-6. The label 'HBW+10\%' means that all trip attraction rates for HBW trips have been increased by 10 percent. The trip attraction rates have the smallest effect on the total VMT outputs in this study. In model year 2000, the largest positive total VMT change is $0.0000034 \%$, when the trip attraction rates decrease $10 \%$ for NHW. The most negative total VMT change is $-0.0000043 \%$, when the trip attraction rates decrease 10\% for HBW. From model year 2005 to 2030, the largest positive total VMT change is $0.000025 \%$ when the trip attraction rates increase $10 \%$ for $\mathrm{HBW}$. The most negative total VMT change is $-0.00036 \%$ at year 2030, when the trip attraction rates decrease 10\% for HBW at year 2030 . 


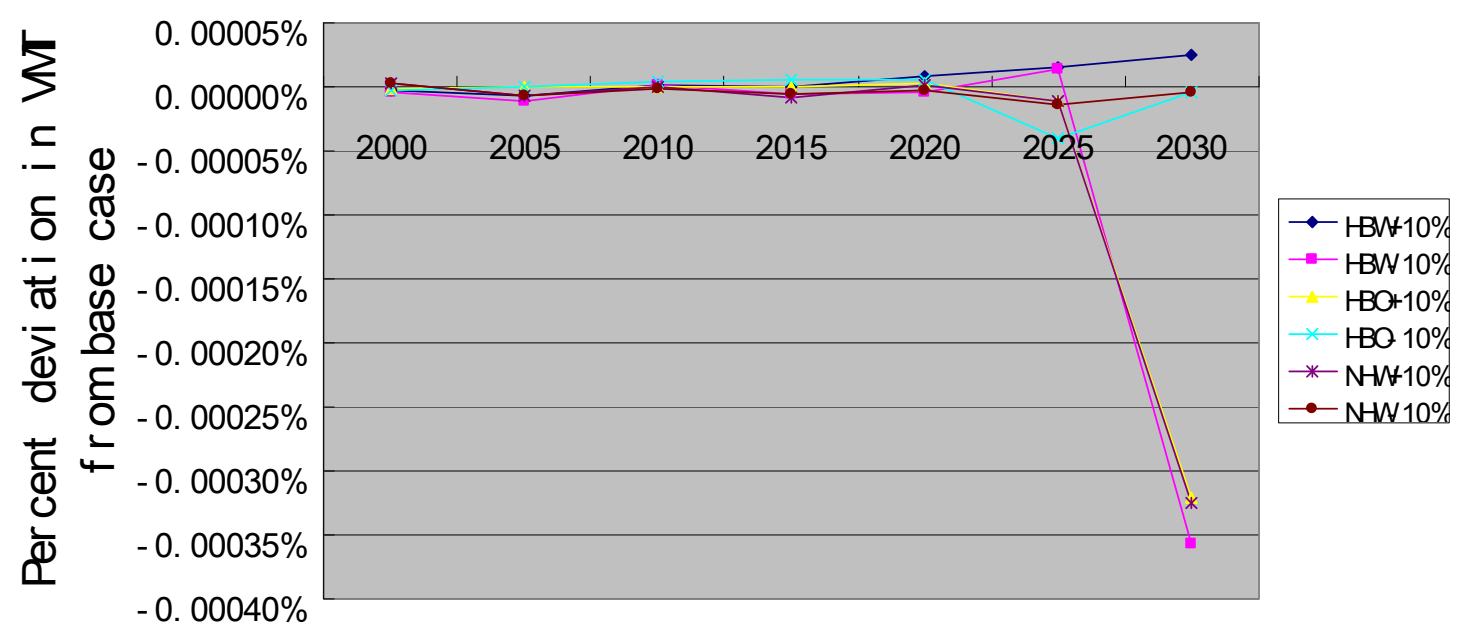

\section{Hor i zon years}

Figure 4-6. Impact of uncertainty in trip attraction rates on the VMT outputs

Figure 4-7 presents the impacts of uncertainty in trip distribution parameters on the total VMT outputs over time. The impacts of uncertainty across model years are quite constant over time for trip distribution parameters. The label 'HBWGammab+10\%' means that trip distribution gamma function parameter b increases by 10 percent for HBW trips. In model year 2000, the largest positive total VMT change is $2.97 \%$, when the trip friction function parameter c value decreases $10 \%$ for HBO. The most negative total VMT change is $-2.21 \%$, when the trip friction function parameter c value increases 10\% for HBO. From model year 2005 to 2030, the largest positive total VMT change is 2.97\%, when the trip friction function parameter c value decreases $10 \%$ for $\mathrm{HBO}$ at year 2010. The most negative total VMT change is $-2.34 \%$, when the trip friction function parameter c value increases 10\% for HBO at year 2005. 


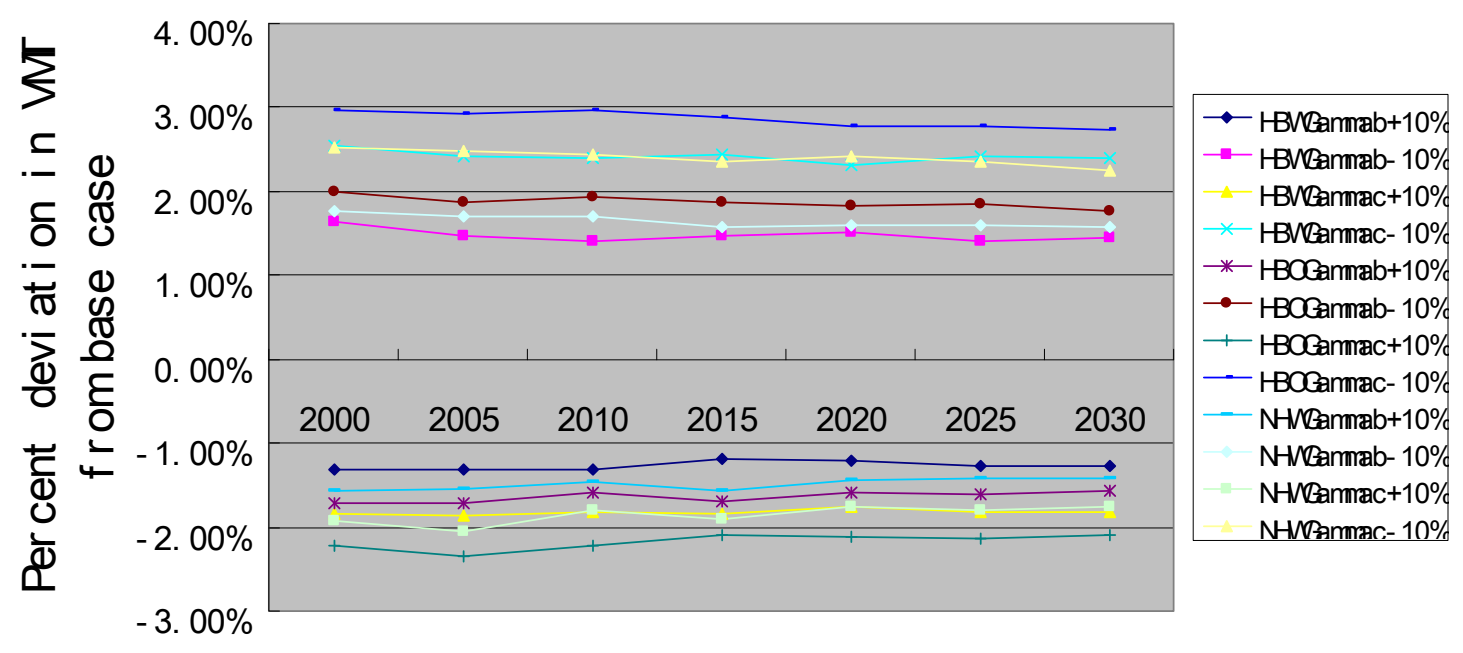

\section{Hori zon years}

Figure 4-7. Impact of uncertainty in trip distribution on the VMT outputs

Figure 4-8 presents the impacts of uncertainty in trip assignment parameters on the total VMT outputs over time. The impacts of uncertainty across model years have high variations over time for trip assignment parameters. The label 'Fclass1BPRab+10\%' means that the values of link performance function parameters a and $b$ increase by 10 percent for functional class 1. In model year 2000, the largest positive total VMT change is $0.12 \%$, when the link performance function parameters a and $\mathrm{b}$ decrease by $10 \%$ for functional class 14 . The most negative total VMT change is $-0.025 \%$, when the link performance function parameters a and b decrease $10 \%$ for functional class 11 . From model year 2005 to 2030, the largest positive total VMT change is $0.092 \%$, when the link performance function parameters a and b decrease by $10 \%$ for functional class 14 at year 2015. The smallest negative total VMT change is $-0.12 \%$, when the link performance function parameters a and b decrease by 10\% for functional class 2 and 6 at year 2005 . 


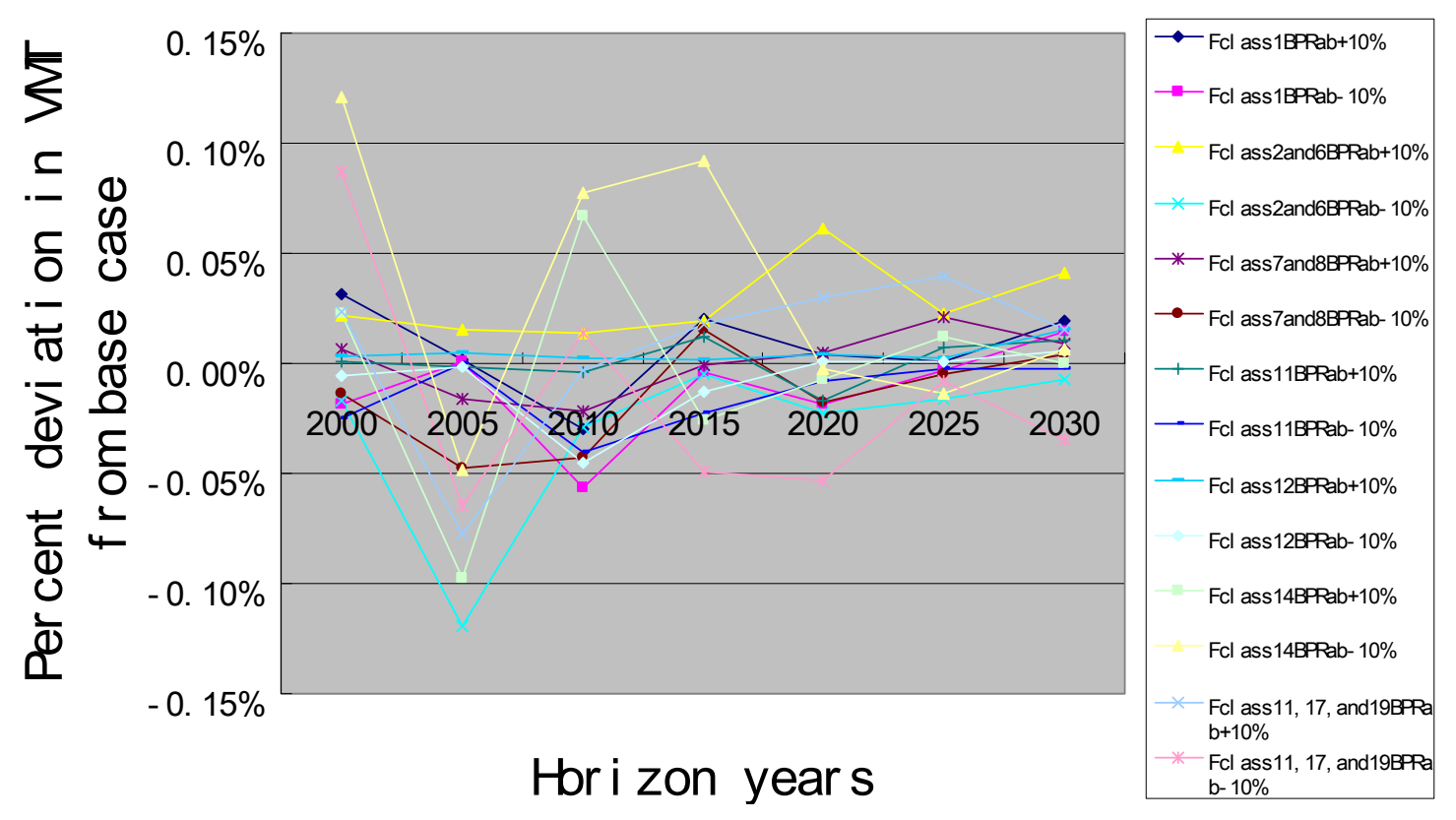

Figure 4-8. Impact of uncertainty in trip assignment on the VMT outputs

In all the changes of the total VMT outputs, it is found that the most important contributors to uncertainty are trip distribution parameters and trip production rates. Trip attraction rates have the smallest sensitivity influence for the total VMT outputs because trip attractions are balanced to trip productions. The total VMT outputs are not highly sensitive to changes in population growth rates and trip assignment parameters.

\subsubsection{VMT by Functional Class}

The sensitivity changes of VMT by functional class are investigated in this chapter. Table 4-4 presents the VMT by functional class from the base case. Among all the functional classes, Rural Interstates have the largest VMT, while Urban Local Roads have the smallest VMT. 
TABLE 4-4. VMT outputs by functional class from the base case

\begin{tabular}{|c|c|c|c|c|c|c|c|}
\hline Functional class & $\begin{array}{l}\text { VMT } \\
(2000) \\
\end{array}$ & $\begin{array}{l}\text { VMT } \\
\text { (2005) } \\
\end{array}$ & $\begin{array}{l}\text { VMT } \\
(2010)\end{array}$ & $\begin{array}{l}\text { VMT } \\
\text { (2015) }\end{array}$ & $\begin{array}{l}\text { VMT } \\
(2020)\end{array}$ & $\begin{array}{l}\text { VMT } \\
(2025)\end{array}$ & $\begin{array}{l}\text { VMT } \\
(2030)\end{array}$ \\
\hline Rural Interstates (1) & 20771177 & 22208841 & 24163899 & 26167730 & 28028175 & 29878852 & 31696927 \\
\hline Other Rural Principal Arterials(2) & 10309482 & 10839104 & 11779892 & 12856373 & 13890630 & 14968980 & 15980926 \\
\hline Rural Minor Arterials(6) & 7121793 & 7478970 & 8211536 & 9046020 & 9897214 & 10814791 & 11930129 \\
\hline Rural Major Collectors(7) & 13128543 & 13689700 & 15038002 & 16517469 & 18377747 & 20464879 & 22982826 \\
\hline Rural Minor Collectors(8) & 397937 & 436349 & 501516 & 574049 & 656070 & 772062 & 894265 \\
\hline Rural Local Roads(9) & 59999 & 60460 & 64365 & 68806 & 74283 & 79727 & 85164 \\
\hline Urban Interstates(11) & 13367127 & 14147682 & 15302655 & 16428696 & 17532298 & 18525374 & 19520055 \\
\hline Other Urban Freeways \& Expwys(12) & 1752124 & 1859576 & 2021972 & 2182475 & 2334565 & 2485444 & 2646778 \\
\hline Other Urban Principal Arterials(14) & 17422227 & 18116966 & 19189498 & 20357111 & 21563942 & 22776723 & 24130189 \\
\hline Urban Minor Arterials(16) & 7755910 & 8148151 & 8720069 & 9249067 & 9749014 & 10294129 & 10819538 \\
\hline Urban Collectors(17) & 813029 & 889735 & 1006620 & 1120447 & 1227686 & 1363164 & 1538545 \\
\hline Urban Local Roads(19) & 50876 & 55662 & 59784 & 61974 & 56391 & 58408 & 59805 \\
\hline
\end{tabular}

Table 4-5 shows the percent change in the VMT by functional class from the base case caused by the different levels of exogenous population growth rate. The VMT has different amounts of changes across functional class. Urban Local roads don't have stable changes over the years. All others are stable. If Urban Local roads are not included, Rural Interstates have the lowest changes, while Rural Minor Collectors have the highest changes, given $\pm 10 \%$ variations of the base population growth rate in each 5 year period. 
TABLE 4-5. Impact of uncertainty in population growth on VMT outputs by functional class compared with the base case

\begin{tabular}{|c|c|c|c|c|c|c|c|c|}
\hline Scenarios & fclass & $\begin{array}{l}\text { VMT } \\
(2000)\end{array}$ & $\begin{array}{l}\text { VMT } \\
(2005)\end{array}$ & $\begin{array}{l}\text { VMT } \\
(2010)\end{array}$ & $\begin{array}{l}\text { VMT } \\
(2015)\end{array}$ & $\begin{array}{l}\text { VMT } \\
(2020)\end{array}$ & $\begin{array}{l}\text { VMT } \\
(2025)\end{array}$ & $\begin{array}{l}\text { VMT } \\
(2030)\end{array}$ \\
\hline & 1 & $0.00 \%$ & $-0.09 \%$ & $0.22 \%$ & $0.01 \%$ & $0.39 \%$ & $0.61 \%$ & $0.43 \%$ \\
\hline & 2 & $0.00 \%$ & $-0.16 \%$ & $0.32 \%$ & $0.66 \%$ & $0.80 \%$ & $0.77 \%$ & $0.94 \%$ \\
\hline Growth & 6 & $0.00 \%$ & $0.21 \%$ & $0.51 \%$ & $0.78 \%$ & $1.06 \%$ & $1.78 \%$ & $2.24 \%$ \\
\hline rate & 7 & $0.00 \%$ & $0.41 \%$ & $0.76 \%$ & $1.30 \%$ & $1.71 \%$ & $2.41 \%$ & $3.15 \%$ \\
\hline increases & 8 & $0.00 \%$ & $0.71 \%$ & $1.47 \%$ & $2.21 \%$ & $4.36 \%$ & $5.76 \%$ & $5.45 \%$ \\
\hline $10 \%$ & 9 & $0.00 \%$ & $0.20 \%$ & $0.62 \%$ & $1.27 \%$ & $1.81 \%$ & $2.44 \%$ & $2.84 \%$ \\
\hline in & 11 & $0.00 \%$ & $0.16 \%$ & $0.43 \%$ & $0.77 \%$ & $0.49 \%$ & $0.63 \%$ & $0.67 \%$ \\
\hline each & 12 & $0.00 \%$ & $0.44 \%$ & $0.52 \%$ & $0.88 \%$ & $1.15 \%$ & $1.25 \%$ & $1.40 \%$ \\
\hline five & 14 & $0.00 \%$ & $0.48 \%$ & $0.84 \%$ & $1.22 \%$ & $1.54 \%$ & $1.90 \%$ & $2.07 \%$ \\
\hline \multirow[t]{5}{*}{ year } & 16 & $0.00 \%$ & $0.70 \%$ & $0.77 \%$ & $1.28 \%$ & $1.74 \%$ & $1.97 \%$ & $2.31 \%$ \\
\hline & 17 & $0.00 \%$ & $0.71 \%$ & $1.35 \%$ & $1.43 \%$ & $2.35 \%$ & $3.30 \%$ & $3.98 \%$ \\
\hline & 19 & $0.00 \%$ & $3.93 \%$ & $-6.64 \%$ & $-8.74 \%$ & $1.19 \%$ & $1.21 \%$ & $1.43 \%$ \\
\hline & 1 & $0.00 \%$ & $-0.22 \%$ & $-0.29 \%$ & $-0.46 \%$ & $0.00 \%$ & $-0.23 \%$ & $-0.59 \%$ \\
\hline & 2 & $0.00 \%$ & $-0.39 \%$ & $-0.32 \%$ & $-0.30 \%$ & $0.03 \%$ & $-0.72 \%$ & $-0.73 \%$ \\
\hline Growth & 6 & $0.00 \%$ & $-0.29 \%$ & $-0.68 \%$ & $-1.07 \%$ & $-1.15 \%$ & $-1.44 \%$ & $-1.63 \%$ \\
\hline rate & 7 & $0.00 \%$ & $-0.31 \%$ & $-0.82 \%$ & $-1.34 \%$ & $-2.42 \%$ & $-2.48 \%$ & $-2.83 \%$ \\
\hline decreases & 8 & $0.00 \%$ & $-0.67 \%$ & $-1.25 \%$ & $-2.24 \%$ & $-3.47 \%$ & $-4.41 \%$ & $-6.58 \%$ \\
\hline $10 \%$ & 9 & $0.00 \%$ & $-0.33 \%$ & $-0.77 \%$ & $-1.46 \%$ & $-2.19 \%$ & $-2.46 \%$ & $-2.64 \%$ \\
\hline in & 11 & $0.00 \%$ & $-0.28 \%$ & $-0.29 \%$ & $-0.16 \%$ & $-0.58 \%$ & $-0.85 \%$ & $-0.92 \%$ \\
\hline each & 12 & $0.00 \%$ & $-0.07 \%$ & $-0.71 \%$ & $-0.66 \%$ & $-1.02 \%$ & $-1.10 \%$ & $-1.56 \%$ \\
\hline five & 14 & $0.00 \%$ & $-0.39 \%$ & $-0.70 \%$ & $-0.91 \%$ & $-1.29 \%$ & $-1.49 \%$ & $-1.97 \%$ \\
\hline \multirow[t]{3}{*}{ year } & 16 & $0.00 \%$ & $-0.18 \%$ & $-1.07 \%$ & $-1.15 \%$ & $-1.23 \%$ & $-1.87 \%$ & $-2.15 \%$ \\
\hline & 17 & $0.00 \%$ & $-0.76 \%$ & $-1.46 \%$ & $-2.04 \%$ & $-2.46 \%$ & $-2.65 \%$ & $-3.43 \%$ \\
\hline & 19 & $0.00 \%$ & $12.02 \%$ & $-10.08 \%$ & $-11.64 \%$ & $5.90 \%$ & $-2.95 \%$ & $-2.42 \%$ \\
\hline
\end{tabular}

Among all the functional classes, Rural Interstates have the largest VMT, while Urban Local Roads have the smallest VMT. Table 4-5 shows the percent change in the VMT by functional class from the base case caused by the different levels of exogenous population growth rate. The VMT has different amounts of changes across functional class. Urban Local roads don't have stable changes over the years. All others are stable. If 
Urban Local roads are not included, Rural Interstates have the lowest changes, while Rural Minor Collectors have the highest changes, given $\pm 10 \%$ variations of the base population growth rate in each 5 year period.

Table 4-6 presents the percent change in the VMT by functional class from the base case caused by the different levels of trip generation rates.

TABLE 4-6. Impact of uncertainty in trip generation rates on VMT outputs by functional class compared with the base case

\begin{tabular}{|c|c|c|c|c|c|c|c|c|}
\hline Scenarios & fclass & $\begin{array}{l}\text { VMT } \\
(2000)\end{array}$ & $\begin{array}{l}\text { VMT } \\
(2005)\end{array}$ & $\begin{array}{l}\text { VMT } \\
(2010)\end{array}$ & $\begin{array}{l}\text { VMT } \\
(2015)\end{array}$ & $\begin{array}{l}\text { VMT } \\
(2020)\end{array}$ & $\begin{array}{l}\text { VMT } \\
(2025)\end{array}$ & $\begin{array}{l}\text { VMT } \\
(2030)\end{array}$ \\
\hline \multirow{6}{*}{$\begin{array}{r}\text { HBW } \\
\text { Rural } \\
\text { trip }\end{array}$} & 1 & $0.33 \%$ & $0.01 \%$ & $0.22 \%$ & $0.08 \%$ & $0.19 \%$ & $0.27 \%$ & $0.22 \%$ \\
\hline & 2 & $1.27 \%$ & $0.82 \%$ & $1.11 \%$ & $1.08 \%$ & $1.06 \%$ & $0.91 \%$ & $0.81 \%$ \\
\hline & 6 & $2.14 \%$ & $2.02 \%$ & $1.74 \%$ & $1.65 \%$ & $1.70 \%$ & $1.66 \%$ & $1.81 \%$ \\
\hline & 7 & $3.15 \%$ & $2.91 \%$ & $2.65 \%$ & $2.54 \%$ & $2.47 \%$ & $2.48 \%$ & $2.56 \%$ \\
\hline & 8 & $2.46 \%$ & $2.28 \%$ & $2.35 \%$ & $2.28 \%$ & $2.32 \%$ & $2.82 \%$ & $2.58 \%$ \\
\hline & 9 & $3.38 \%$ & $2.98 \%$ & $3.19 \%$ & $3.04 \%$ & $2.89 \%$ & $3.13 \%$ & $2.95 \%$ \\
\hline \multirow{3}{*}{$\begin{array}{r}\text { generation } \\
\text { rate } \\
\text { increases }\end{array}$} & 11 & $0.20 \%$ & $0.27 \%$ & $0.46 \%$ & $0.54 \%$ & $0.19 \%$ & $0.55 \%$ & $0.51 \%$ \\
\hline & 12 & $0.65 \%$ & $0.97 \%$ & $0.66 \%$ & $0.69 \%$ & $0.89 \%$ & $0.82 \%$ & $0.63 \%$ \\
\hline & 14 & $0.94 \%$ & $0.98 \%$ & $1.02 \%$ & $1.00 \%$ & $1.24 \%$ & $1.19 \%$ & $1.28 \%$ \\
\hline \multirow{3}{*}{$10 \%$} & 16 & $1.04 \%$ & $1.14 \%$ & $0.89 \%$ & $1.06 \%$ & $1.21 \%$ & $1.28 \%$ & $1.37 \%$ \\
\hline & 17 & $1.63 \%$ & $1.43 \%$ & $1.74 \%$ & $1.62 \%$ & $1.81 \%$ & $2.14 \%$ & $2.69 \%$ \\
\hline & 19 & $2.80 \%$ & $4.52 \%$ & $-6.70 \%$ & $0.68 \%$ & $0.81 \%$ & $0.64 \%$ & $1.21 \%$ \\
\hline \multirow{4}{*}{ HBW } & 1 & $-0.19 \%$ & $-0.30 \%$ & $-0.26 \%$ & $-0.19 \%$ & $-0.12 \%$ & $-0.23 \%$ & $-0.09 \%$ \\
\hline & 2 & $-1.30 \%$ & $-1.46 \%$ & $-1.06 \%$ & $-0.96 \%$ & $-0.57 \%$ & $-0.83 \%$ & $-0.70 \%$ \\
\hline & 6 & $-2.26 \%$ & $-1.95 \%$ & $-1.87 \%$ & $-1.89 \%$ & $-1.76 \%$ & $-1.58 \%$ & $-1.71 \%$ \\
\hline & 7 & $-3.10 \%$ & $-2.81 \%$ & $-2.69 \%$ & $-2.60 \%$ & $-2.91 \%$ & $-2.51 \%$ & $-2.57 \%$ \\
\hline \multirow{2}{*}{$\begin{array}{r}\text { Rural } \\
\text { trip }\end{array}$} & 8 & $-2.51 \%$ & $-2.33 \%$ & $-2.22 \%$ & $-2.34 \%$ & $-2.40 \%$ & $-2.68 \%$ & $-2.61 \%$ \\
\hline & 9 & $-3.47 \%$ & $-3.20 \%$ & $-3.14 \%$ & $-3.13 \%$ & $-3.07 \%$ & $-3.08 \%$ & $-2.94 \%$ \\
\hline \multirow{3}{*}{$\begin{array}{r}\text { generation } \\
\text { rate } \\
\text { decreases }\end{array}$} & 11 & $-0.40 \%$ & $-0.33 \%$ & $-0.28 \%$ & $-0.24 \%$ & $-0.58 \%$ & $-0.54 \%$ & $-0.54 \%$ \\
\hline & 12 & $-0.78 \%$ & $-0.53 \%$ & $-0.94 \%$ & $-0.87 \%$ & $-0.87 \%$ & $-0.84 \%$ & $-0.82 \%$ \\
\hline & 14 & $-0.94 \%$ & $-0.86 \%$ & $-0.81 \%$ & $-0.93 \%$ & $-1.04 \%$ & $-1.09 \%$ & $-1.24 \%$ \\
\hline \multirow{3}{*}{$10 \%$} & 16 & $-0.73 \%$ & $-0.58 \%$ & $-1.10 \%$ & $-1.05 \%$ & $-1.10 \%$ & $-1.26 \%$ & $-1.32 \%$ \\
\hline & 17 & $-1.22 \%$ & $-1.39 \%$ & $-1.70 \%$ & $-1.71 \%$ & $-1.60 \%$ & $-2.16 \%$ & $-2.88 \%$ \\
\hline & 19 & $4.02 \%$ & $11.71 \%$ & $-10.67 \%$ & $-2.35 \%$ & $0.59 \%$ & $-0.16 \%$ & $-0.05 \%$ \\
\hline
\end{tabular}


Due to the limited space, only the scenarios in which trip generation rates increase or decrease $10 \%$ for rural HBW trips are included in Table 4-6. Figure 4-5 shows that, in these two scenarios, the total VMT has the largest positive or the smallest negative changes. From Table 4-6, Urban Local roads don't have stable changes over the years. All others are stable. If Urban Local roads are not included, Rural Interstates have the lowest changes, while Rural Local Roads have the highest changes, given $\pm 10 \%$ variations of the trip generation rates.

Table 4-7 presents the percent change in the VMT by functional class from the base case caused by the different levels of trip attraction rates. Only the trip attraction rates increase or decrease $10 \%$ for HBW trips are included in this table. Figure 4-6 shows that, in these two scenarios, the total VMT has the largest variations. According to Table 4-7, all roads have very small changes over the years, given $\pm 10 \%$ variations of the trip attraction rates.

TABLE 4-7. Impact of uncertainty in trip attraction rates on VMT outputs by functional class compared with the base case

\begin{tabular}{rrlllllll}
\hline \multirow{2}{*}{ Scenarios } & fclass & $\begin{array}{l}\text { VMT } \\
\text { (2000) }\end{array}$ & $\begin{array}{l}\text { VMT } \\
(2005)\end{array}$ & $\begin{array}{l}\text { VMT } \\
(2010)\end{array}$ & $\begin{array}{l}\text { VMT } \\
(2015)\end{array}$ & $\begin{array}{l}\text { VMT } \\
(2020)\end{array}$ & $\begin{array}{l}\text { VMT } \\
(2025)\end{array}$ & $\begin{array}{l}\text { VMT } \\
(2030)\end{array}$ \\
\hline & 1 & $0.000 \%$ & $0.000 \%$ & $0.000 \%$ & $0.000 \%$ & $0.000 \%$ & $0.000 \%$ & $0.000 \%$ \\
& 2 & $0.000 \%$ & $0.000 \%$ & $0.000 \%$ & $0.000 \%$ & $0.000 \%$ & $0.000 \%$ & $0.000 \%$ \\
HBW & 6 & $0.000 \%$ & $0.000 \%$ & $0.000 \%$ & $0.000 \%$ & $0.000 \%$ & $0.000 \%$ & $0.003 \%$ \\
trip & 7 & $0.000 \%$ & $0.000 \%$ & $0.000 \%$ & $0.000 \%$ & $0.000 \%$ & $0.000 \%$ & $0.000 \%$ \\
attraction & 9 & $0.000 \%$ & $0.000 \%$ & $0.000 \%$ & $0.000 \%$ & $0.000 \%$ & $0.000 \%$ & $0.000 \%$ \\
rate & 11 & $0.000 \%$ & $0.000 \%$ & $0.000 \%$ & $0.000 \%$ & $0.000 \%$ & $0.000 \%$ & $0.000 \%$ \\
increases & 12 & $0.000 \%$ & $0.000 \%$ & $0.000 \%$ & $0.000 \%$ & $0.000 \%$ & $0.000 \%$ & $0.000 \%$ \\
$10 \%$ & 14 & $0.000 \%$ & $0.000 \%$ & $0.000 \%$ & $0.000 \%$ & $0.000 \%$ & $0.000 \%$ & $0.003 \%$ \\
& 16 & $0.000 \%$ & $0.000 \%$ & $0.000 \%$ & $0.000 \%$ & $0.000 \%$ & $0.000 \%$ & $-0.008 \%$ \\
& 17 & $0.000 \%$ & $0.000 \%$ & $0.000 \%$ & $0.000 \%$ & $0.000 \%$ & $0.000 \%$ & $-0.007 \%$ \\
& 19 & $0.000 \%$ & $0.000 \%$ & $0.000 \%$ & $0.000 \%$ & $0.000 \%$ & $0.000 \%$ & $-0.015 \%$ \\
\hline
\end{tabular}




\begin{tabular}{rrlllllll} 
Scenarios & fclass & $\begin{array}{l}\text { VMT } \\
\text { (2000) }\end{array}$ & $\begin{array}{l}\text { VMT } \\
(2005)\end{array}$ & $\begin{array}{l}\text { VMT } \\
(2010)\end{array}$ & $\begin{array}{l}\text { VMT } \\
(2015)\end{array}$ & $\begin{array}{l}\text { VMT } \\
(2020)\end{array}$ & $\begin{array}{l}\text { VMT } \\
(2025)\end{array}$ & $\begin{array}{l}\text { VMT } \\
(2030)\end{array}$ \\
\hline & 1 & $0.000 \%$ & $0.000 \%$ & $0.000 \%$ & $0.000 \%$ & $0.000 \%$ & $0.000 \%$ & $0.001 \%$ \\
& 2 & $0.000 \%$ & $0.000 \%$ & $0.000 \%$ & $0.000 \%$ & $0.000 \%$ & $0.000 \%$ & $-0.002 \%$ \\
HBW & 6 & $0.000 \%$ & $0.000 \%$ & $0.000 \%$ & $0.000 \%$ & $0.000 \%$ & $0.000 \%$ & $0.001 \%$ \\
trip & 7 & $0.000 \%$ & $0.000 \%$ & $0.000 \%$ & $0.000 \%$ & $0.000 \%$ & $0.000 \%$ & $-0.001 \%$ \\
attraction & 9 & $-0.000 \%$ & $0.000 \%$ & $0.000 \%$ & $0.000 \%$ & $0.000 \%$ & $0.000 \%$ & $0.001 \%$ \\
rate & 11 & $0.000 \%$ & $0.000 \%$ & $0.000 \%$ & $0.000 \%$ & $0.000 \%$ & $0.000 \%$ & $0.006 \%$ \\
decreases & 12 & $0.000 \%$ & $0.000 \%$ & $0.000 \%$ & $0.000 \%$ & $0.000 \%$ & $-0.001 \%$ & $0.002 \%$ \\
$10 \%$ & 14 & $0.000 \%$ & $0.000 \%$ & $0.000 \%$ & $0.000 \%$ & $0.000 \%$ & $0.000 \%$ & $-0.002 \%$ \\
& 16 & $0.000 \%$ & $0.000 \%$ & $0.000 \%$ & $0.000 \%$ & $0.000 \%$ & $0.000 \%$ & $-0.011 \%$ \\
& 17 & $0.000 \%$ & $0.000 \%$ & $0.000 \%$ & $0.000 \%$ & $0.000 \%$ & $0.000 \%$ & $-0.008 \%$ \\
& 19 & $0.000 \%$ & $0.000 \%$ & $0.000 \%$ & $0.000 \%$ & $0.000 \%$ & $0.000 \%$ & $-0.015 \%$ \\
\hline
\end{tabular}

Table 4-8 presents the percent change in VMT by functional class from the base case caused by the different levels of trip distribution parameters. Only the $10 \%$ increase or decrease trip distribution gamma function parameter c for HBO trips is included in this table. Figure 4-7 shows that, in these two scenarios, the total VMT has the largest variations. From Table 4-8, Urban Local roads don't have stable changes over the years. All others are stable. If Urban Local roads are not included, Rural Interstates have the lowest changes, while Rural Minor Collectors and Urban Collectors have the first or second highest changes, given $\pm 10 \%$ variations of the trip distribution gamma function parameter c. 
TABLE 4-8. Impact of uncertainty in trip distribution on VMT outputs by functional class compared with the base case

\begin{tabular}{|c|c|c|c|c|c|c|c|c|}
\hline Scenario & fclass & $\begin{array}{l}\text { VMT } \\
(2000)\end{array}$ & $\begin{array}{l}\text { VMT } \\
(2005)\end{array}$ & $\begin{array}{l}\text { VMT } \\
(2010)\end{array}$ & $\begin{array}{l}\text { VMT } \\
(2015)\end{array}$ & $\begin{array}{l}\text { VMT } \\
(2020)\end{array}$ & $\begin{array}{l}\text { VMT } \\
(2025)\end{array}$ & $\begin{array}{l}\text { VMT } \\
(2030)\end{array}$ \\
\hline & 1 & $0.34 \%$ & $-0.40 \%$ & $-0.06 \%$ & $0.07 \%$ & $-0.20 \%$ & $-0.09 \%$ & $-0.26 \%$ \\
\hline & 2 & $-1.27 \%$ & $-1.58 \%$ & $-1.16 \%$ & $-0.95 \%$ & $-0.80 \%$ & $-0.92 \%$ & $-0.75 \%$ \\
\hline & 6 & $-2.38 \%$ & $-1.94 \%$ & $-2.08 \%$ & $-2.38 \%$ & $-1.93 \%$ & $-2.06 \%$ & $-2.03 \%$ \\
\hline HBO & 7 & $-3.18 \%$ & $-3.16 \%$ & $-3.40 \%$ & $-3.25 \%$ & $-3.26 \%$ & $-3.31 \%$ & $-3.11 \%$ \\
\hline friction & 8 & $-3.95 \%$ & $-3.74 \%$ & $-3.85 \%$ & $-4.12 \%$ & $-4.26 \%$ & $-4.67 \%$ & $-4.43 \%$ \\
\hline factor & 9 & $-3.21 \%$ & $-2.58 \%$ & $-3.23 \%$ & $-3.50 \%$ & $-3.88 \%$ & $-3.68 \%$ & $-3.95 \%$ \\
\hline gamma C & 11 & $-2.24 \%$ & $-2.12 \%$ & $-1.92 \%$ & $-1.65 \%$ & $-2.07 \%$ & $-2.03 \%$ & $-1.79 \%$ \\
\hline increases & 12 & $-3.32 \%$ & $-2.75 \%$ & $-3.15 \%$ & $-3.03 \%$ & $-2.63 \%$ & $-2.64 \%$ & $-2.99 \%$ \\
\hline \multirow[t]{7}{*}{$10 \%$} & 14 & $-4.01 \%$ & $-4.15 \%$ & $-4.01 \%$ & $-3.78 \%$ & $-3.70 \%$ & $-3.61 \%$ & $-3.64 \%$ \\
\hline & 16 & $-3.88 \%$ & $-3.74 \%$ & $-3.76 \%$ & $-3.81 \%$ & $-3.58 \%$ & $-3.78 \%$ & $-3.57 \%$ \\
\hline & 17 & $-4.07 \%$ & $-4.09 \%$ & $-4.60 \%$ & $-4.88 \%$ & $-4.68 \%$ & $-4.54 \%$ & $-4.59 \%$ \\
\hline & 19 & $2.23 \%$ & $10.30 \%$ & $7.13 \%$ & $-6.15 \%$ & $6.29 \%$ & $-1.08 \%$ & $0.24 \%$ \\
\hline & 1 & $0.16 \%$ & $0.14 \%$ & $0.46 \%$ & $0.12 \%$ & $0.38 \%$ & $0.25 \%$ & $0.20 \%$ \\
\hline & 2 & $1.92 \%$ & $1.69 \%$ & $1.66 \%$ & $1.63 \%$ & $1.37 \%$ & $1.42 \%$ & $1.37 \%$ \\
\hline & 6 & $3.14 \%$ & $3.13 \%$ & $3.00 \%$ & $2.75 \%$ & $2.77 \%$ & $2.94 \%$ & $2.95 \%$ \\
\hline HBO & 7 & $4.32 \%$ & $4.14 \%$ & $4.13 \%$ & $4.32 \%$ & $4.17 \%$ & $4.24 \%$ & $4.33 \%$ \\
\hline friction & 8 & $5.06 \%$ & $5.31 \%$ & $5.33 \%$ & $5.58 \%$ & $5.86 \%$ & $6.42 \%$ & $6.05 \%$ \\
\hline factor & 9 & $4.20 \%$ & $4.49 \%$ & $4.89 \%$ & $4.79 \%$ & $4.81 \%$ & $4.94 \%$ & $5.22 \%$ \\
\hline gamma C & 11 & $3.08 \%$ & $2.82 \%$ & $3.03 \%$ & $3.24 \%$ & $2.54 \%$ & $2.48 \%$ & $2.40 \%$ \\
\hline decreases & 12 & $4.12 \%$ & $4.14 \%$ & $3.95 \%$ & $3.75 \%$ & $3.62 \%$ & $3.76 \%$ & $3.81 \%$ \\
\hline \multirow[t]{4}{*}{$10 \%$} & 14 & $4.95 \%$ & $5.14 \%$ & $5.02 \%$ & $4.84 \%$ & $4.64 \%$ & $4.66 \%$ & $4.56 \%$ \\
\hline & 16 & $4.21 \%$ & $4.66 \%$ & $4.43 \%$ & $4.33 \%$ & $4.47 \%$ & $4.40 \%$ & $4.29 \%$ \\
\hline & 17 & $4.66 \%$ & $4.94 \%$ & $5.40 \%$ & $5.41 \%$ & $5.53 \%$ & $5.46 \%$ & $5.06 \%$ \\
\hline & 19 & $4.02 \%$ & $-1.76 \%$ & $-7.62 \%$ & $-6.25 \%$ & $8.14 \%$ & $2.96 \%$ & $1.71 \%$ \\
\hline
\end{tabular}

Table 4-9 presents the percent change in the VMT by functional class from the base case caused by the different levels of trip assignment BPR parameters. Only the BPR parameters decrease $10 \%$ for functional class 2 and 6, or 14 are included in this table. Figure 4-8 shows that in these two scenarios, the total VMT has the largest variations. From Table 4-9, the roads don't have stable changes over the years. The changes are 
around the zero line. Urban Local roads have the largest absolute changes. Other roads don't have high changes, given $\pm 10 \%$ variations of the trip assignment BPR parameters.

TABLE 4-9. Impact of uncertainty in trip assignment on VMT outputs by functional class compared with the base case

\begin{tabular}{|c|c|c|c|c|c|c|c|c|}
\hline Scenarios & class & $\begin{array}{l}\text { VMT } \\
(2000)\end{array}$ & $\begin{array}{l}\text { VMT } \\
\text { (2005) }\end{array}$ & $\begin{array}{l}\text { VMT } \\
(2010)\end{array}$ & $\begin{array}{l}\text { VMT } \\
\text { (2015) }\end{array}$ & $\begin{array}{l}\text { VMT } \\
(2020)\end{array}$ & $\begin{array}{l}\text { VMT } \\
(2025)\end{array}$ & $\begin{array}{l}\text { VMT } \\
(2030)\end{array}$ \\
\hline \multirow{12}{*}{$\begin{array}{r}\text { Functional } \\
\text { class } \\
2 \text { and } 6 \\
\text { BPR a and b } \\
\text { parameters } \\
\text { decrease } \\
10 \%\end{array}$} & 1 & $0.46 \%$ & $0.03 \%$ & $0.17 \%$ & $0.26 \%$ & $0.12 \%$ & $0.28 \%$ & $0.22 \%$ \\
\hline & 2 & $-0.54 \%$ & & $-0.51 \%$ & $-1.05 \%$ & $-0.64 \%$ & $-0.76 \%$ & $-0.61 \%$ \\
\hline & 6 & $-0.80 \%$ & & $-0.66 \%$ & & & & \\
\hline & 7 & $0.17 \%$ & $0.30 \%$ & $0.31 \%$ & $0.71 \%$ & $0.38 \%$ & $0.36 \%$ & $0.32 \%$ \\
\hline & 8 & $0.14 \%$ & $0.16 \%$ & $0.20 \%$ & $0.08 \%$ & $0.35 \%$ & $0.48 \%$ & $0.42 \%$ \\
\hline & 9 & $0.19 \%$ & $0.19 \%$ & $0.44 \%$ & $0.49 \%$ & $0.13 \%$ & $0.35 \%$ & $0.32 \%$ \\
\hline & 11 & $-0.05 \%$ & $-0.39 \%$ & $0.01 \%$ & $0.14 \%$ & $-0.09 \%$ & $0.00 \%$ & $0.13 \%$ \\
\hline & 12 & $-0.37 \%$ & $-0.33 \%$ & $-0.20 \%$ & $-0.27 \%$ & $-0.27 \%$ & $-0.33 \%$ & $-0.58 \%$ \\
\hline & 14 & $-0.02 \%$ & $0.08 \%$ & $-0.03 \%$ & $-0.04 \%$ & $0.01 \%$ & $-0.02 \%$ & \\
\hline & 16 & $-0.06 \%$ & $-0.01 \%$ & $0.01 \%$ & $-0.02 \%$ & $0.02 \%$ & $-0.03 \%$ & $0.02 \%$ \\
\hline & 17 & $0.06 \%$ & $-0.02 \%$ & $0.02 \%$ & $-0.09 \%$ & $0.05 \%$ & $0.03 \%$ & $-0.16 \%$ \\
\hline & 19 & $-0.48 \%$ & & & & & & $-1.17 \%$ \\
\hline \multirow{6}{*}{$\begin{array}{r}\text { Functional } \\
\text { class } \\
14\end{array}$} & 1 & $0.63 \%$ & $-0.16 \%$ & $0.71 \%$ & $0.22 \%$ & $-0.10 \%$ & $-0.03 \%$ & $0.07 \%$ \\
\hline & 2 & $-0.11 \%$ & $-0.33 \%$ & $0.10 \%$ & -0.0 & & $0.06 \%$ & $0.10 \%$ \\
\hline & 6 & $-0.21 \%$ & $0.22 \%$ & $-0.26 \%$ & $-0.04 \%$ & $0.20 \%$ & $0.27 \%$ & $0.11 \%$ \\
\hline & 7 & $-0.08 \%$ & $0.10 \%$ & $-0.31 \%$ & $-0.02 \%$ & $-0.12 \%$ & $-0.22 \%$ & $-0.17 \%$ \\
\hline & 8 & $-0.09 \%$ & $-0.10 \%$ & $0.00 \%$ & $-0.05 \%$ & $-0.19 \%$ & $0.22 \%$ & $0.06 \%$ \\
\hline & 9 & $-0.10 \%$ & $-0.11 \%$ & $-0.11 \%$ & $-0.05 \%$ & $-0.34 \%$ & $-0.31 \%$ & $0.01 \%$ \\
\hline \multirow{3}{*}{$\begin{array}{r}\text { BPR a and } b \\
\text { parameters } \\
\text { decrease }\end{array}$} & 11 & $0.24 \%$ & $-0.09 \%$ & $-0.24 \%$ & $0.40 \%$ & $-0.18 \%$ & $-0.10 \%$ & $0.05 \%$ \\
\hline & 12 & $0.09 \%$ & $0.21 \%$ & $-0.13 \%$ & $0.08 \%$ & $0.15 \%$ & $0.24 \%$ & $0.09 \%$ \\
\hline & 14 & $-0.13 \%$ & $-0.08 \%$ & $0.16 \%$ & $0.11 \%$ & $0.15 \%$ & $0.08 \%$ & $0.00 \%$ \\
\hline \multirow{3}{*}{$10 \%$} & 16 & $0.12 \%$ & $0.11 \%$ & $-0.23 \%$ & $-0.19 \%$ & $0.11 \%$ & $-0.07 \%$ & $-0.07 \%$ \\
\hline & 17 & $-0.15 \%$ & $0.42 \%$ & $0.12 \%$ & $-0.36 \%$ & $-0.21 \%$ & $-0.29 \%$ & $-0.27 \%$ \\
\hline & 19 & $-2.40 \%$ & $11.16 \%$ & $-8.83 \%$ & $-13.68 \%$ & $6.04 \%$ & $-0.96 \%$ & $-0.10 \%$ \\
\hline
\end{tabular}




\subsection{Summary}

Based on changes in total VMT outputs, the most important contributors to uncertainty are trip distribution parameters and trip production rates. Trip attraction rates have the smallest sensitivity influence for the VMT outputs because trip attractions are balanced to trip productions. The VMT outputs are not highly sensitive to changes in population growth rates and trip assignment parameters.

The sensitivity changes of VMT by functional class are also investigated in this study. In most scenarios, Urban Local roads don't have stable changes over the years. If Urban Local roads are not considered, Rural Interstates have the lowest changes, while Rural Local Roads, Rural Minor Collectors and Urban Collectors have higher changes, given $\pm 10 \%$ variations of the input data and function parameters. Trip attraction rates don't have sensitivity influence for the VMT outputs because trip attractions are balanced to trip productions. The VMT outputs are not highly sensitive to changes in trip assignment parameters.

This study investigates the sensitivity of the VMT outputs on the model parameters and input data using an Indiana integrated ISTDM-LUCI2 model system. Results indicate that the VMT outputs are mostly sensitive to trip distribution gamma function parameters and trip production rates. Population growth rates don't have very much influence on the VMT outputs. This result agrees with Clay and Johnston (2005). Contrary to the previous study by Krishnamurthy and Kockelman (2003), the exponent of the link performance function is not found to be highly sensitive for the VMT outputs in this study.

This study is valuable for policy-makers in understanding the impacts of the model parameters and input data on the VMT outputs. Greatest effort and care in assigning values to model parameters and input data should be devoted to those that cause the greatest changes in the model outputs. Statewide models in other states should be tested on multiple scenarios to investigate the impacts of model parameters and input data on the model outputs.

A univariate approach to the uncertainty analysis is used in this study. The simulations are performed by varying one set of the model parameters or input data by 
at a time. The marginal impacts of the VMT outputs are then compared and discussed in this study. The future work should focus on investigating the uncertainty effect of the model parameters and input data simultaneously. Multiple levels of variations should also be considered for the future comparisons. 


\section{REFERENCES}

Abraham, J. E., Hunt, J. D., "Firm Location in the MEPLAN Model of Sacramento", Transportation Research Record No. 1685, 1999, pp. 187-198.

Batty, M., "Recent Developments in Land-use Modelling: A Review of British Research”, Urban Studies, 9:2, 1972, pp. 151 - 177.

Berechman, J., Small, K. A., "Modeling Land Use and Transportation: an Interpretive Review for Growth Areas”, Environment and planning A, Volume 20, 1988, pp. 12851309.

Cambridge Systematics and Science Application International Corporation, Use of Data from Continuous Monitoring Sites, Volume II: Documentation, FHWA, 1994.

Clay, M. J. and Johnston, R. A., "Univariate Uncertainty Analysis of an Integrated Land Use and Transportation Model: MEPLAN", Transportation Planning and Technology, Vol. 28, No. 3, 2005, pp. 149-165.

Fricker, J. D. and Ottensmann, J. R., Proposal for Part I research Study: Development of Integrated Land Use - Transportation Model for Indiana, Joint Transportation Research Program, Project No. C-36-70H, 2005.

Hensher, D. A., Button, K.J., Eds., Handbook of Transport Modelling (Handbooks in Transport), Pergamon, 2002.

Indiana Statewide Travel Demand Model Upgrade-Technical Memorandum: Model Update and Validation, Bernardin, Lochmueller \& Associates, Inc. and Cambridge Systematics, Inc., 2005.

Johnston, R. A., Caroline J. R., Melanie C., John A., Air Quality Impacts of Regional Land Use Policies: Final Report for the Environmental Protection Agency, Department of Environmental Science and Policy, University of California - Davis, 2000.

Krishnamurthy, S. and Kockelman, K. M., "Propagation of Uncertainty in Transportation Land Use Models: Investigation of DRAM-EMPAL and UTPP Predictions in Austin, Texas”, Transportation Research Record No. 1831, 2003, pp. 219-229.

Lo, H. K. and Wong, S. C., "Recent Methodological Advances in Urban Transportation Planning”, Journal of Urban Planning and Development, Volume 128, Issue 4, 2002, pp. 167-168. 
Lowry, I. S., A Model of Metropolis, Rand Corporation, 1964.

Miller, E. J., Kriger, D. S., Hunt, J. D., Badoe, D. A., Integrated Urban Models for Simulation of Transit and Land-Use Policies, Final Report, TCRP Project H-12, Toronto: Joint Program of Transportation, University of Toronto, 1998.

Miller, E. J., Kriger, D. S., and Hunt, J. D., "Research and Development Program for Integrated Urban Models”, Transportation Research Record 1685, 1999. pp. 161-170.

Meyer, M. D., Miller, E. J., Urban Transportation Planning: A Decision-oriented Approach, Mcgraw-Hill Publishing Co., 2001.

Morgan, M. G. and Henrion, M., Uncertainty: A Guide to Dealing with Uncertainty in Quantitative Risk and Policy Analysis, Cambridge University Press, Cambridge, 1990.

Niemeiera, D. and Mannering, F., "Bridging Research and Practice: A Synthesis of Best Practices in Travel Demand Modeling”, Transportation Research Part A: Policy and Practice, Volume 41, Issue 5, 2007, pp. 365-366.

Ortúzar, J. de D., Willumsen, L. G., Modelling Transport, Wiley, 2001.

Ottensmann, J. R., “LUCI Land Use in Central Indiana Model and the Relationships of Public Infrastructure to Urban Development”, Public Works Management \& Policy, Vol. 8, 2003, pp. 62-76.

Ottensmann, J. R., LUCI2IN Statewide Model Report on Land Use Classification and Model Estimation, 2007.

Pfaffenbichler, P., The strategic, dynamic and integrated urban land use and transport model MARS (Metropolitan Activity Relocation Simulator), Ph.D. thesis, Vienna University of Technology, 2003.

Pradhan, A. and Kockelman, K.M., "Uncertainty propagation in an integrated land usetransportation modeling framework: output variation via UrbanSim”, Transportation Research Record 1805, 2002, pp. 128-135.

Prastacos, P., “An Integrated Land-Use-Transportation Model for the San Francisco Region: 1. Design and Mathematical Structure”, Environment and Planning A, Volume 18, 1985, pp. 307-322.

Prastacos, P., "Urban Development Models for the San Francisco Region: From PLUM to PLIS”, Transportation Research Record 1046, 1985, pp. 37-44.

Putman, S.H., Integrated Urban Models, Pion Limited, London, England, 1983.

Rodrigue, J. P., Comtois, C., Slack, B., The Geography of Transport Systems, Routledge, 2006.

Southworth, F., A Technical Review of Urban Land Use-Transportation Models as Tools for Evaluating Vehicle Travel Reduction Strategies, Technical Report ORNL-6881, U.S. Department of Energy, Washington, D.C., 1995.

Timmermans, H., “Modeling Land Use and Transportation Dynamics: Methodological 
Issues, State-of-Art, and Applications in Developing Conutries”, Discussion Paper Series Vol. 2006-06, Eindhoven University of Technology, 2006.

Van Est, J., “The Lowry Model Revised to Fit a Dutch Region”, Chapter 11 in New Developments in Modelling Travel Demand and Urban Systems (C. Jansen, G.R.M., Bovy, P.H.L., Van Est, J.P.J.M. and Le Clerg, F. Eds), Saxon House, England, 1979.

Waddell, P., "UrbanSim: Modeling Urban Development for Land Use, Transportation and Environmental Planning”, Journal of the American Planning Association 68(3), 2002, pp.297-314.

Wegener, M., Fuerst, F., Land-Use Transport Interaction: State of the Art, EconWPA, 2004.

Yen, Y. M., An Integrated Transportation Land Use modeling System, Ph.D. thesis, Purdue University, 1996.

Zhao, F., Chung, S., Shaw, S. L., Xin, X., Modeling the Interactions between Land Use and Transportation Investments, Final Report for BC851, 2003.

Zhao, Y. and Kockelman, K.M., "The propagation of uncertainty through travel demand models: an exploratory analysis”, Annals of Regional Science, Vol. 36, 2002, pp. 145-163. 


\title{
User's Guide to INT RLUDE
}

\section{The INtegrated TRansportation Land Use Demand Estimation Model for Indiana}

\author{
April 2008
}

For use with TransCAD 5.0

\author{
Li J in \\ Research Assistant \\ J on D. Fricker \\ Professor \\ Purdue University \\ School of Civil Engineering \\ April 2008 \\ J oint Transportation Research Program
}




\section{TABLE OF CONTENTS}

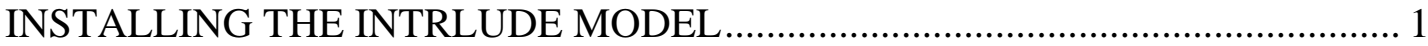

CREATING STATEWIDE ROADWAY NETWORK CHANGES ......................... 6

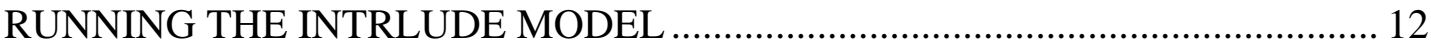

OUTPUT FILES FOR THE INTRLUDE MODEL ................................................ 18

\section{FOREWORD}

The Indiana Statewide Travel Demand Model (ISTDM) was developed by Bernardin, Lochmueller \& Associates and Cambridge Systematics under the supervision of the Indiana Department of Transportation. The Land Use in Central Indiana (LUCI) model was developed by Prof. John Ottensmann of Indiana Purdue University Indianapolis (IUPUI). A later version (luci2) forecasts urban development in a 44county region of central Indiana for up to 40 years into the future.

(http://luci.urbancenter.iupui.edu) Under the auspices of research project SPR-3051 Development of an Integrated Land Use Transportation Model for Indiana,

- The luci2 model was expanded to match the geographic coverage and zone structure of the ISTDM. The expanded luci2 model was also revised to be compatible with other characteristics of the ISTDM.

- The revised LUCI model and the ISTDM were integrated using script written in TransCAD's GISDK.

The resulting INtegrated TRansportation Land $\underline{\text { Use }}$ Demand Estimation (INTRLUDE) Model for Indiana is truly integrated. Data are transferred between the land use and travel demand models without human intervention. Because of the complexities of the two models and the large (4500-zone) area being analyzed, one run of the integrated model for a 30-year horizon may take more than five hours. The integrated model has been tested, however, many times with a variety of input values. This user's guide is intended to enable the first time (or occasional) user to be successful running the integrated model. 


\section{INSTALLING THE INTRLUDE MODEL ON TRANSCAD 5.0}

Step1. Copy and unzip the two files that are named luci2INcl.zip and ISTDM-LUCI2.zip on the provided DVD disc.

Step2. Click setup.exe file in the luci2INcl folder, and follow the instructions to install LUCI2INcl model on the computer. (You must use the default model directory provided by the setup.exe file to install the LUCI2INcl model.)

Step 3. Create a directory on the hard drive of the machine to be the INTRLUDE model directory. Copy all the unzipped files from ISTDM-LUCI2.zip to this directory.

Step 4. Copy all the unzipped code files from INTRLUDEcodetranscad5.zip to the INTRLUDE model directory.

Step 5. Right click the TransCAD icon for the Standard Geographic Database file and select Properties. In the Target input, make sure that only "C:Program Files\TransCAD $\backslash$ tcw.exe" appears.

Step 6. Click OK.

Step 7. Open TransCAD by clicking the TransCAD icon. 
Step 8. Click Tools, then click Setup Add-Ins..., it will show:

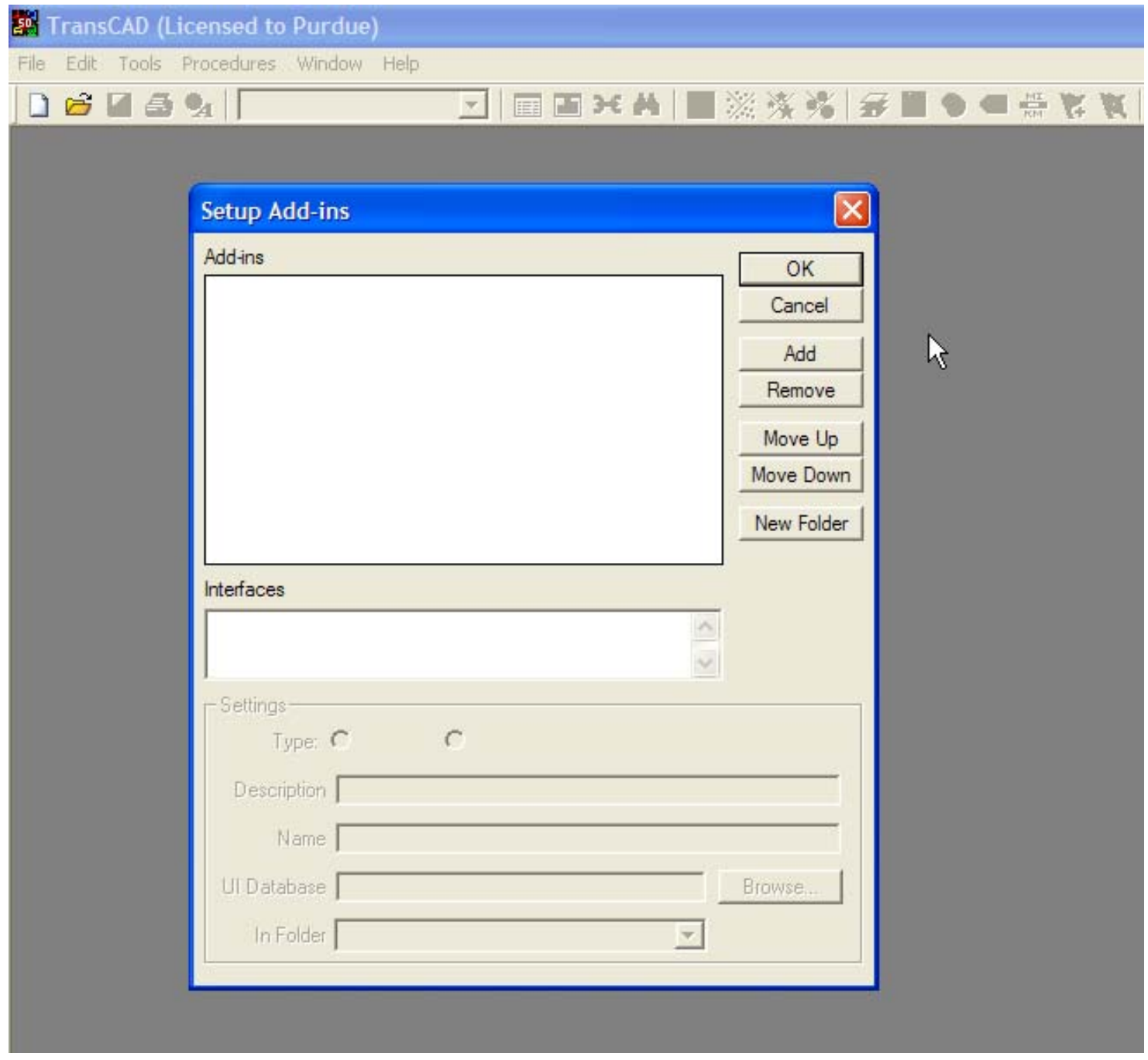


Step 9. Click Add. The screen will appear as:

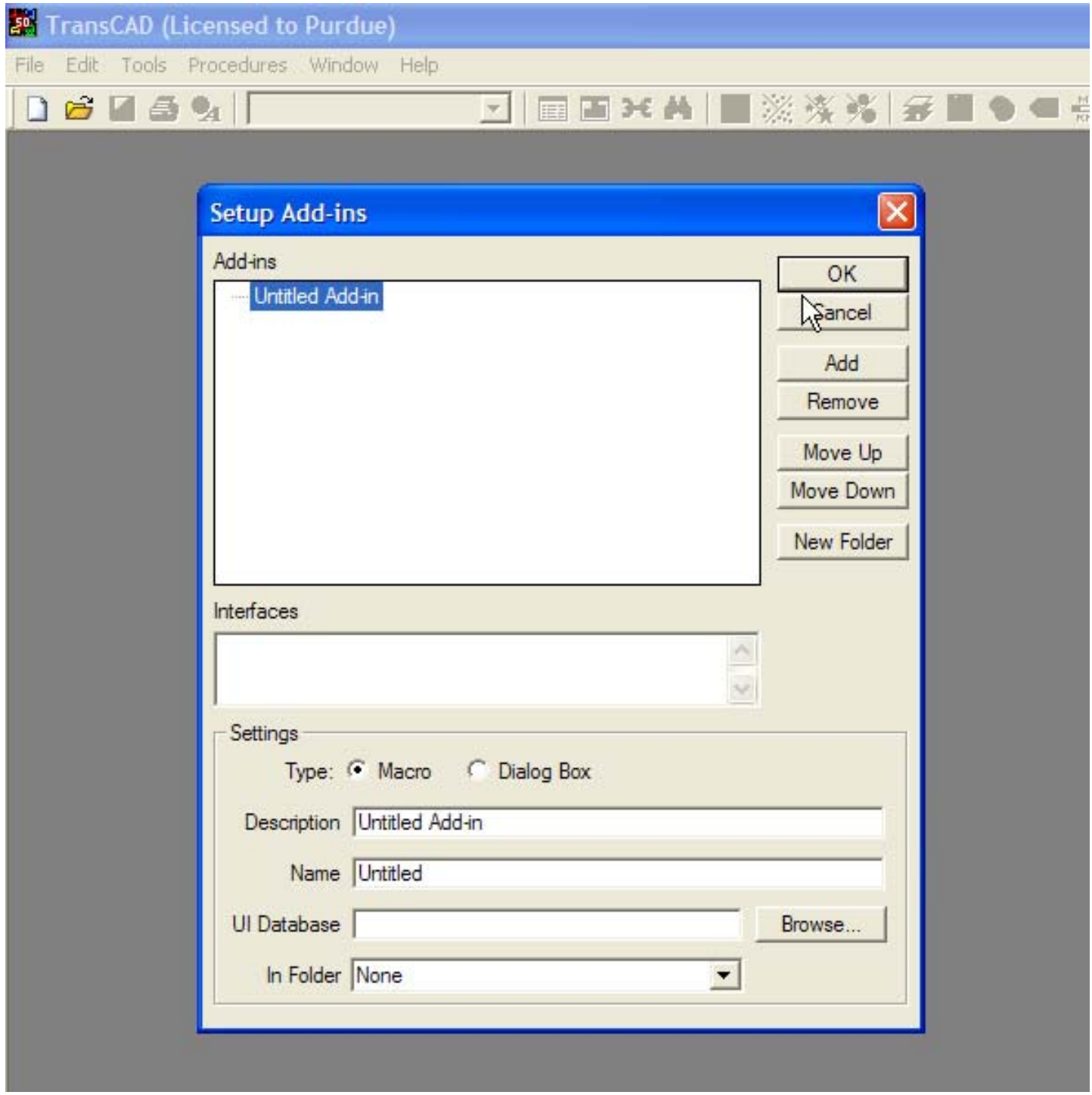


Step 10. Please type INTRLUDE into the Description and INTRLUDE into the Name, as shown below. Click Browse, find and choose the file name "intrlude.dbd" in the installed INTRLUDE model files' directory. The display may look like this:

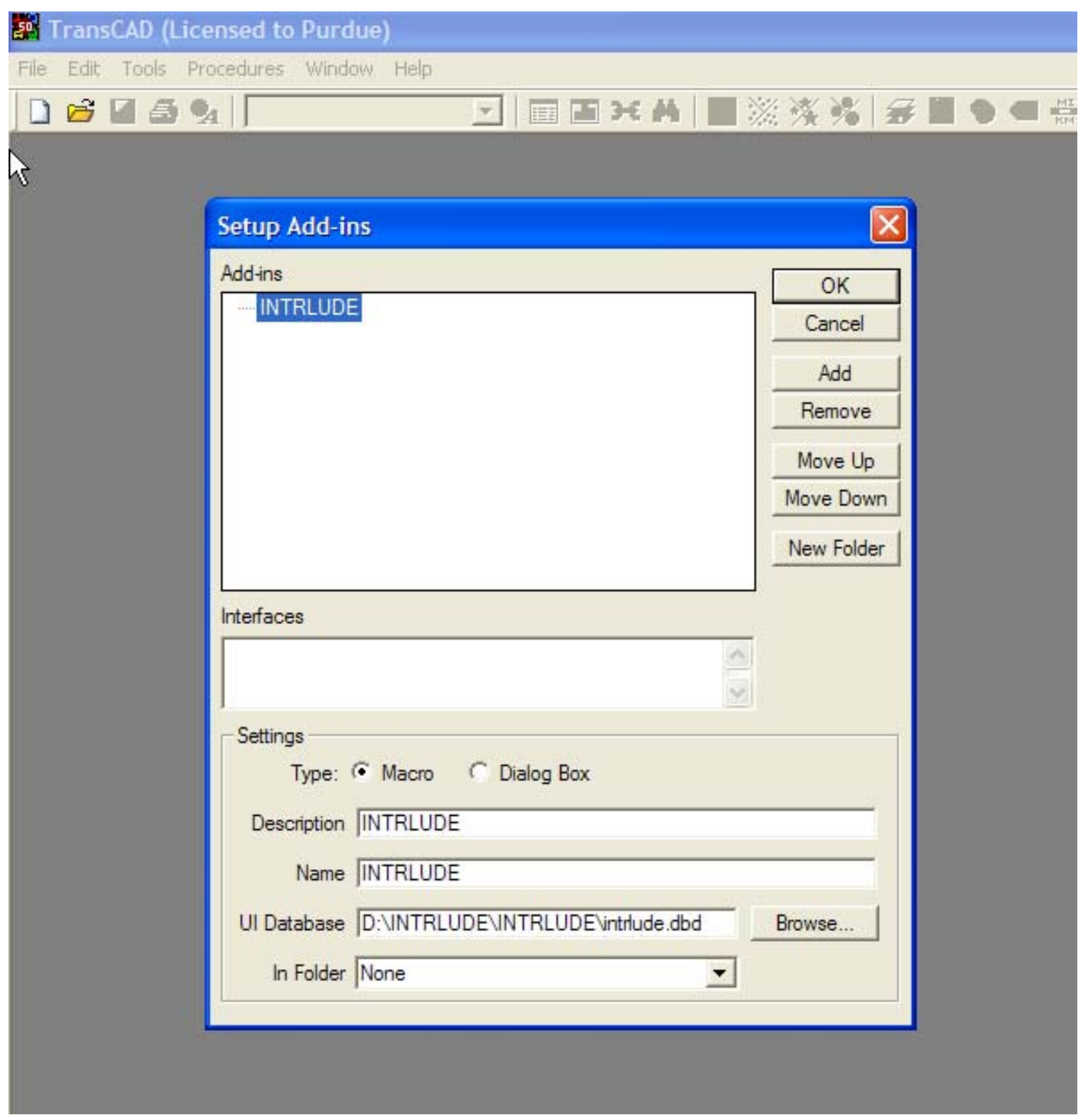


Step 11. Click OK.

Step 12. Click Tools, then click Add-Ins, then click INTRLUDE The INTRLUDE menu should now appear on the top of the TransCAD window:

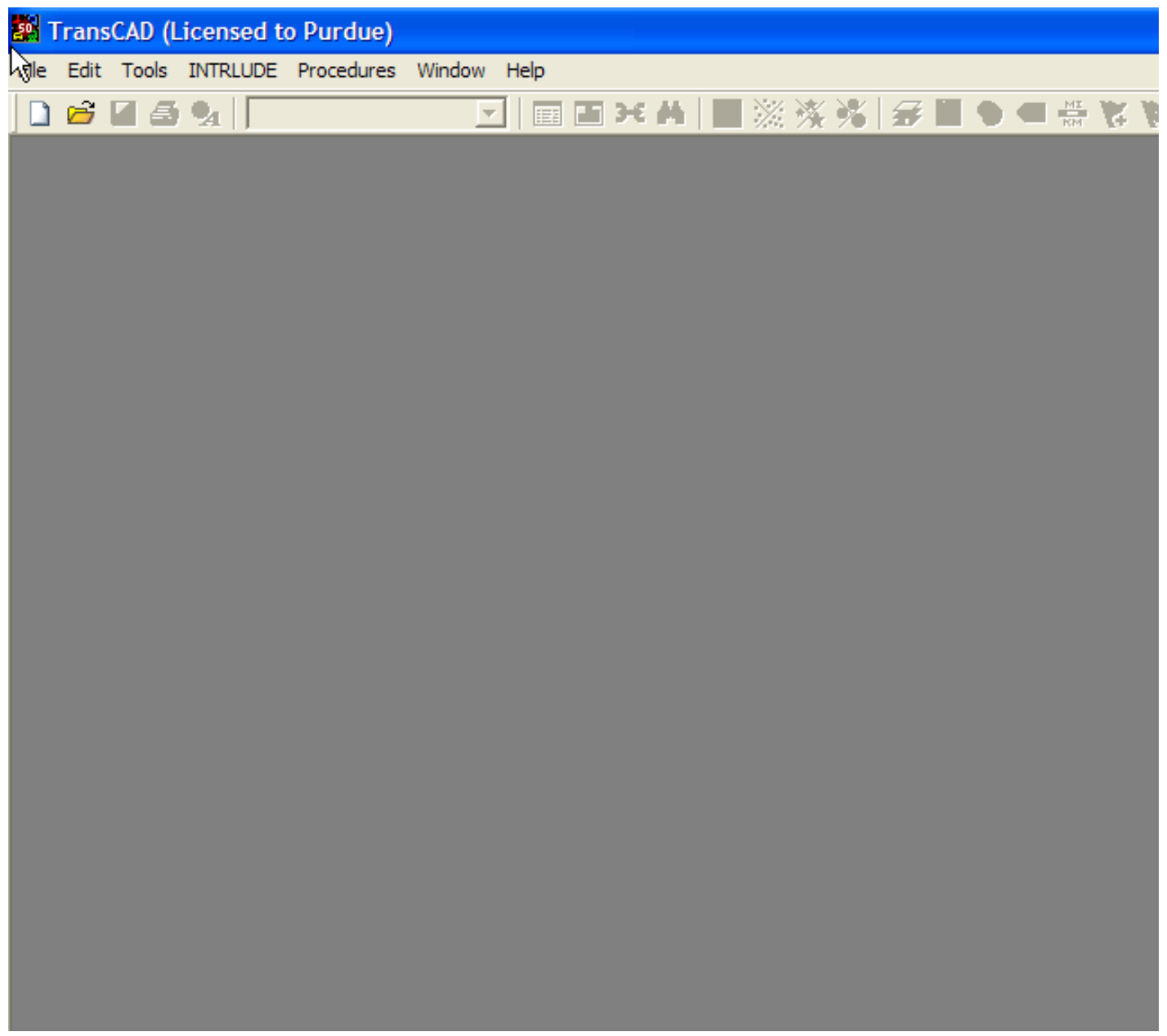

Step 13. The INTRLUDE menu will disappear each time when users close TransCAD program. The next time a user re-enters TransCAD program, click Tools, then click AddIns, then click INTRLUDE to let INTRLUDE menu re-appear on the top of the TransCAD window. 


\section{CREATING STATEWIDE ROADWAY NETWORK CHANGES}

This version of the INTRLUDE model can allow users to specify changes to the state network that may be proposed at certain years before the horizon year.

Step 14. Click File, then click Open. Go to the installed INTRLUDE model directory and, in the hwy folder, find the “ISTDM_MASTERNET.dbd” file and open it.

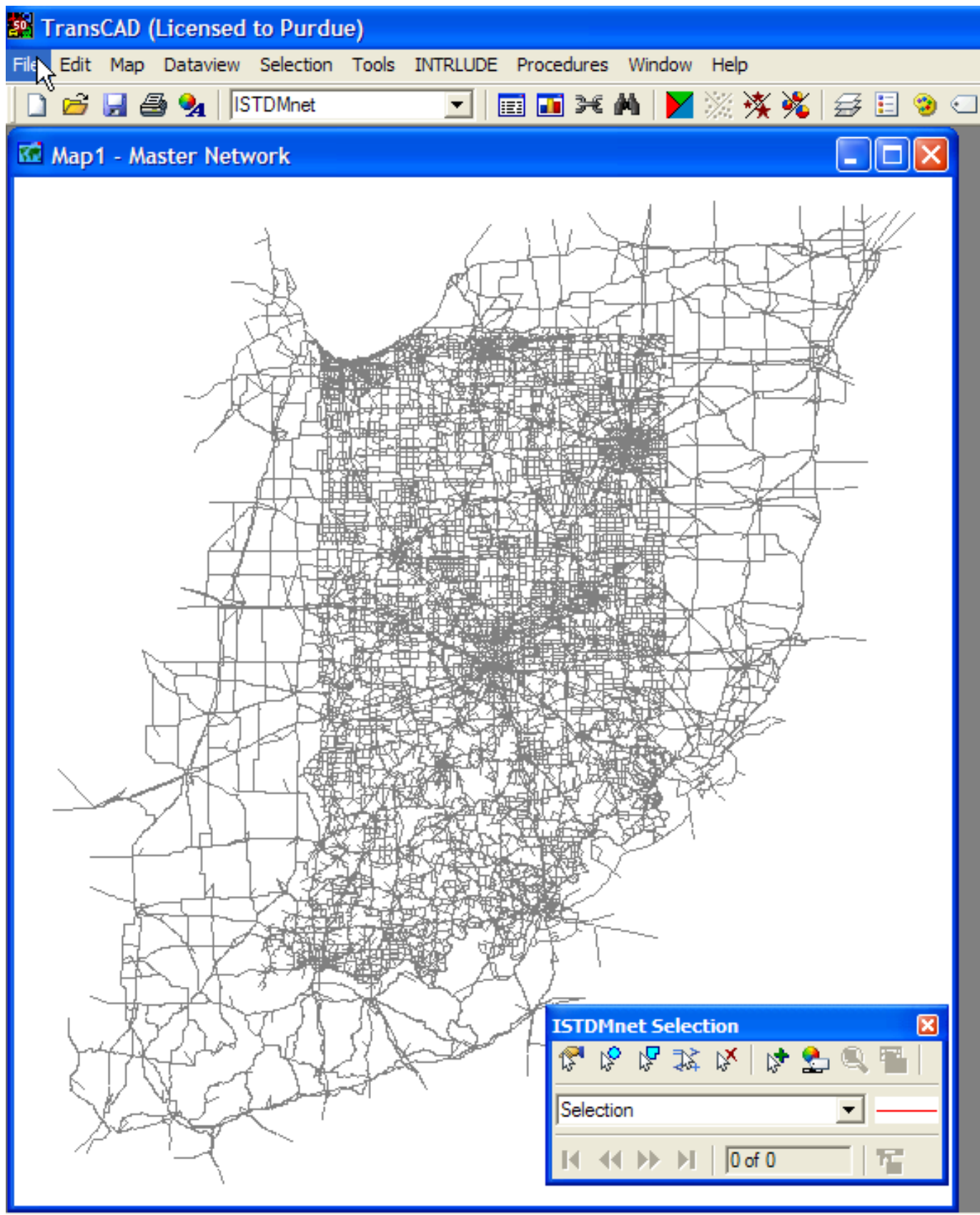


Step 15. There are 7 scenarios coded in the Master network file. Please click New Dataview, users will find some fields names "Net_1”, “Net_2”,..."Net_7”. These will serve as flag fields for different scenarios.

The 7 scenarios are:

Scenario 1: Year 2000 Base Network

Scenario 2: Existing plus Committed

Scenario 3: Long Range Plan

Scenario 4: I-69 + committed

Scenario 5: HERS E+C w/I-69

Scenario 6: Old LRP E+C

Scenario 7: LRP w/o I-69

Users can choose different scenarios from the INTRLUDE interface showed in the following RUNNING THE INTRLUDE MODEL section.

The“Net_1”, “Net_2”,..."Net_7”will be read as the flag field of the chosen scenario. If the values of that field for some roadway links are null (show as --) or larger than the corresponding scenario number, the roadway links will not be read and not be assigned in the travel demand model for that chosen scenario. 


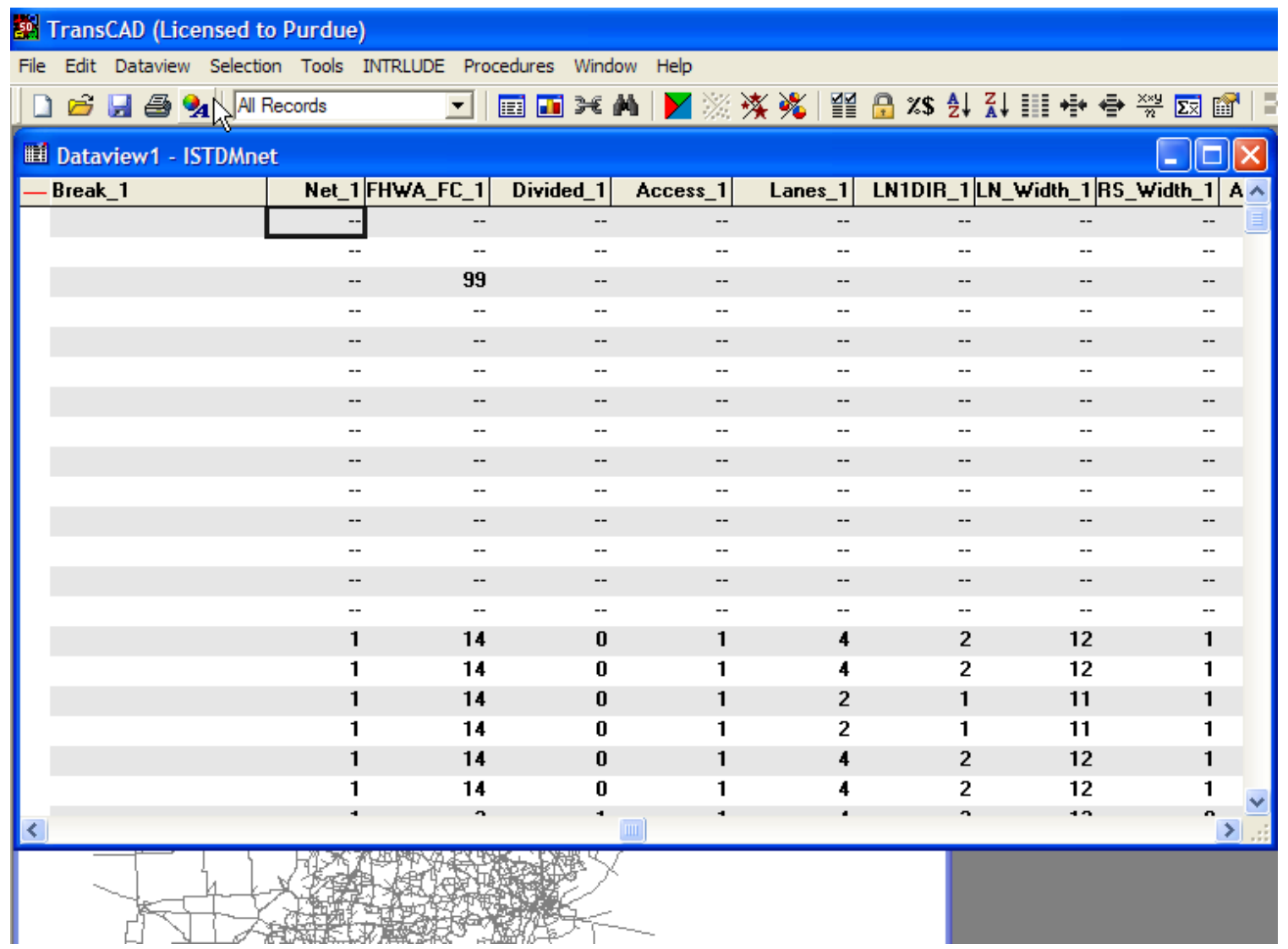

Step 16. To create a future year network changes, for example, users want to create a roadway network changed from year 2020. First please click INTRLUDE, then click Add Network Scenario. 


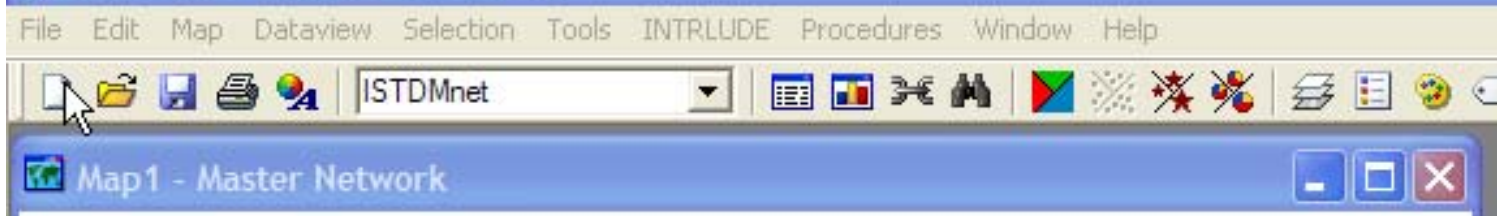

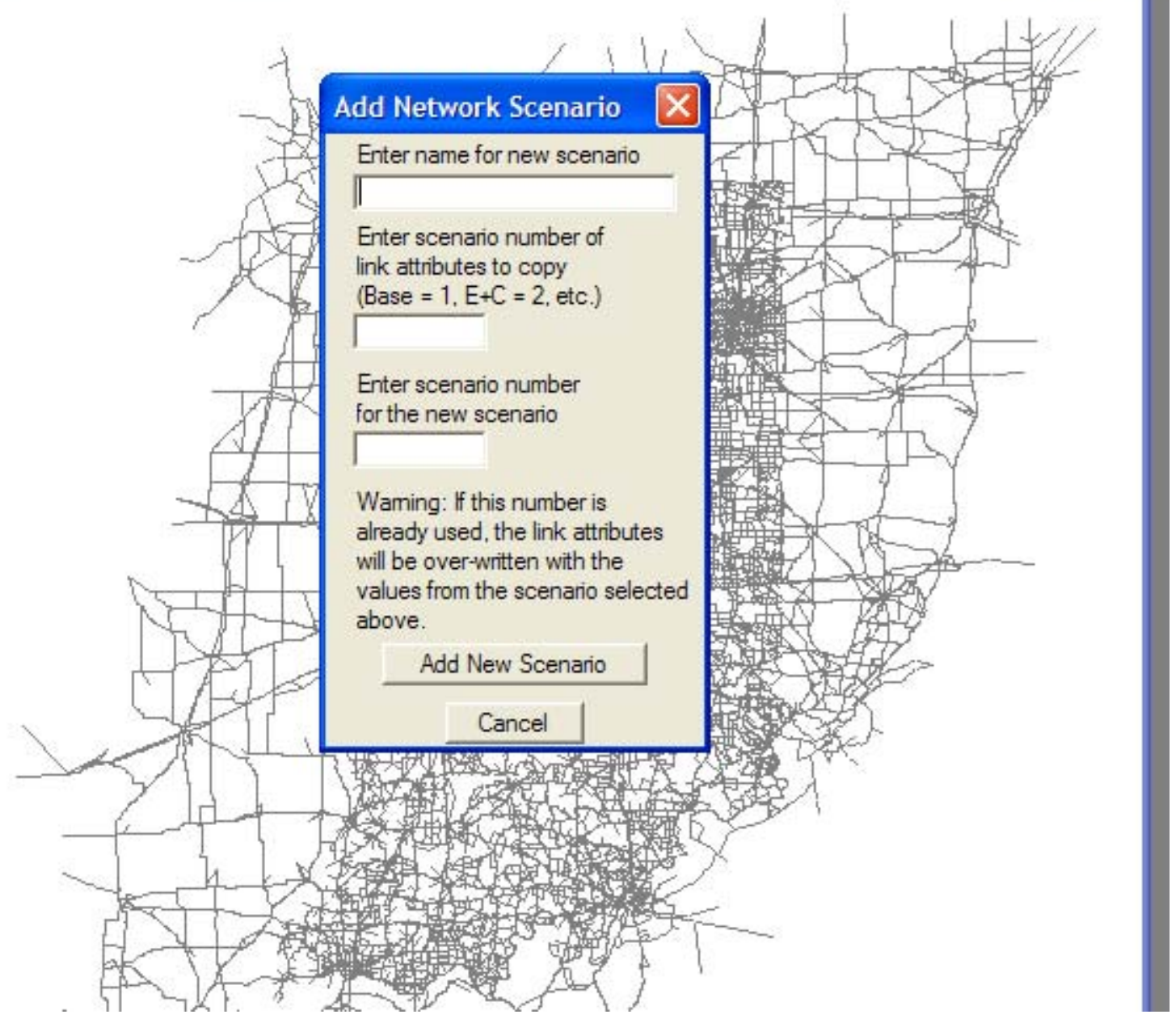

Step 17. At the starting point, users can copy any of 7 scenarios to be the starting points of year 2020 roadway network. In this example, scenario 1 is copied to be the year 2020 network and named as test. 


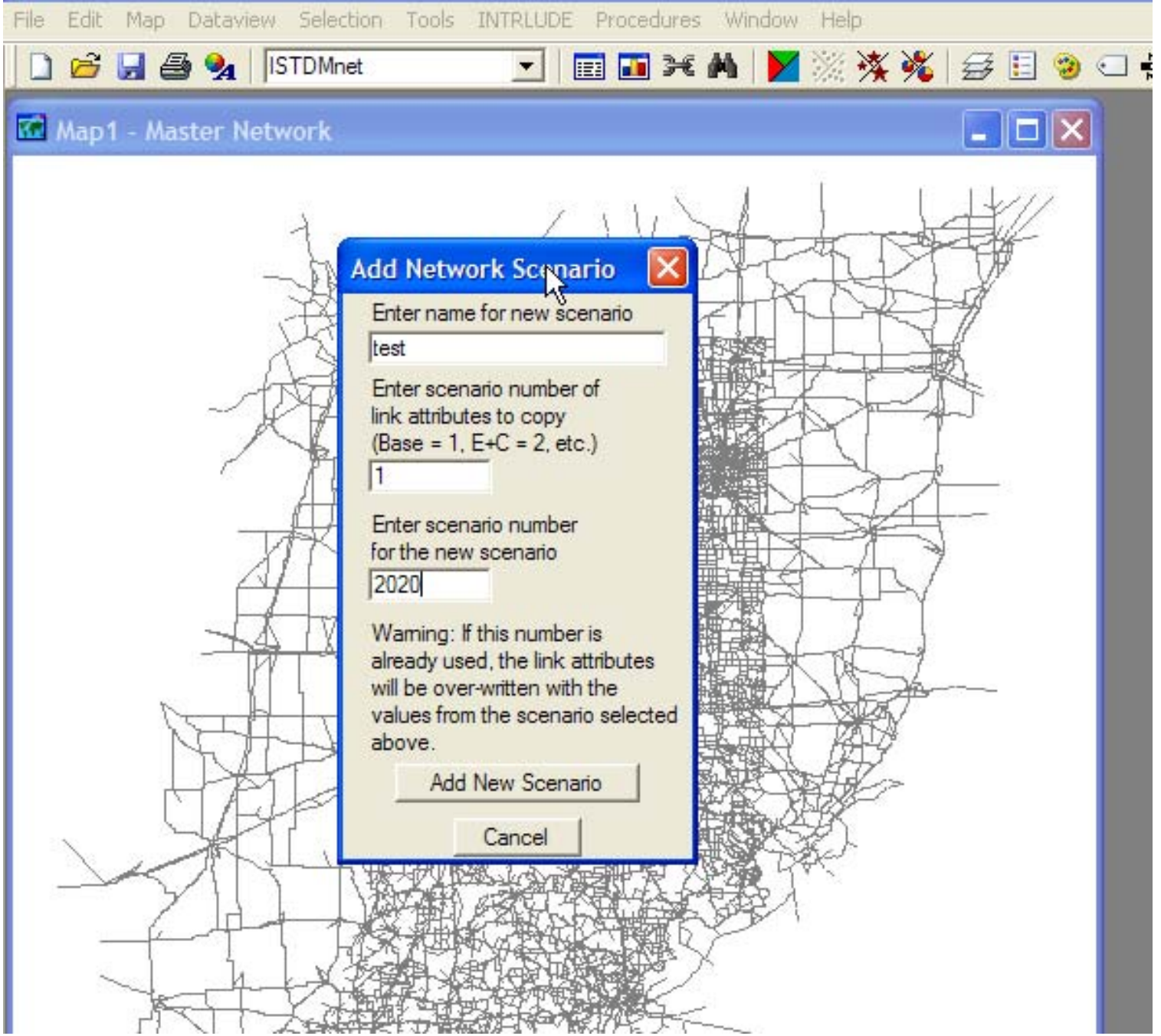

Step 18. Please click Add New Scenario. After Add Scenario process is finished, please go to Dataview, new fields including Net_2020 will show up in the window. 


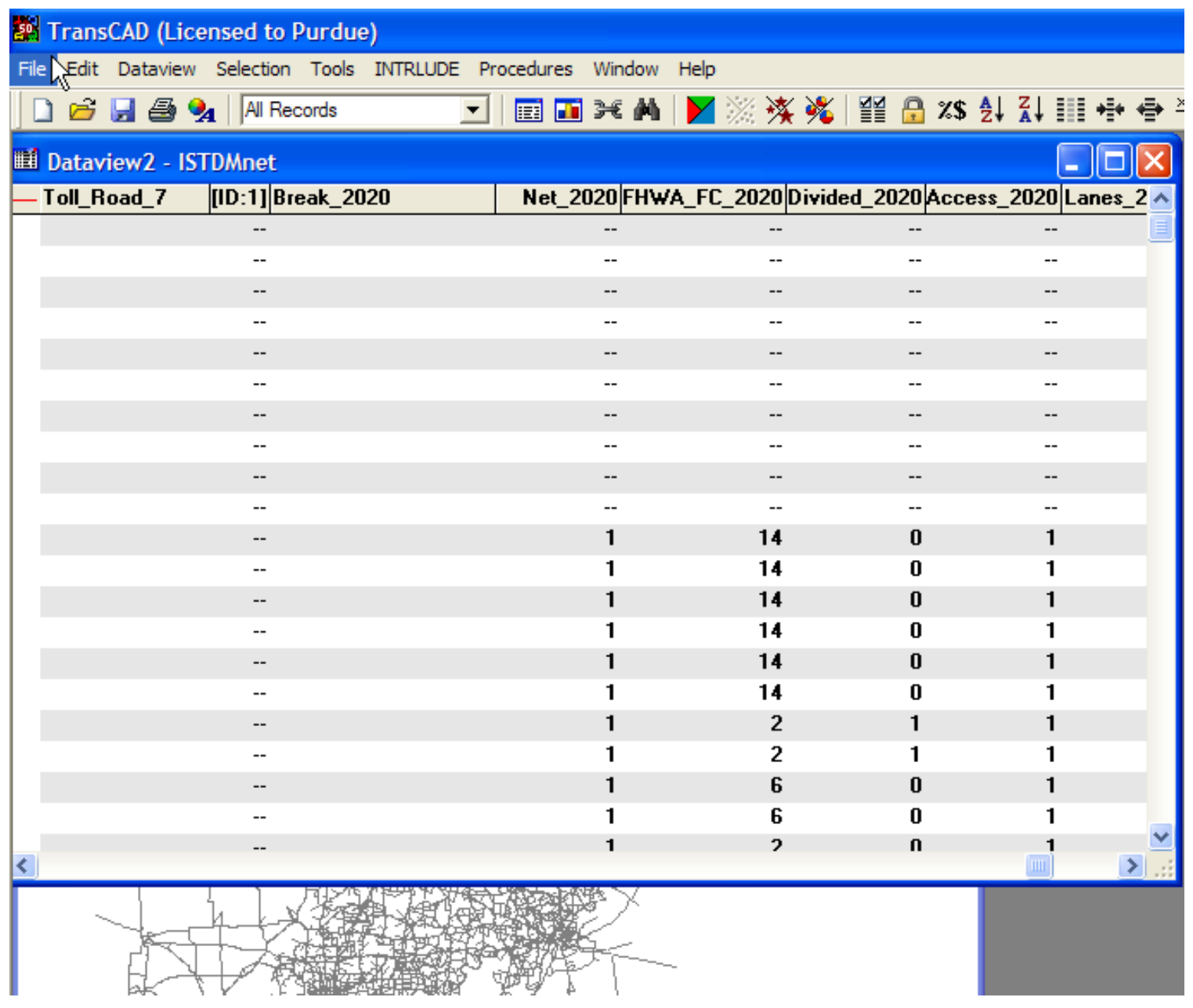

Step 19. Users can then manually add more links or changed links’ input values using TransCAD Tools-Map Editing-Toolbox. If the value for some links in the field of Net_2020 is null (showed as -- in the Dataview) or larger than 2020, the links will not be read from the year 2020. All the links with the value less than or equal to 2020 will be automatically read and used in the travel demand model from year 2020.

Step 20. Users can click INTRLUDE, then click Delete Network Scenario, and input the scenario number (for example, it is 2020 for this example) to delete the year 2020 network changes.

Step 21. During running the INTRLUDE, the script will automatically scan the flag field from the Dataview of the file "ISTDM_MASTERNET.dbd" in each 5-year period (Please only use 5 years as the basic unit.). In this example, from year 2020, the roadway network will be different with the year 2000 roadway network. Thus, users can add the roadway network changes for each 5-year period (2005, 2010, 2015, 2020, 2025,....until the target year). 


\section{RUNNING THE INTRLUDE MODEL ON TRANSCAD 5.0}

Step 22. If the "ISTDM_MASTERNET.dbd” file is not opened, please click File, then click Open. Go to the unzipped ISTDM-LUCI2 model directory and, in the hwy folder, find the "ISTDM_MASTERNET.dbd" file and open it.

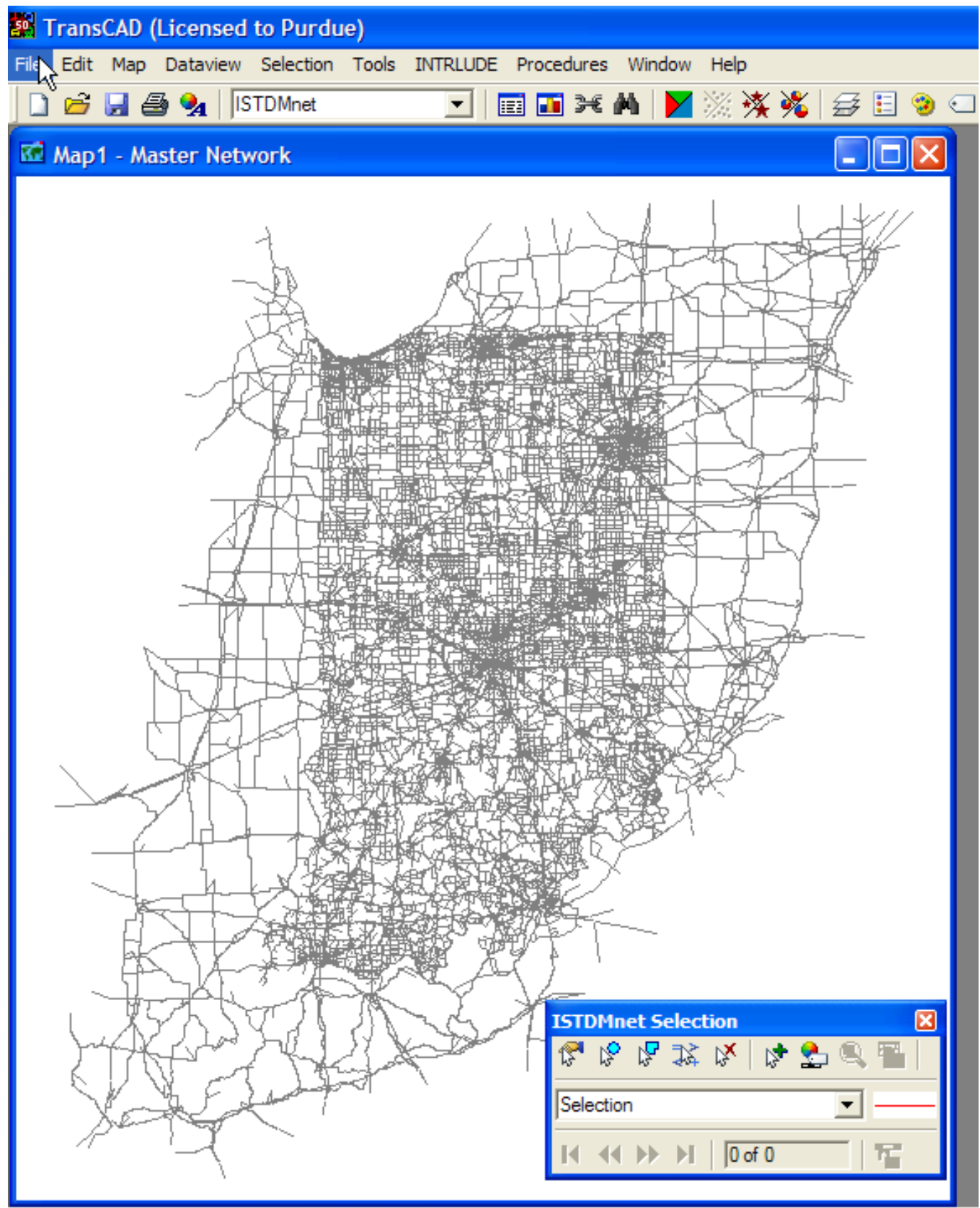


Step 23. Click the layers icon, then click Add Layer. Choose "ISTDM_TAZ2000_120704.dbd" in the taz folder and open it. Now we have opened both the master network layer and the taz layer. "Close" the Layers window.

50.7 TransCAD (Licensed to Purdue)

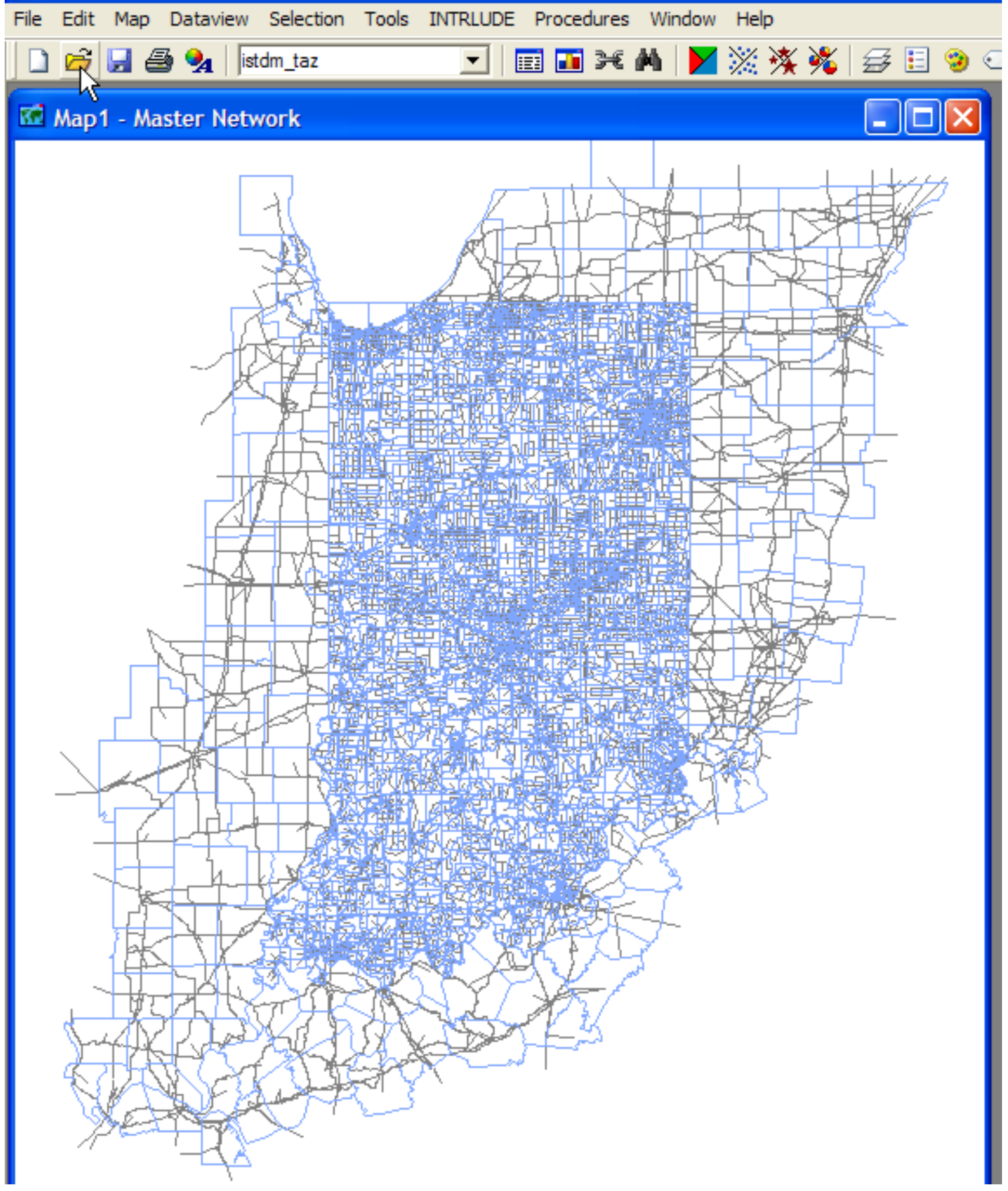


Step 24. Click the INTRLUDE menu and choose INTRLUDE Interface. The INTRLUDE interface will pop up.

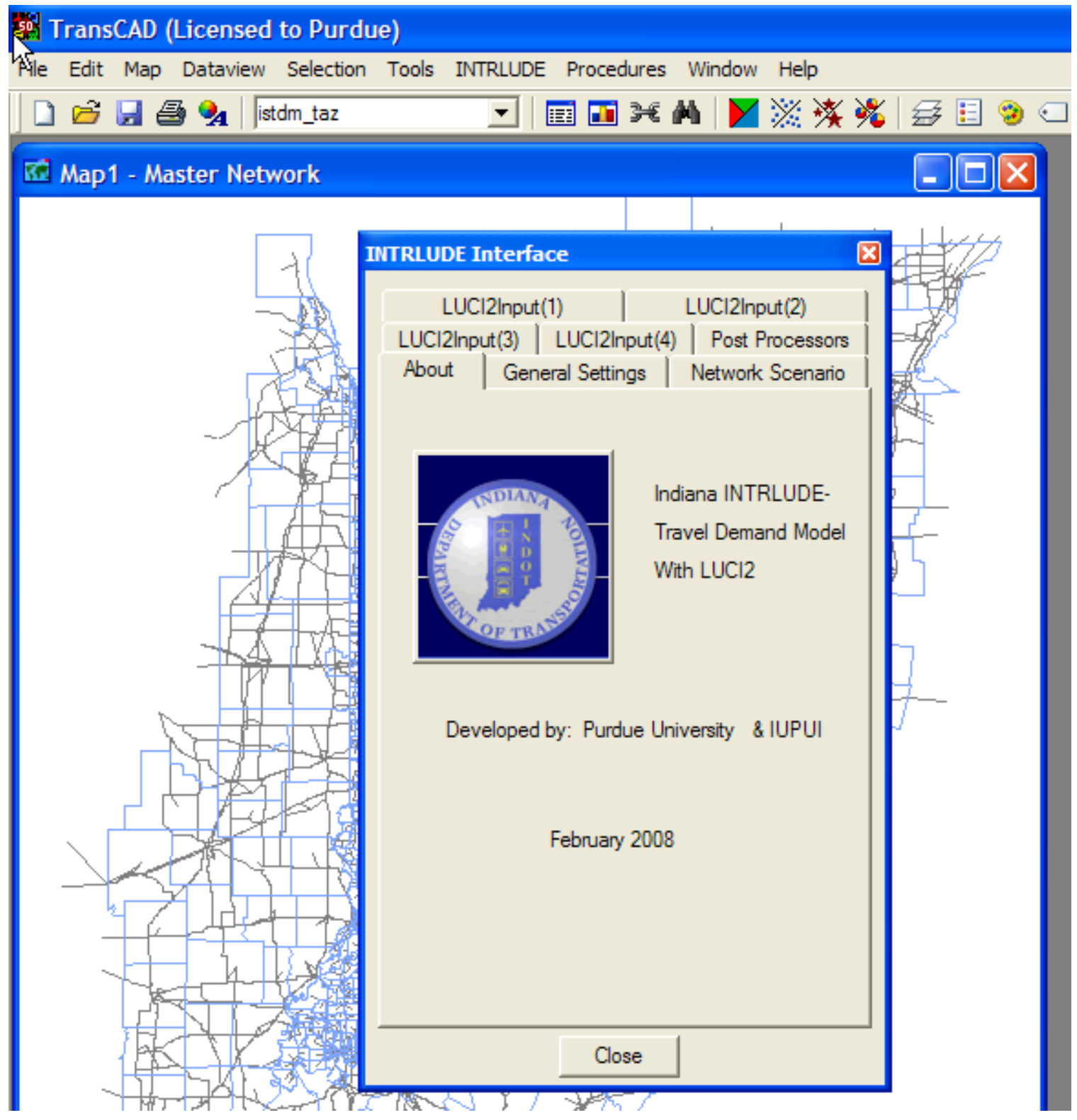

Step 25. In the INTRLUDE interface, first go to the General Settings tab and enter the inputs that are specified by the ISTDM v4 model: 


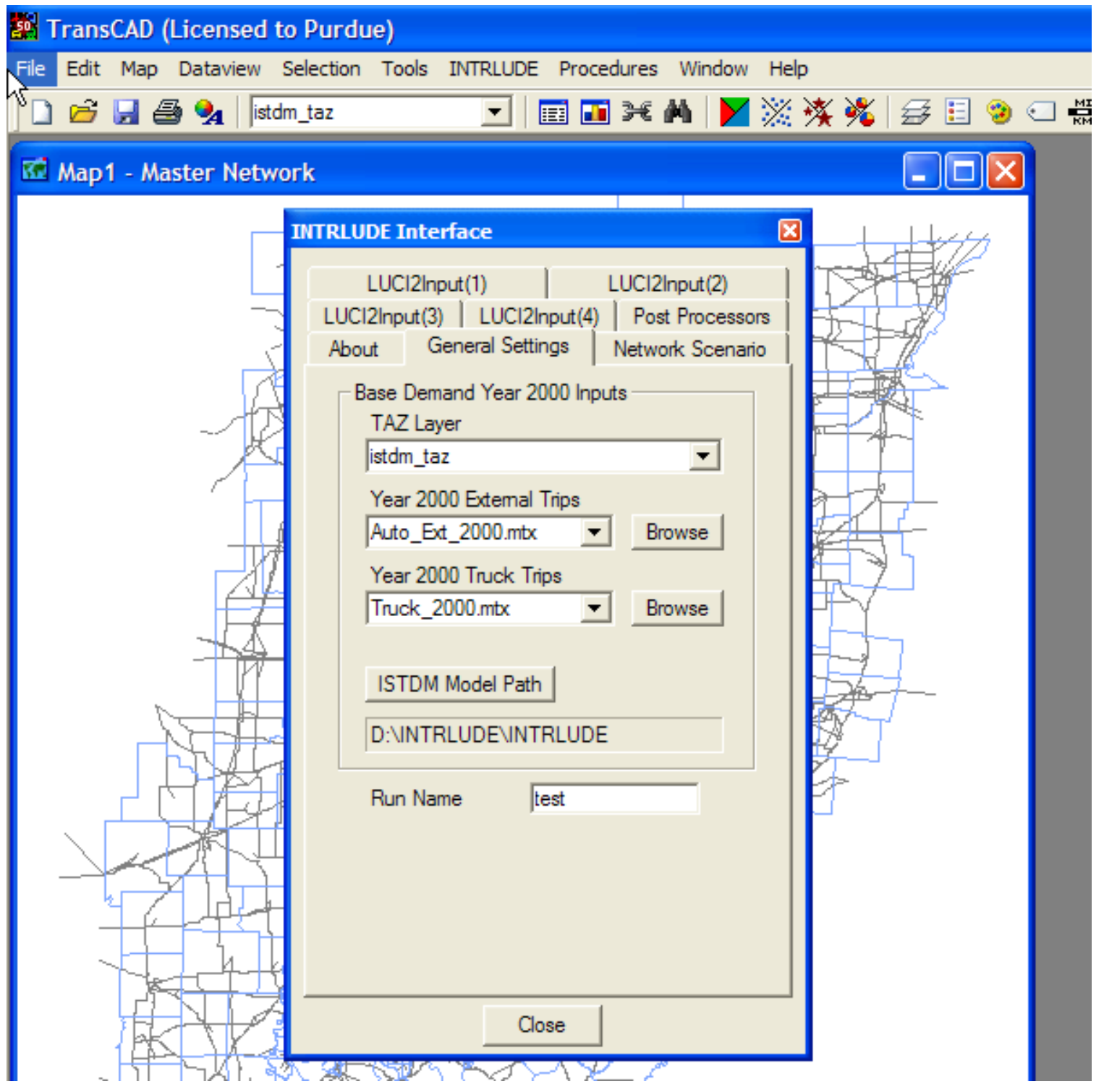

After making the three entries, click on the ISTDM Model Path button, choose the installed model directory for ISTDM model. In this example, the installed directory is D:IINTRLUDE \INTRLUDE. After finish the ISTDM Model Path, enter the Run Name. 
Step 26. Select the "Network Scenario" tab and enter the inputs that are specified by the ISTDM v4 model:

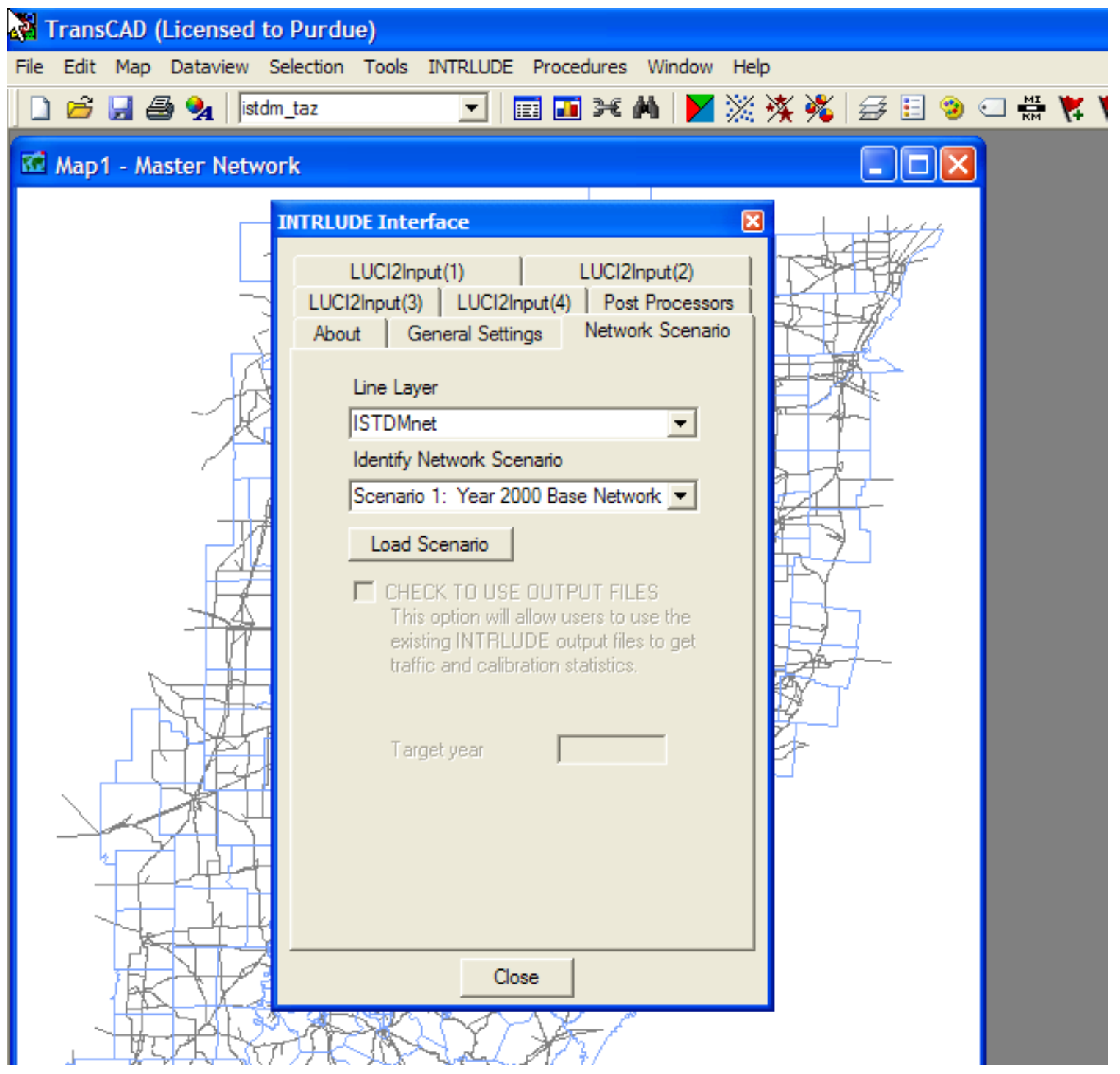

Users can identify one of the seven network scenario. After it is specified, please click Load Scenario to load the scenario in the model. The script will automatically generate the geographic file "Net_runname_2000" from the master network in the output folder and use it in the travel demand model run. 
Step 27. Go to the LUCI2Input (1), (2), (3), and (4) tabs, and enter the LUCI2 inputs. If no changes are needed from the default options, we can leave the spaces blank. At the LUCI2Input (4) tab, click "Load LUCI2 Scenario", which will activate the "Run INTRLUDE Model” button. Enter the target year and click "Run INTRLUDE Model”. The INTRLUDE model will start to run, stopping at the target year.

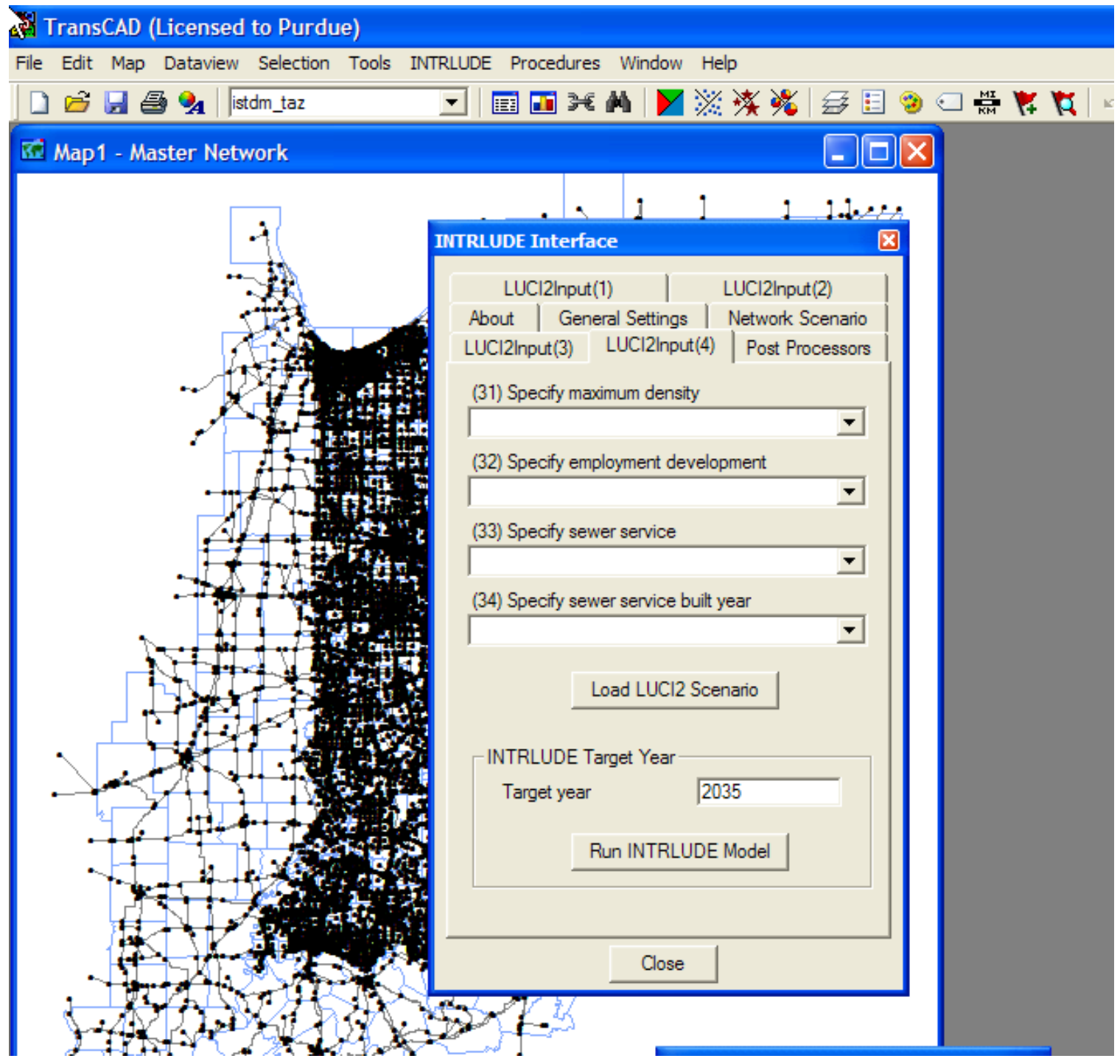

Step 18. After the model run has finished, go to Post Processors to get traffic statistics and calibration statistics. 


\section{OUTPUT FILES FOR THE ISTDM-LUCI2 MODEL}

Output files from the travel demand part of the ISTDM-LUCI2 model:

runname: the run name given by the user year: the target year given by the user the path: the ISTDM-LUCI2 model directory

\begin{tabular}{|c|c|c|}
\hline Output & Contents & File Path \& Name \\
\hline Roadway file & & $\begin{array}{l}\text { the path+ } \\
\text { "\output } \backslash \text { Net_runname_year.dbd" }\end{array}$ \\
\hline $\begin{array}{l}\text { Trip } \\
\text { Productions }\end{array}$ & $\begin{array}{l}\mathrm{HBW}, \mathrm{HBO}, \mathrm{NHB} \text { trip } \\
\text { productions }\end{array}$ & $\begin{array}{l}\text { the path+ } \\
\text { "Itg\TAZ_PRODUCTIONS_year.dbf" }\end{array}$ \\
\hline $\begin{array}{l}\text { Trip } \\
\text { Productions }\end{array}$ & Long trip productions & the path+”|tg\TAZ_LPRODS_year.dbf” \\
\hline $\begin{array}{l}\text { Trip } \\
\text { Productions }\end{array}$ & $\begin{array}{l}\text { HBW, HBO, NHB, and } \\
\text { Long trip productions }\end{array}$ & $\begin{array}{l}\text { the path+ } \\
\text { "'tg\FINAL_TAZ_PRODS_year.dbf" }\end{array}$ \\
\hline $\begin{array}{l}\text { Trip } \\
\text { Attractions }\end{array}$ & $\begin{array}{l}\text { HBW, HBO, NHB, and } \\
\text { Long trip attractions }\end{array}$ & $\begin{array}{l}\text { the path+ } \\
\text { "Itg\TAZ_ATTRACTIONS_year.dbf" }\end{array}$ \\
\hline $\begin{array}{l}\text { Trip } \\
\text { Productions } \\
\text { \& Trip } \\
\text { Attractions }\end{array}$ & $\begin{array}{l}\text { HBW, } \mathrm{HBO}, \mathrm{NHB} \text {, and } \\
\text { Long trip productions \& } \\
\text { attractions }\end{array}$ & the path+"\tg\TAZ_PS_AS_year.dbf” \\
\hline $\begin{array}{l}\text { Trip } \\
\text { Productions } \\
\text { \& Trip } \\
\text { Attractions }\end{array}$ & $\begin{array}{l}\text { HBW, HBO, NHB, and } \\
\text { Long trip balance } \\
\text { productions \& attractions }\end{array}$ & the path+”|tg\PATAB_year.dbf” \\
\hline $\begin{array}{l}\text { Trip } \\
\text { Productions } \\
\text { \& Trip } \\
\text { Attractions }\end{array}$ & $\begin{array}{l}\text { HBW, HBO, NHB, and } \\
\text { Long trip post balance } \\
\text { productions \& attractions } \\
\text { (make NHB productions } \\
\text { equal to NHB attractions) }\end{array}$ & the path+”|tg|Final_PA_Bal_year.bin” \\
\hline Network file & Free flow network file & the path+”'hwy\Hwy_Auto_FF.net” \\
\hline $\begin{array}{l}\text { Trip } \\
\text { distribution }\end{array}$ & Free flow skim tree & the path+"`td\FF_Skim.mtx" \\
\hline $\begin{array}{l}\text { Trip } \\
\text { distribution }\end{array}$ & $\begin{array}{l}\text { Trip distribution after the } \\
\text { gravity model }\end{array}$ & the path+"|td\Cgrav_ff_year.mtx” \\
\hline $\begin{array}{l}\text { Trip } \\
\text { distribution }\end{array}$ & $\begin{array}{l}\text { Transpose the Auto daily } \\
\text { trips into o-d format and } \\
\text { combines external station \& } \\
\text { trucks }\end{array}$ & the path+"|mc|Final_od_dly_year.mtx" \\
\hline $\begin{array}{l}\text { Trip } \\
\text { assignment }\end{array}$ & $\begin{array}{l}\text { Assign the daily vehicle trips } \\
\text { to the network }\end{array}$ & $\begin{array}{l}\text { the path+ } \\
\text { "'assign\runname_FINAL_DLY_FLOW_ } \\
\text { year.bin" }\end{array}$ \\
\hline
\end{tabular}


INTRLUDE Model User's Guide

\begin{tabular}{|c|c|c|}
\hline $\begin{array}{l}\text { Trip } \\
\text { assignment }\end{array}$ & Congested skim tree & $\begin{array}{l}\text { the path+ } \\
\text { "\td\AUTO_congestSPMAT_year.mtx" }\end{array}$ \\
\hline Network file & Congested flow network file & the path+"'hwy\Hwy_Auto_congestF.net" \\
\hline TAZ file & $\begin{array}{l}\text { TAZ file with all outputs } \\
\text { from LUCI2 }\end{array}$ & the path+”'output|runname_taz.dbd” \\
\hline $\begin{array}{l}\text { Post } \\
\text { calculation }\end{array}$ & $\begin{array}{l}\text { Traffic statistics \& } \\
\text { performance measures }\end{array}$ & $\begin{array}{l}\text { the path+ } \\
\text { "loutput } \backslash P O S T \text { runname_year.dbf" }\end{array}$ \\
\hline $\begin{array}{l}\text { Post } \\
\text { calculation }\end{array}$ & $\begin{array}{l}\text { Traffic statistics \& } \\
\text { performance measures }\end{array}$ & $\begin{array}{l}\text { the path+ } \\
\text { "'ppost\POST_runname_year_LINKS.dbf" }\end{array}$ \\
\hline
\end{tabular}




\title{
User's Guide to INT RLUDE
}

\section{The INtegrated TRansportation Land Use Demand Estimation Model for Indiana}

\author{
April 2008
}

For use with TransCAD 5.0

\author{
Li J in \\ Research Assistant \\ J on D. Fricker \\ Professor \\ Purdue University \\ School of Civil Engineering \\ April 2008 \\ J oint Transportation Research Program
}




\section{TABLE OF CONTENTS}

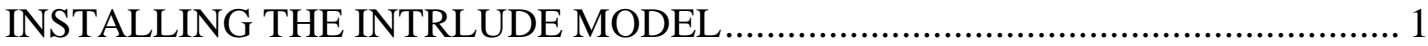

CREATING STATEWIDE ROADWAY NETWORK CHANGES.......................... 6

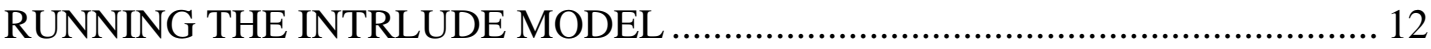

OUTPUT FILES FOR THE INTRLUDE MODEL ................................................ 18

\section{FOREWORD}

The Indiana Statewide Travel Demand Model (ISTDM) was developed by Bernardin, Lochmueller \& Associates and Cambridge Systematics under the supervision of the Indiana Department of Transportation. The Land Use in Central Indiana (LUCI) model was developed by Prof. John Ottensmann of Indiana Purdue University Indianapolis (IUPUI). A later version (luci2) forecasts urban development in a 44county region of central Indiana for up to 40 years into the future.

(http://luci.urbancenter.iupui.edu) Under the auspices of research project SPR-3051 Development of an Integrated Land Use Transportation Model for Indiana,

- The luci2 model was expanded to match the geographic coverage and zone structure of the ISTDM. The expanded luci2 model was also revised to be compatible with other characteristics of the ISTDM.

- The revised LUCI model and the ISTDM were integrated using script written in TransCAD's GISDK.

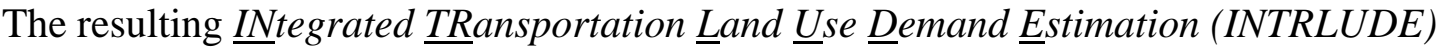
Model for Indiana is truly integrated. Data are transferred between the land use and travel demand models without human intervention. Because of the complexities of the two models and the large (4500-zone) area being analyzed, one run of the integrated model for a 30-year horizon may take more than five hours. The integrated model has been tested, however, many times with a variety of input values. This user's guide is intended to enable the first time (or occasional) user to be successful running the integrated model. 


\section{INSTALLING THE INTRLUDE MODEL ON TRANSCAD 5.0}

Step1. Copy and unzip the two files that are named luci2INcl.zip and ISTDM-LUCI2.zip on the provided DVD disc.

Step2. Click setup.exe file in the luci2INcl folder, and follow the instructions to install LUCI2INcl model on the computer. (You must use the default model directory provided by the setup.exe file to install the LUCI2INcl model.)

Step 3. Create a directory on the hard drive of the machine to be the INTRLUDE model directory. Copy all the unzipped files from ISTDM-LUCI2.zip to this directory.

Step 4. Copy all the unzipped code files from INTRLUDEcodetranscad5.zip to the INTRLUDE model directory.

Step 5. Right click the TransCAD icon for the Standard Geographic Database file and select Properties. In the Target input, make sure that only "C:IProgram Files\TransCAD $\backslash$ tcw.exe" appears.

Step 6. Click OK.

Step 7. Open TransCAD by clicking the TransCAD icon. 
Step 8. Click Tools, then click Setup Add-Ins..., it will show:

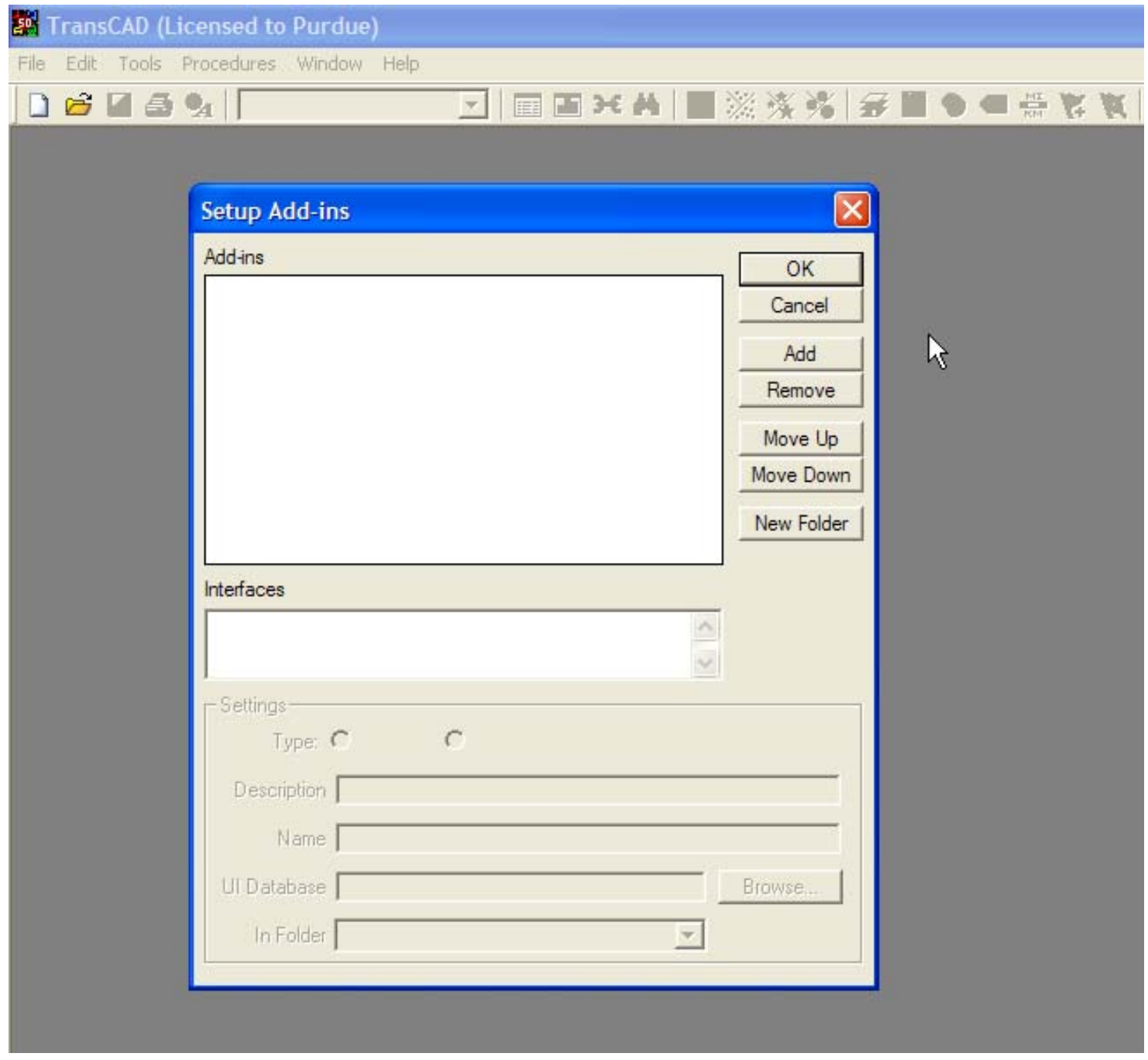


Step 9. Click Add. The screen will appear as:

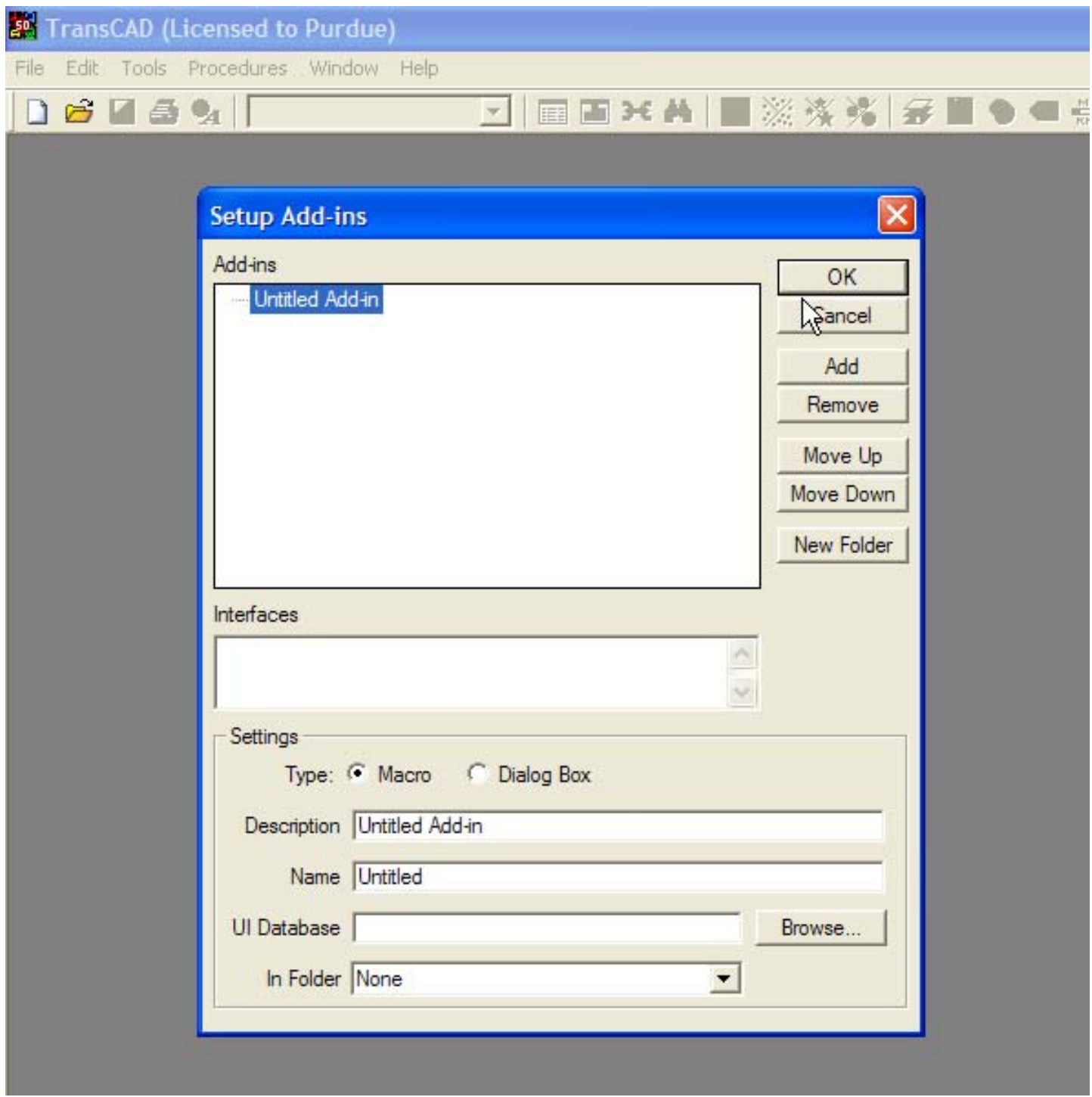


Step 10. Please type INTRLUDE into the Description and INTRLUDE into the Name, as shown below. Click Browse, find and choose the file name "intrlude.dbd" in the installed INTRLUDE model files' directory. The display may look like this:

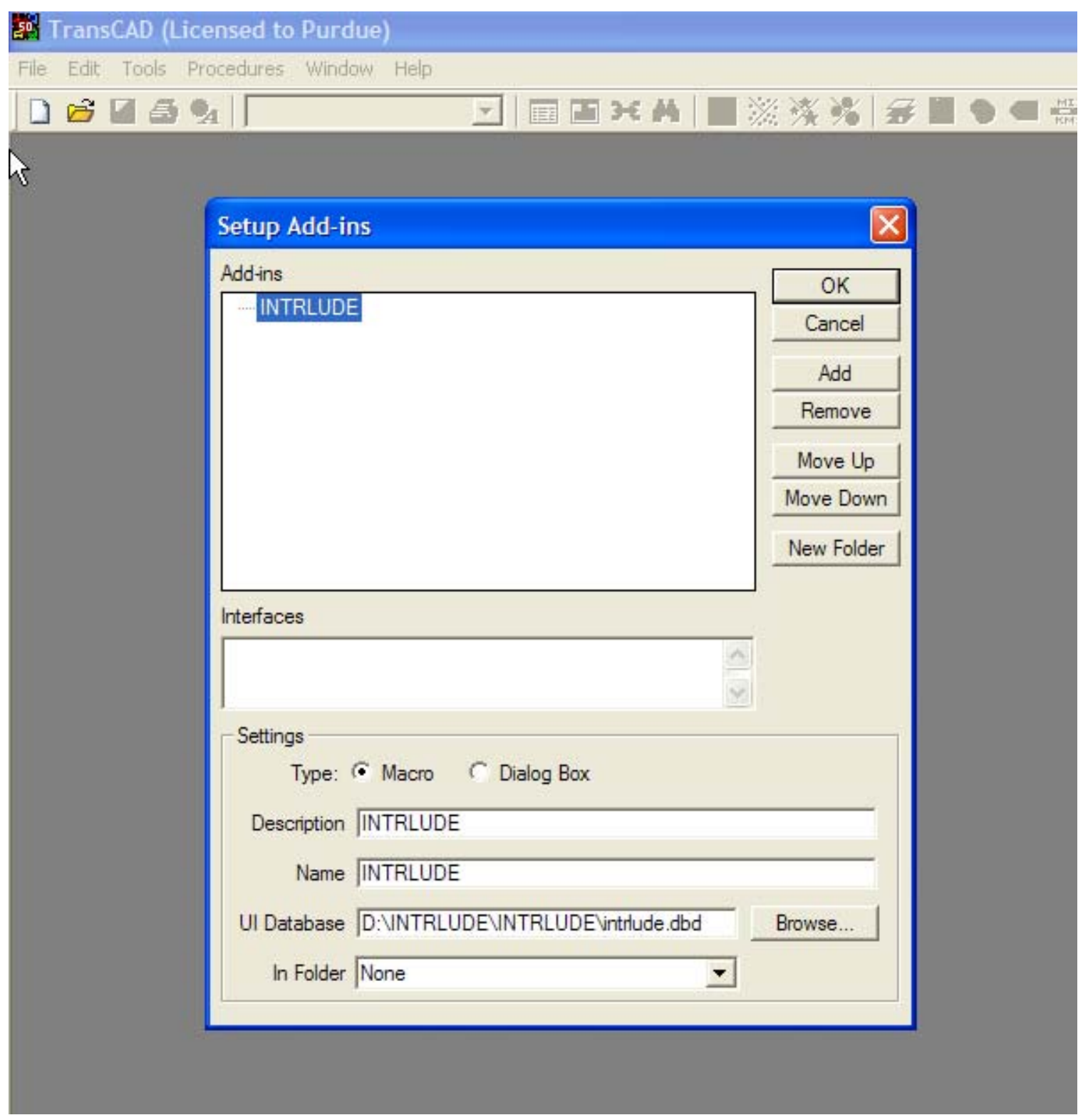


Step 11. Click OK.

Step 12. Click Tools, then click Add-Ins, then click INTRLUDE The INTRLUDE menu should now appear on the top of the TransCAD window:

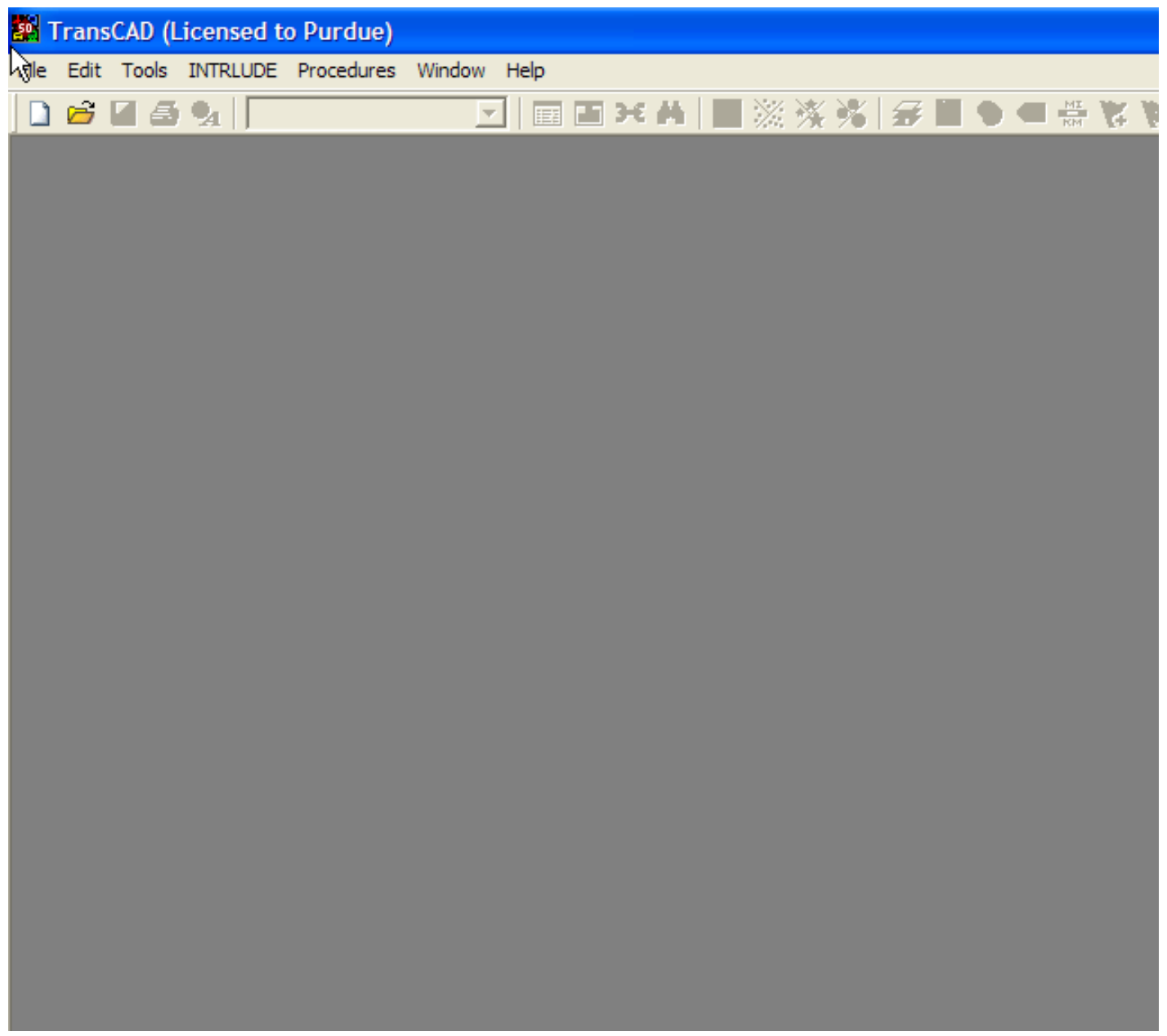

Step 13. The INTRLUDE menu will disappear each time when users close TransCAD program. The next time a user re-enters TransCAD program, click Tools, then click AddIns, then click INTRLUDE to let INTRLUDE menu re-appear on the top of the TransCAD window. 


\section{CREATING STATEWIDE ROADWAY NETWORK CHANGES}

This version of the INTRLUDE model can allow users to specify changes to the state network that may be proposed at certain years before the horizon year.

Step 14. Click File, then click Open. Go to the installed INTRLUDE model directory and, in the hwy folder, find the "ISTDM_MASTERNET.dbd” file and open it.

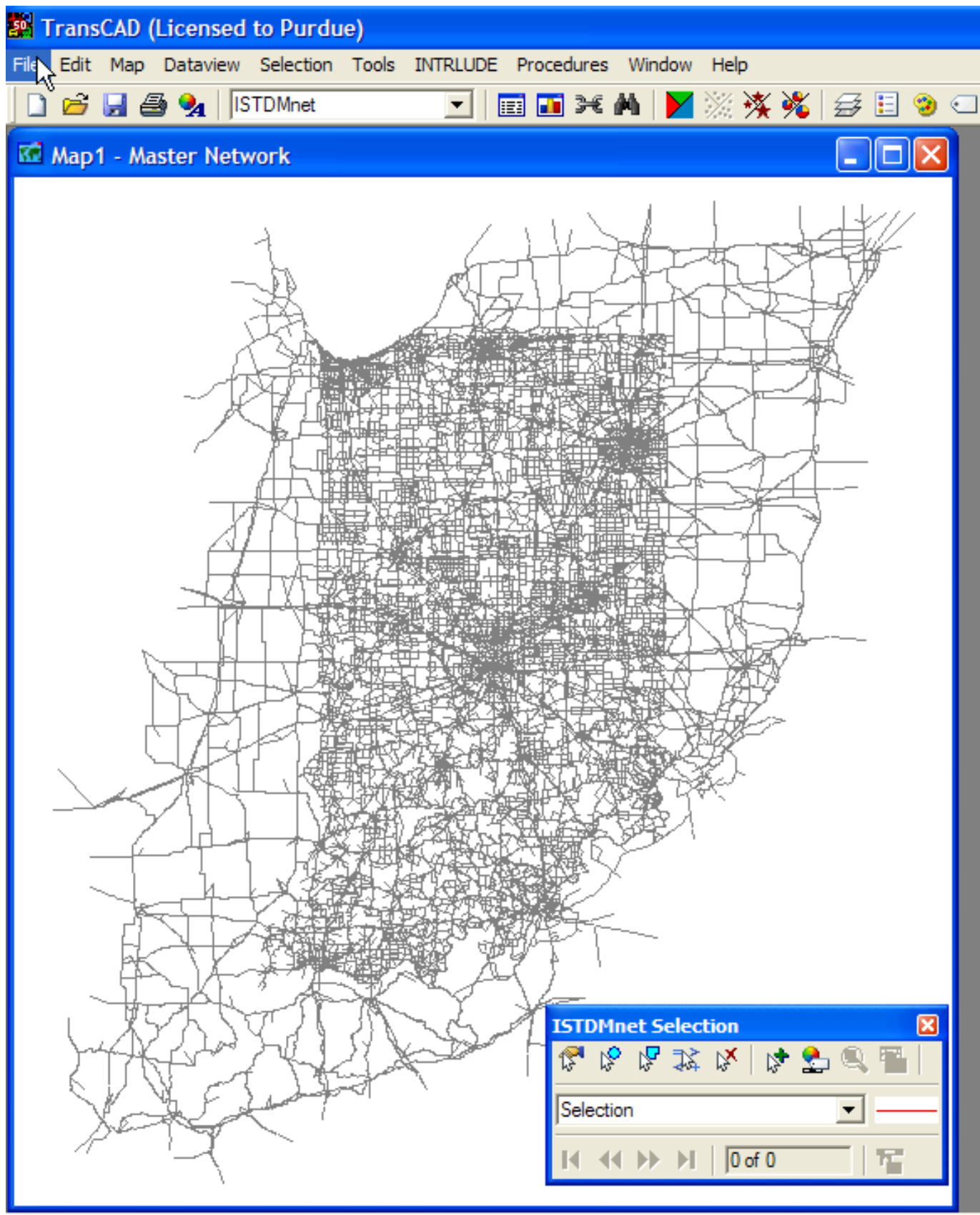


Step 15. There are 7 scenarios coded in the Master network file. Please click New Dataview, users will find some fields names "Net_1”, “Net_2”,..."Net_7”. These will serve as flag fields for different scenarios.

The 7 scenarios are:

Scenario 1: Year 2000 Base Network

Scenario 2: Existing plus Committed

Scenario 3: Long Range Plan

Scenario 4: I-69 + committed

Scenario 5: HERS E+C w/I-69

Scenario 6: Old LRP E+C

Scenario 7: LRP w/o I-69

Users can choose different scenarios from the INTRLUDE interface showed in the following RUNNING THE INTRLUDE MODEL section.

The“Net_1”, “Net_2”,..."Net_7”will be read as the flag field of the chosen scenario. If the values of that field for some roadway links are null (show as --) or larger than the corresponding scenario number, the roadway links will not be read and not be assigned in the travel demand model for that chosen scenario. 


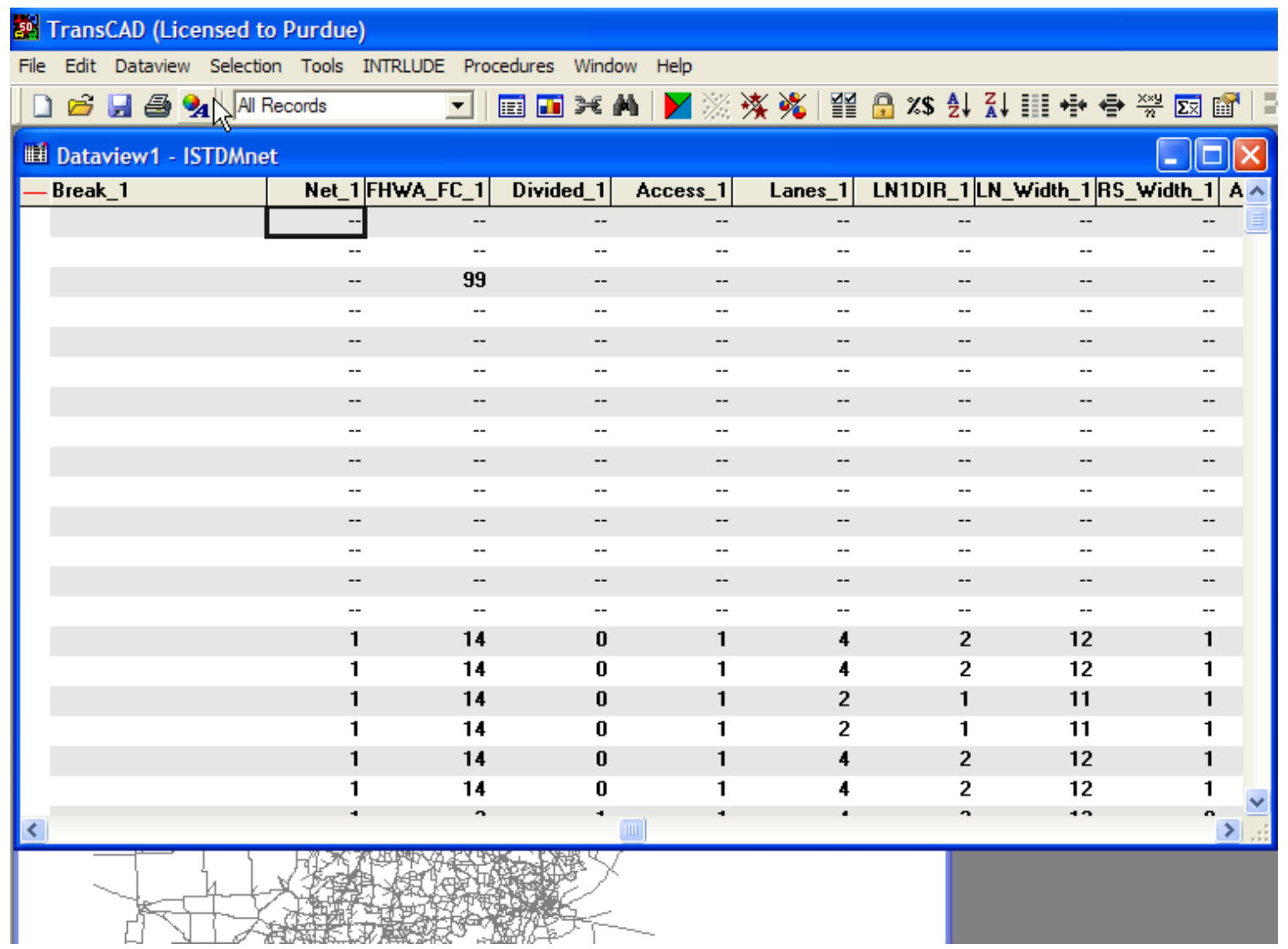

Step 16. To create a future year network changes, for example, users want to create a roadway network changed from year 2020. First please click INTRLUDE, then click Add Network Scenario. 


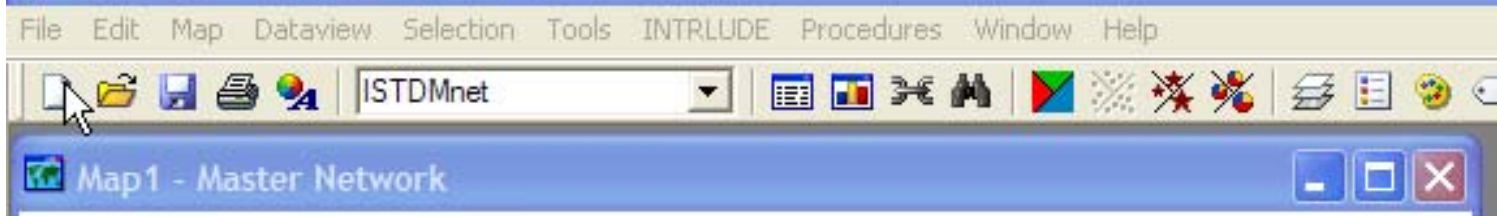

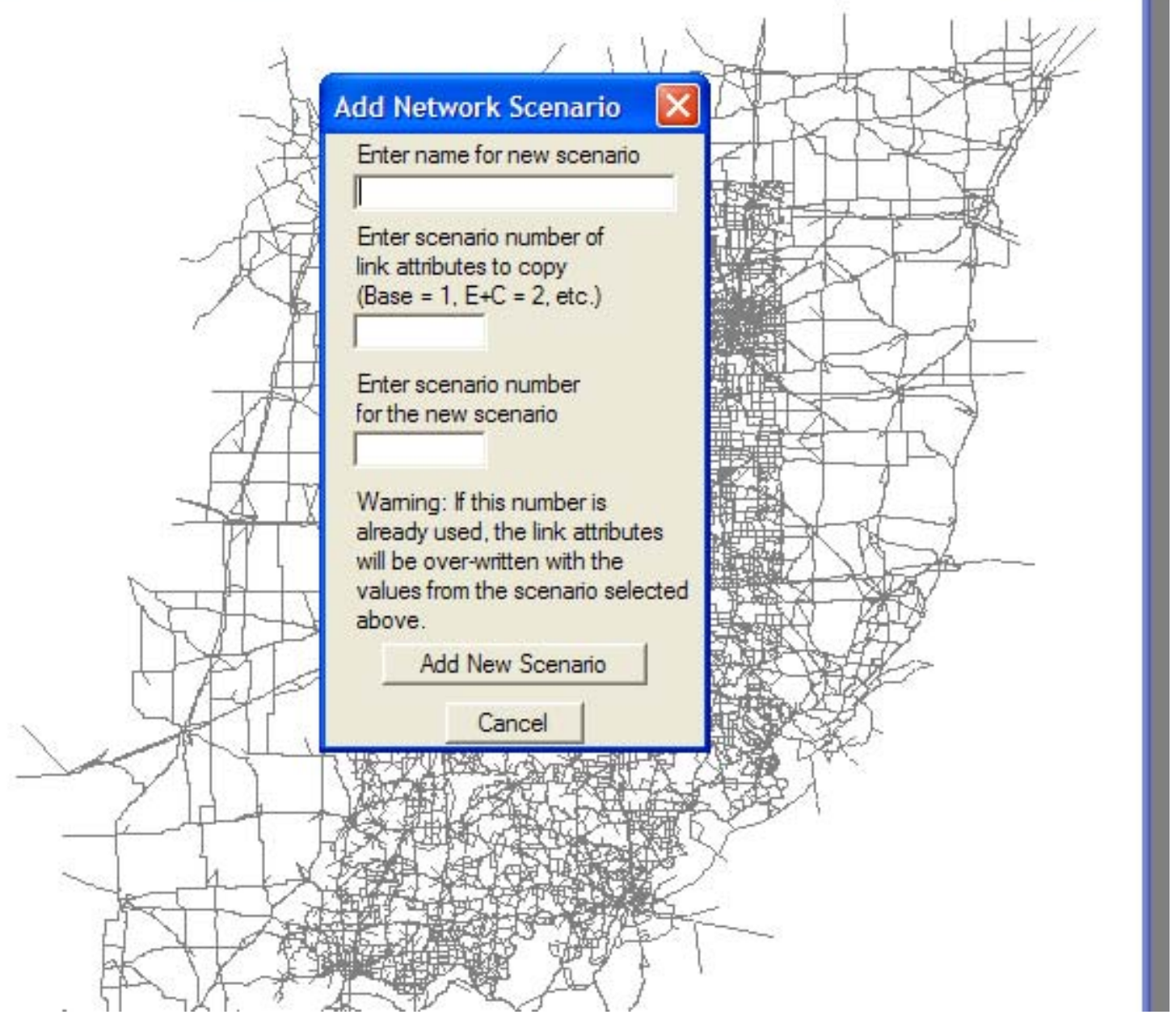

Step 17. At the starting point, users can copy any of 7 scenarios to be the starting points of year 2020 roadway network. In this example, scenario 1 is copied to be the year 2020 network and named as test. 


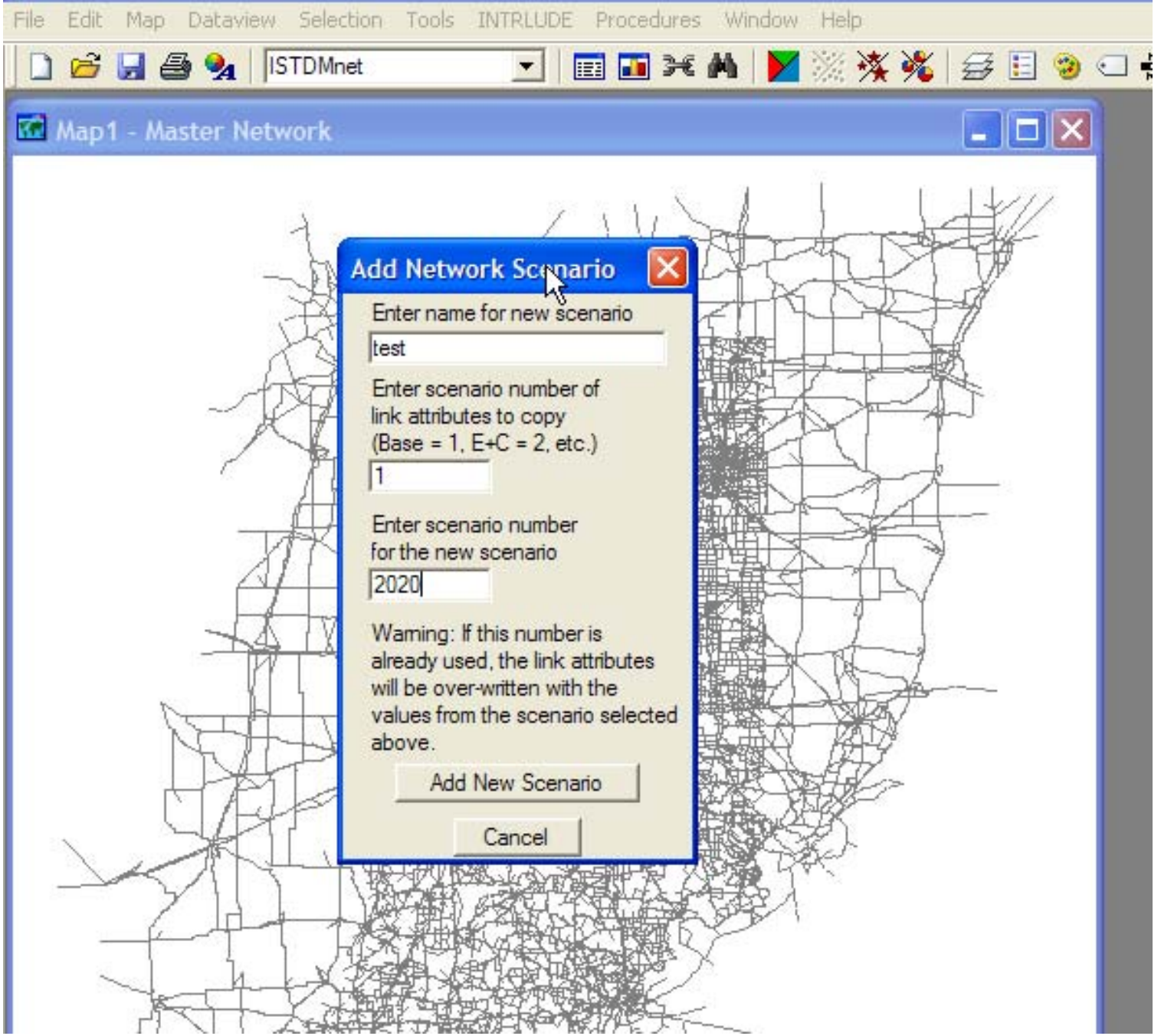

Step 18. Please click Add New Scenario. After Add Scenario process is finished, please go to Dataview, new fields including Net_2020 will show up in the window. 


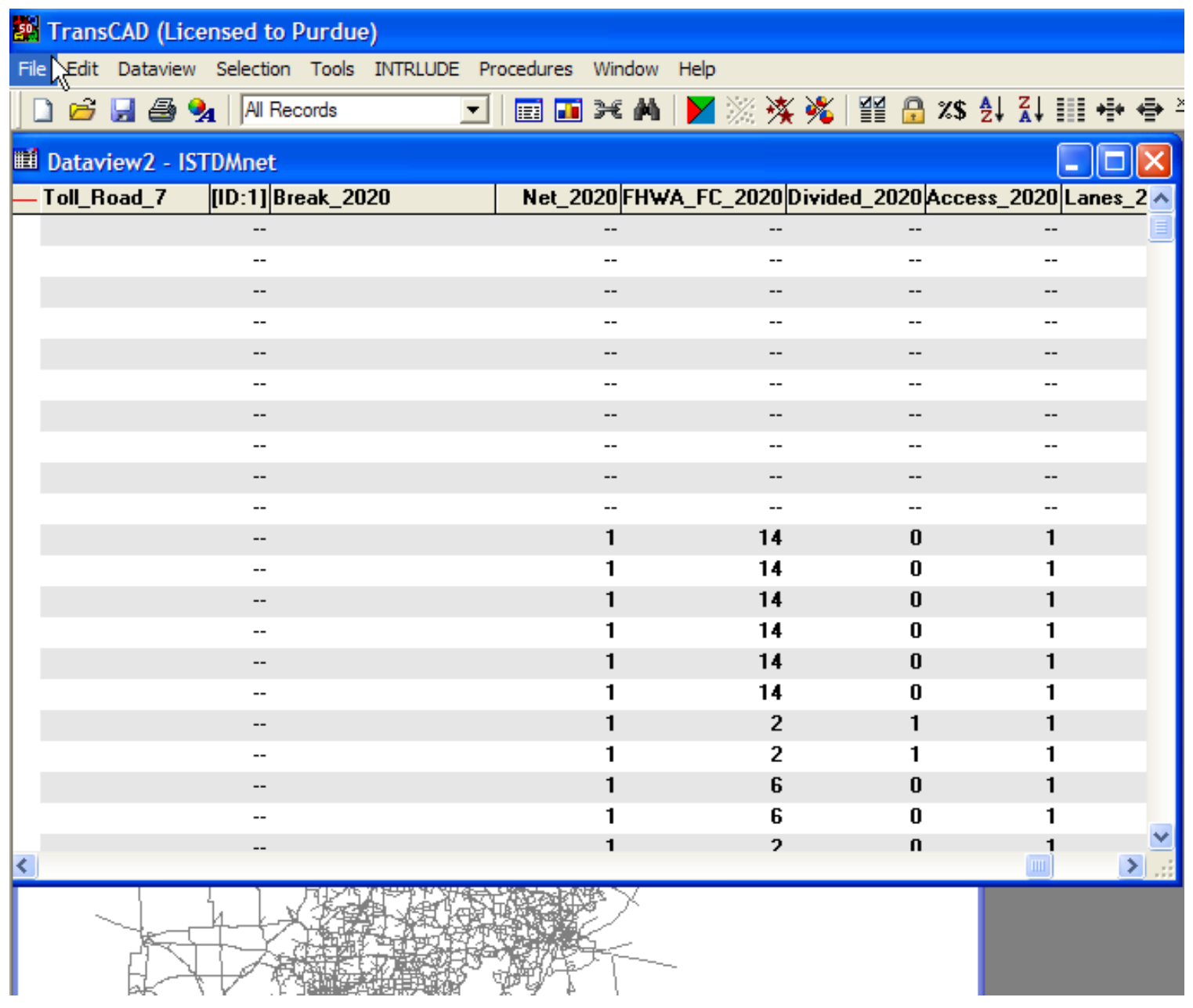

Step 19. Users can then manually add more links or changed links’ input values using TransCAD Tools-Map Editing-Toolbox. If the value for some links in the field of Net_2020 is null (showed as -- in the Dataview) or larger than 2020, the links will not be read from the year 2020. All the links with the value less than or equal to 2020 will be automatically read and used in the travel demand model from year 2020.

Step 20. Users can click INTRLUDE, then click Delete Network Scenario, and input the scenario number (for example, it is 2020 for this example) to delete the year 2020 network changes.

Step 21. During running the INTRLUDE, the script will automatically scan the flag field from the Dataview of the file "ISTDM_MASTERNET.dbd" in each 5-year period (Please only use 5 years as the basic unit.). In this example, from year 2020, the roadway network will be different with the year 2000 roadway network. Thus, users can add the roadway network changes for each 5-year period (2005, 2010, 2015, 2020, 2025,....until the target year). 


\section{RUNNING THE INTRLUDE MODEL ON TRANSCAD 5.0}

Step 22. If the "ISTDM_MASTERNET.dbd" file is not opened, please click File, then click Open. Go to the unzipped ISTDM-LUCI2 model directory and, in the hwy folder, find the "ISTDM_MASTERNET.dbd" file and open it.

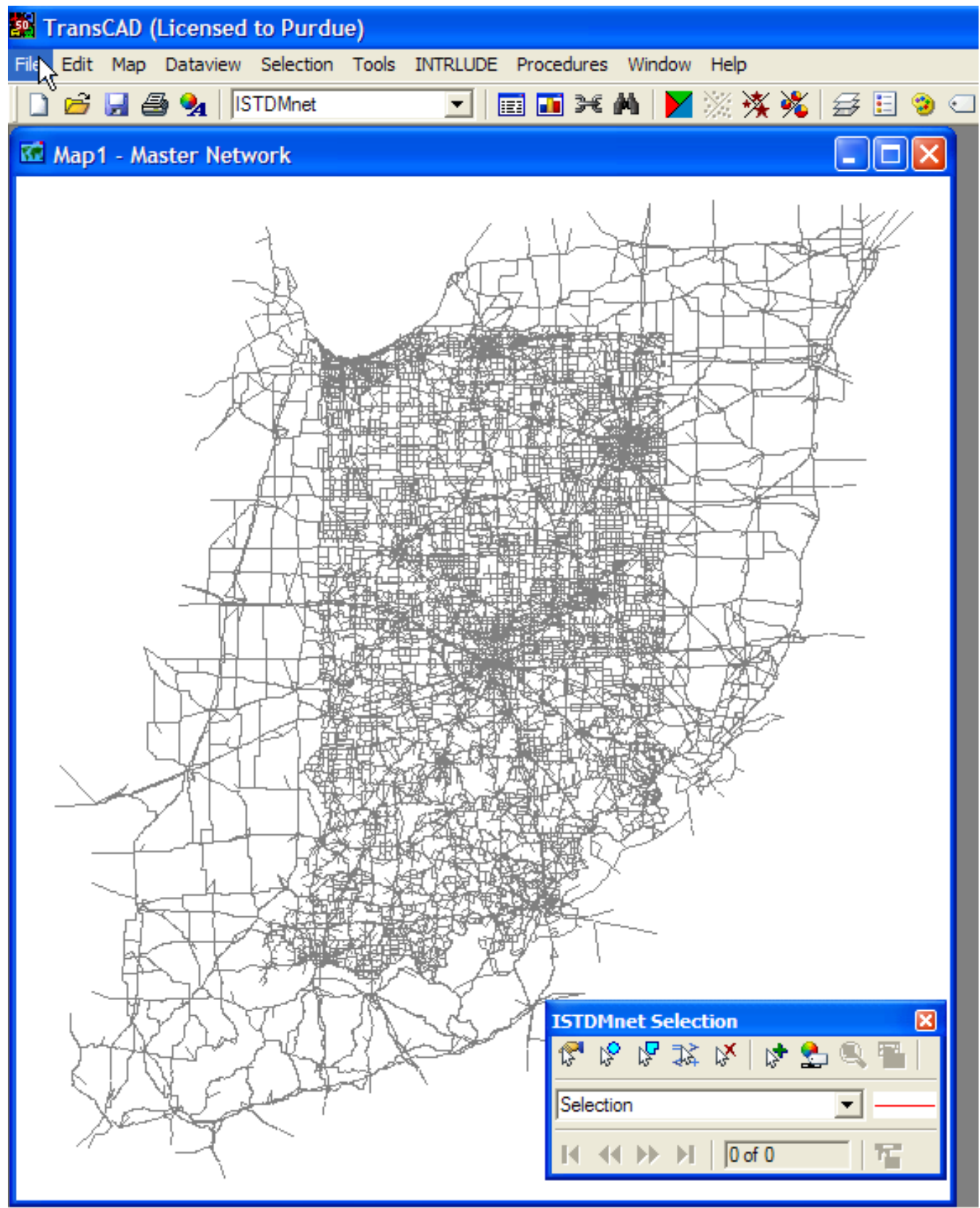


Step 23. Click the layers icon, then click Add Layer. Choose "ISTDM_TAZ2000_120704.dbd" in the taz folder and open it. Now we have opened both the master network layer and the taz layer. "Close" the Layers window.

50.7 TransCAD (Licensed to Purdue)

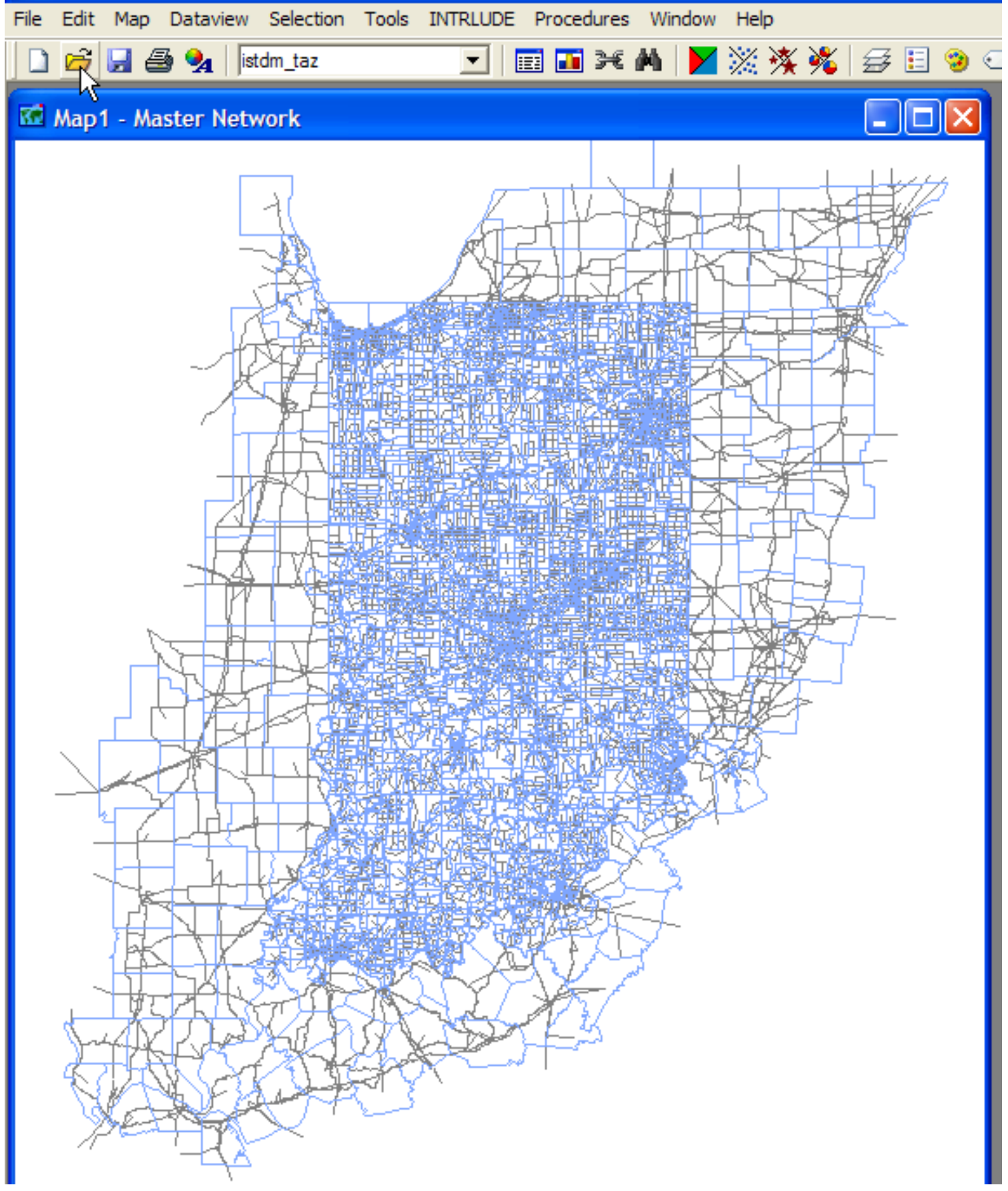


Step 24. Click the INTRLUDE menu and choose INTRLUDE Interface. The INTRLUDE interface will pop up.

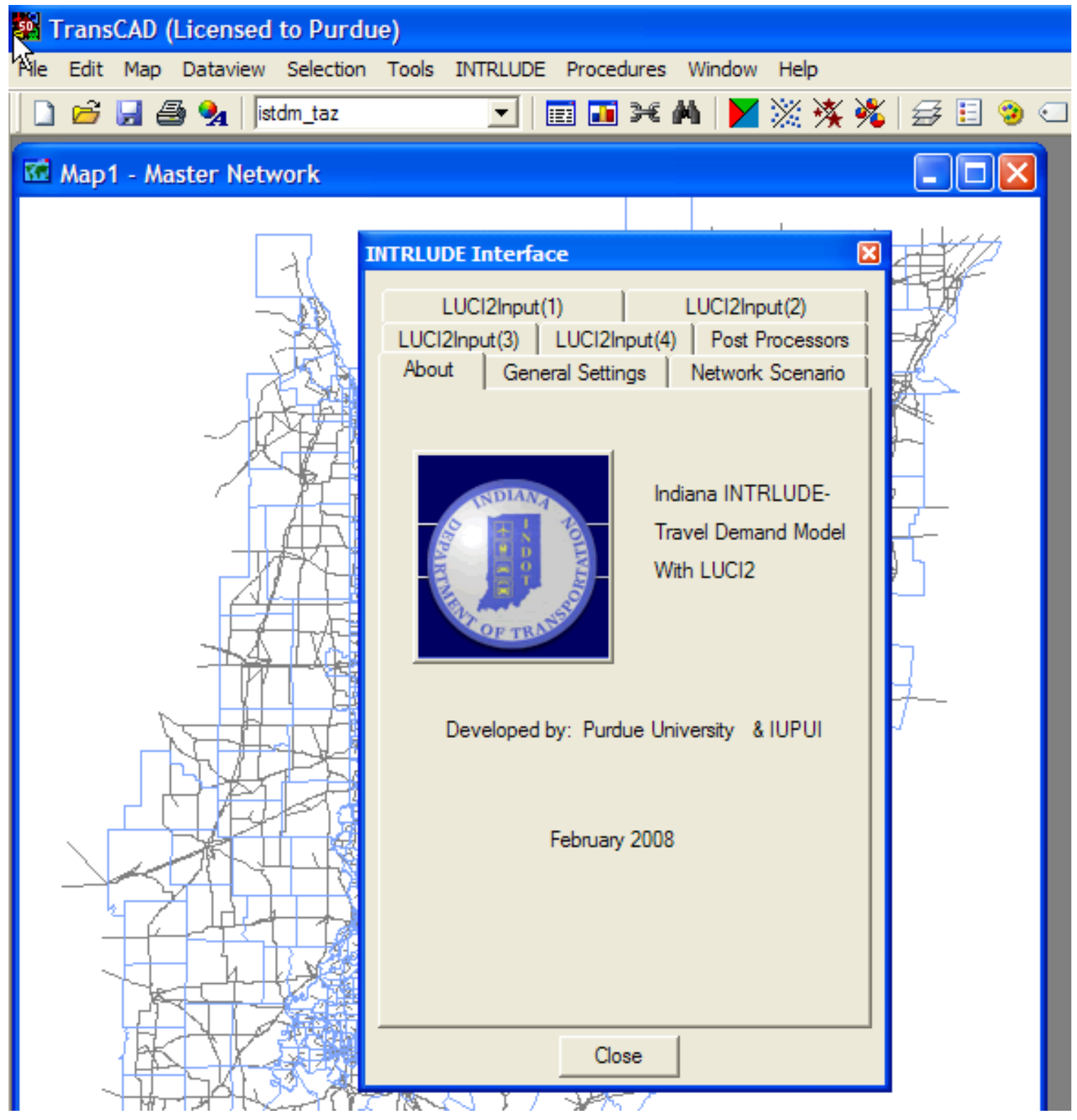

Step 25. In the INTRLUDE interface, first go to the General Settings tab and enter the inputs that are specified by the ISTDM v4 model: 


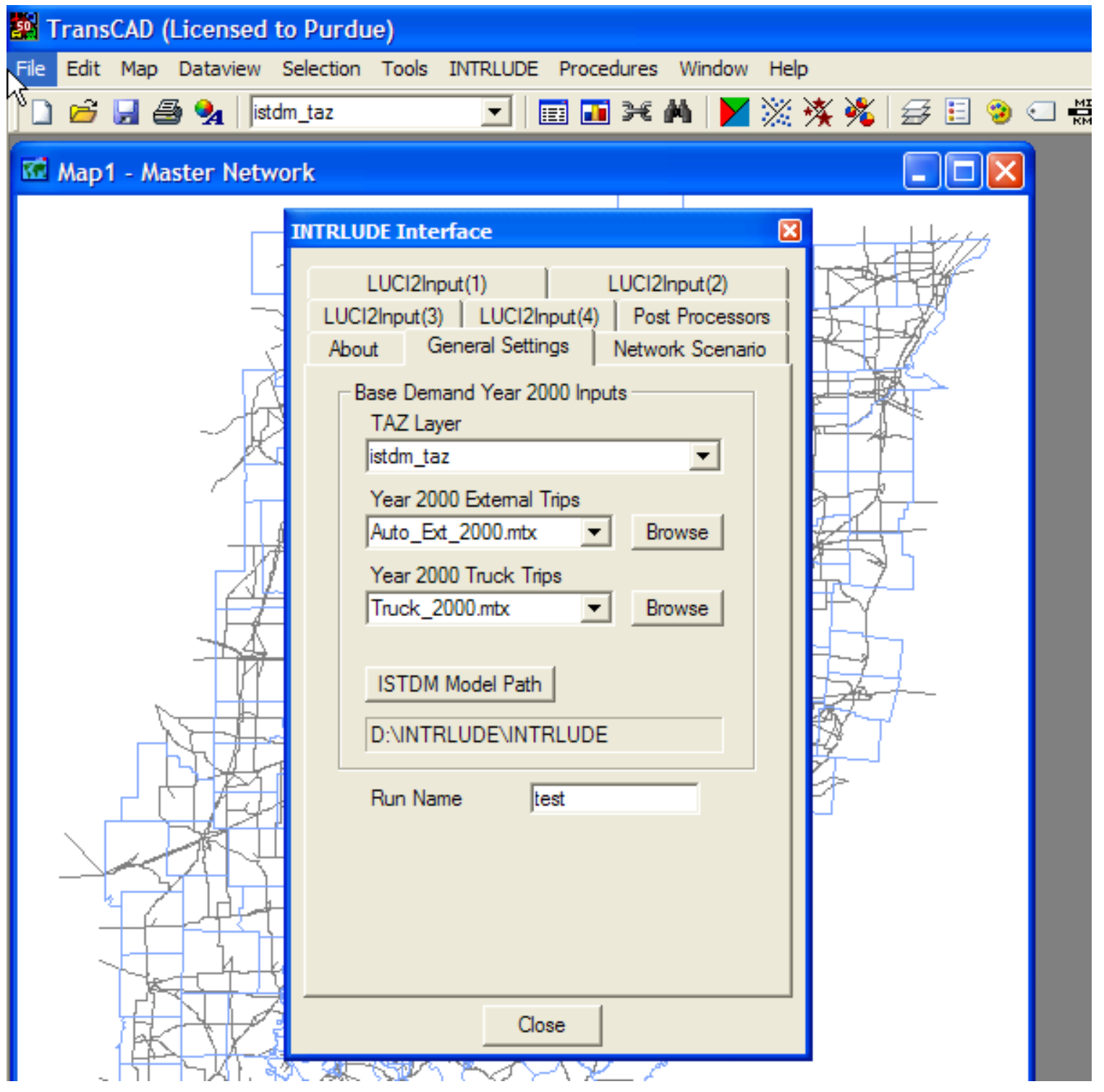

After making the three entries, click on the ISTDM Model Path button, choose the installed model directory for ISTDM model. In this example, the installed directory is D:IINTRLUDE \INTRLUDE. After finish the ISTDM Model Path, enter the Run Name. 
Step 26. Select the "Network Scenario" tab and enter the inputs that are specified by the ISTDM v4 model:

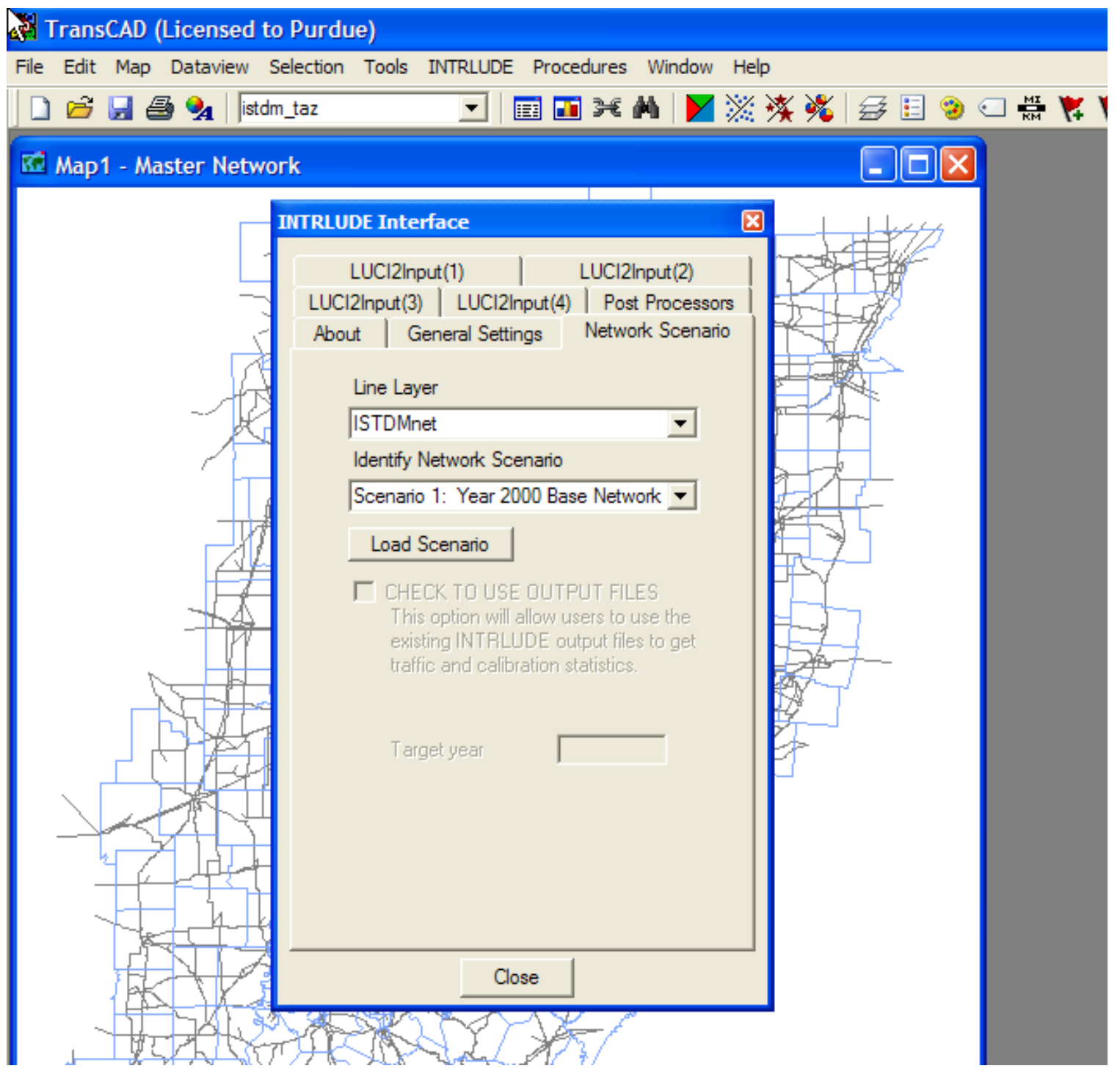

Users can identify one of the seven network scenario. After it is specified, please click Load Scenario to load the scenario in the model. The script will automatically generate the geographic file "Net_runname_2000" from the master network in the output folder and use it in the travel demand model run. 
Step 27. Go to the LUCI2Input (1), (2), (3), and (4) tabs, and enter the LUCI2 inputs. If no changes are needed from the default options, we can leave the spaces blank. At the LUCI2Input (4) tab, click "Load LUCI2 Scenario", which will activate the "Run INTRLUDE Model” button. Enter the target year and click "Run INTRLUDE Model”. The INTRLUDE model will start to run, stopping at the target year.

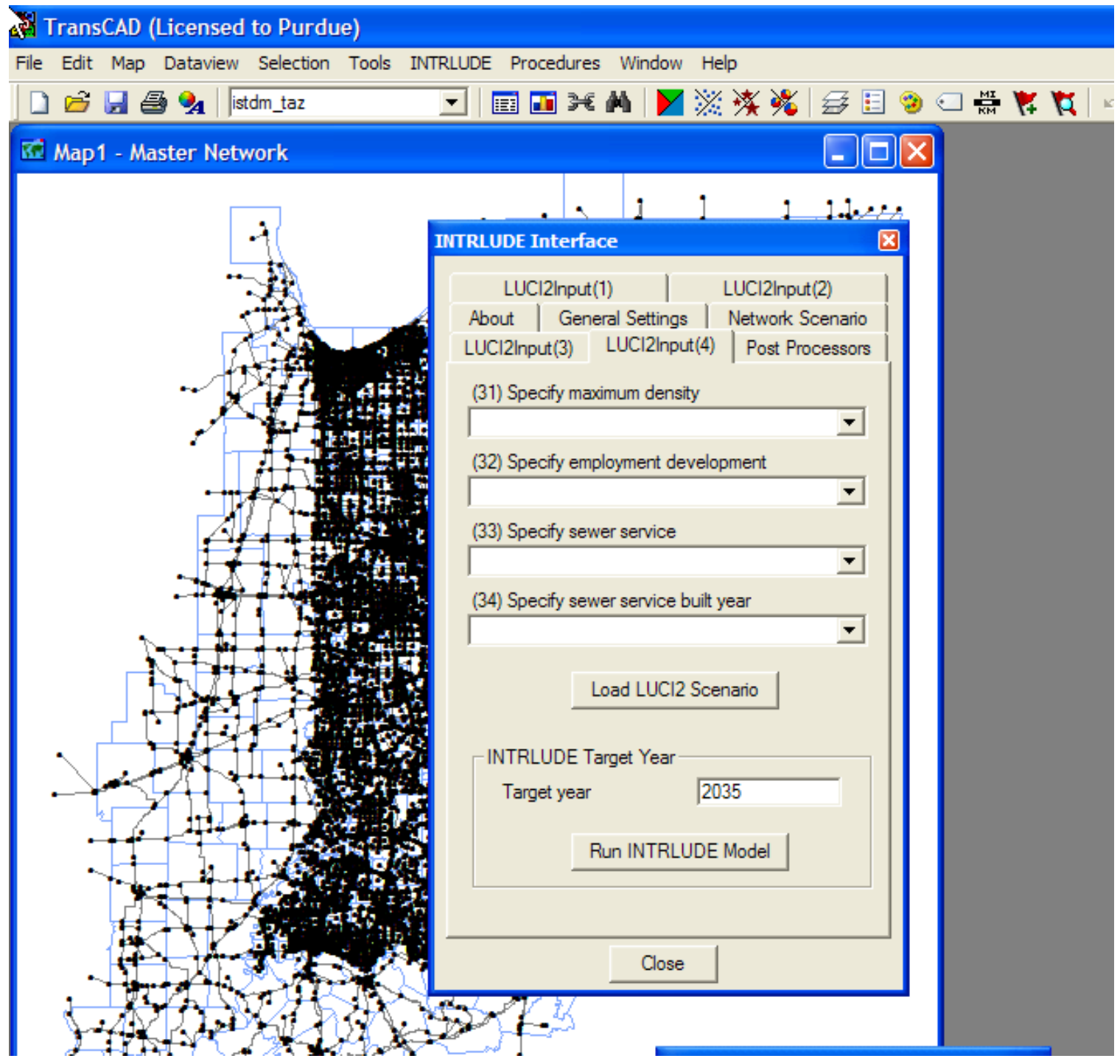

Step 18. After the model run has finished, go to Post Processors to get traffic statistics and calibration statistics. 


\section{OUTPUT FILES FOR THE ISTDM-LUCI2 MODEL}

Output files from the travel demand part of the ISTDM-LUCI2 model:

runname: the run name given by the user year: the target year given by the user the path: the ISTDM-LUCI2 model directory

\begin{tabular}{|c|c|c|}
\hline Output & Contents & File Path \& Name \\
\hline Roadway file & & $\begin{array}{l}\text { the path+ } \\
\text { "\output } \backslash \text { Net_runname_year.dbd" }\end{array}$ \\
\hline $\begin{array}{l}\text { Trip } \\
\text { Productions }\end{array}$ & $\begin{array}{l}\mathrm{HBW}, \mathrm{HBO}, \mathrm{NHB} \text { trip } \\
\text { productions }\end{array}$ & $\begin{array}{l}\text { the path+ } \\
\text { "Itg\TAZ_PRODUCTIONS_year.dbf" }\end{array}$ \\
\hline $\begin{array}{l}\text { Trip } \\
\text { Productions }\end{array}$ & Long trip productions & the path+"'tg\TAZ_LPRODS_year.dbf” \\
\hline $\begin{array}{l}\text { Trip } \\
\text { Productions }\end{array}$ & $\begin{array}{l}\text { HBW, HBO, NHB, and } \\
\text { Long trip productions }\end{array}$ & $\begin{array}{l}\text { the path+ } \\
\text { "Itg\FINAL_TAZ_PRODS_year.dbf" }\end{array}$ \\
\hline $\begin{array}{l}\text { Trip } \\
\text { Attractions }\end{array}$ & $\begin{array}{l}\text { HBW, HBO, NHB, and } \\
\text { Long trip attractions }\end{array}$ & $\begin{array}{l}\text { the path+ } \\
\text { "Itg\TAZ_ATTRACTIONS_year.dbf" }\end{array}$ \\
\hline $\begin{array}{l}\text { Trip } \\
\text { Productions } \\
\text { \& Trip } \\
\text { Attractions }\end{array}$ & $\begin{array}{l}\text { HBW, } \mathrm{HBO}, \mathrm{NHB} \text {, and } \\
\text { Long trip productions \& } \\
\text { attractions }\end{array}$ & the path+"\tg\TAZ_PS_AS_year.dbf” \\
\hline $\begin{array}{l}\text { Trip } \\
\text { Productions } \\
\text { \& Trip } \\
\text { Attractions }\end{array}$ & $\begin{array}{l}\text { HBW, HBO, NHB, and } \\
\text { Long trip balance } \\
\text { productions \& attractions }\end{array}$ & the path+”|tg\PATAB_year.dbf” \\
\hline $\begin{array}{l}\text { Trip } \\
\text { Productions } \\
\text { \& Trip } \\
\text { Attractions }\end{array}$ & $\begin{array}{l}\text { HBW, HBO, NHB, and } \\
\text { Long trip post balance } \\
\text { productions \& attractions } \\
\text { (make NHB productions } \\
\text { equal to NHB attractions) }\end{array}$ & the path+”|tg|Final_PA_Bal_year.bin” \\
\hline Network file & Free flow network file & the path+”'hwy\Hwy_Auto_FF.net” \\
\hline $\begin{array}{l}\text { Trip } \\
\text { distribution }\end{array}$ & Free flow skim tree & 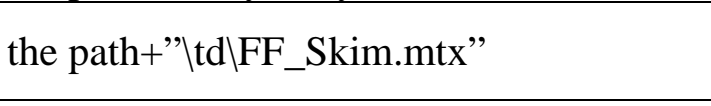 \\
\hline $\begin{array}{l}\text { Trip } \\
\text { distribution }\end{array}$ & $\begin{array}{l}\text { Trip distribution after the } \\
\text { gravity model }\end{array}$ & the path+"|td\Cgrav_ff_year.mtx” \\
\hline $\begin{array}{l}\text { Trip } \\
\text { distribution }\end{array}$ & $\begin{array}{l}\text { Transpose the Auto daily } \\
\text { trips into o-d format and } \\
\text { combines external station \& } \\
\text { trucks }\end{array}$ & the path+"|mc|Final_od_dly_year.mtx" \\
\hline $\begin{array}{l}\text { Trip } \\
\text { assignment }\end{array}$ & $\begin{array}{l}\text { Assign the daily vehicle trips } \\
\text { to the network }\end{array}$ & $\begin{array}{l}\text { the path+ } \\
\text { "'assign\runname_FINAL_DLY_FLOW_ } \\
\text { year.bin" }\end{array}$ \\
\hline
\end{tabular}


INTRLUDE Model User's Guide

\begin{tabular}{|c|c|c|}
\hline $\begin{array}{l}\text { Trip } \\
\text { assignment }\end{array}$ & Congested skim tree & $\begin{array}{l}\text { the path+ } \\
\text { "\td\AUTO_congestSPMAT_year.mtx" }\end{array}$ \\
\hline Network file & Congested flow network file & the path+"'hwy\Hwy_Auto_congestF.net" \\
\hline TAZ file & $\begin{array}{l}\text { TAZ file with all outputs } \\
\text { from LUCI2 }\end{array}$ & the path+”'output\runname_taz.dbd” \\
\hline $\begin{array}{l}\text { Post } \\
\text { calculation }\end{array}$ & $\begin{array}{l}\text { Traffic statistics \& } \\
\text { performance measures }\end{array}$ & $\begin{array}{l}\text { the path+ } \\
\text { "loutput } \backslash P O S T \text { runname_year.dbf" }\end{array}$ \\
\hline $\begin{array}{l}\text { Post } \\
\text { calculation }\end{array}$ & $\begin{array}{l}\text { Traffic statistics \& } \\
\text { performance measures }\end{array}$ & $\begin{array}{l}\text { the path+ } \\
\text { "'ppost\POST_runname_year_LINKS.dbf" }\end{array}$ \\
\hline
\end{tabular}

